\title{
The South Pacific Convergence Zone as Depicted in Reanalysis and Satellite Products
}

\author{
By
}

Thomas Luke Harvey

\begin{abstract}
A thesis
Submitted to Victoria University of Wellington

In partial fulfilment of requirements for the degree of

Master of Science in Physical Geography
\end{abstract}

School of Geography, Environment and Earth Sciences

Victoria University of Wellington

2018 


\section{Abstract}

The South Pacific Convergence Zone (SPCZ) is the largest rainfall feature in the Southern Hemisphere, and is a critical component of the climate of Southwest Pacific Island nations. The small size and isolated nature of these islands leaves them vulnerable to short and long term changes in the position of the SPCZ. Its location and strength is strongly modulated by the El Niño-Southern Oscillation (ENSO) cycle and the Inter-decadal Pacific Oscillation (IPO), leading to large inter-annual and decadal variability in rainfall across the Southwest Pacific. Much of the analysis on the SPCZ has been restricted to the modern period, more specifically the "satellite era", starting in 1979.

Here, the representation of the SPCZ in the Twentieth Century Reanalysis (20CR) product, which reconstructs the three-dimensional state of the atmosphere based only on surface observations is discussed. The performance of two versions of the 20CR (versions 2 and 2c) in the satellite era is tested via inter-comparison with other reanalysis and observational satellite products, before using 20CR version 2c (20CRv2c) to perform extended analysis back to the early twentieth century.

This study demonstrates that 20CR performs well in the satellite era, and is considered suitable for extended analysis. It is established that extra data added in the SPCZ region between 20CR versions 2 and 2c has improved the representation of the SPCZ during 1908-1958. Well-established relationships between ENSO and the IPO with the SPCZ are shown to be present through the entire 1908-2011 period, although it is suggested that the physical link between the IPO and the SPCZ has changed between the first and second half of the twentieth century. Finally, evidence of a southward trend of the SPCZ over the past century is presented, potentially due to an expansion of the tropics as a result of climate change. 


\section{Acknowledgements}

Firstly, I would like to thank my supervisors James Renwick and Andrew Lorrey for their help and guidance through the course of my Master of Science degree. James, thank you for being so approachable and available from the very start of this process, and your enduring patience with my many questions. Drew, thank you for providing me the opportunity to research this topic as well as your expert guidance along the way. It has been an absolute pleasure working with you both.

Initial ideas, research framework, and financial support for this thesis came from the National Institute of Water and Atmosphere (NIWA) project "Climate Present and Past". NIWA also part funded a trip to Auckland to attend the C3S data rescue workshop. Support and assistance was also provided by Victoria University of Wellington. I am very grateful for the financial support I have received over the course of this thesis.

A big thank you to my flatmates of the past two years (Jack, Lauren, Brad, Lucas and Lauren). We all went through this together (some literally) and I couldn't have asked for a better bunch of people to live with throughout this experience. Thank you also to my office mates, in particular Lisa, Adam, Brad, Lucas, Mel and Maggie, for always keeping the mood light and making this such an enjoyable experience. To my close friends, with special mention to Vic, thank you for the always great chat, numerous adventures, and getting me out of the office to take my mind off things.

To my brothers Jake and Ben, and their better halves Rowan and Rotdany, thank you. I look forward to repaying the food and drinks that I have received in your presence over the past few years. Thank you also to Sharon for providing editing duties, and David for providing painting and labouring to help with the finances. Finally, to Mum and Dad, thank you for everything. I can't express how much your unwavering support and patience, in all manner of ways means to me, so instead I dedicate this thesis to you. 


\section{Table of Contents}

Acknowledgements

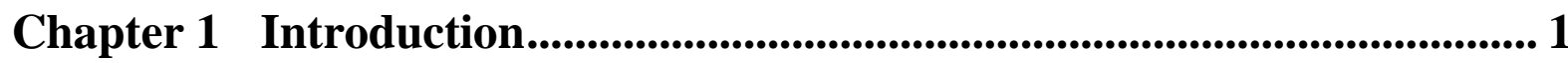

1.1 General Introduction to the South Pacific Convergence Zone ....................................................

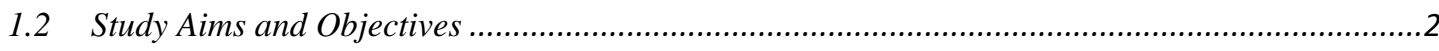

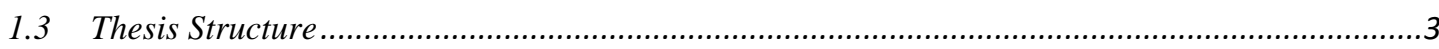

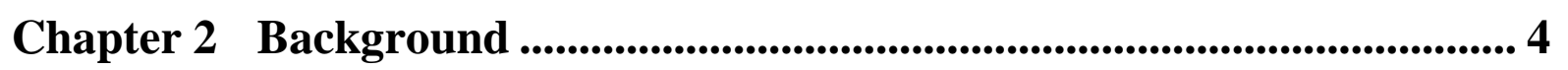

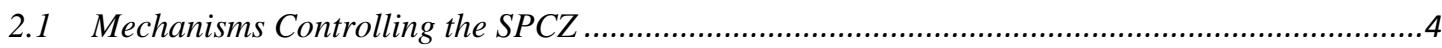

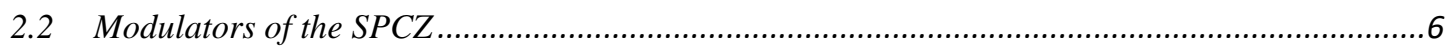

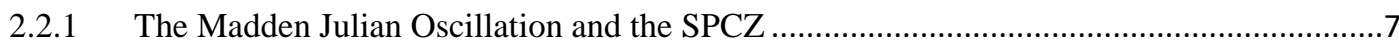

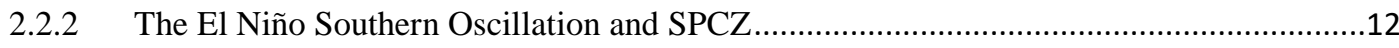

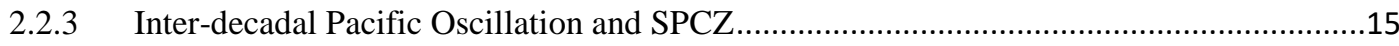

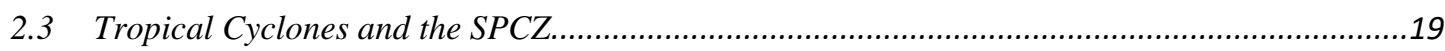

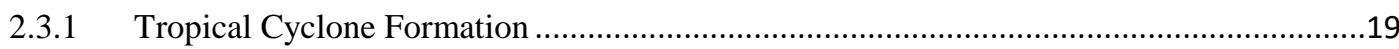

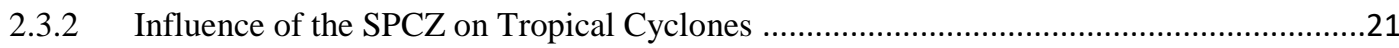

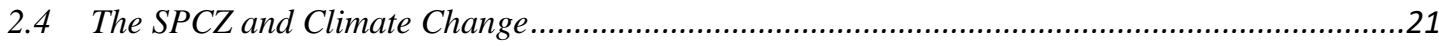

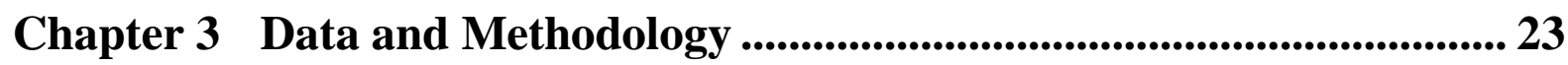

$3.1 \quad$ Data

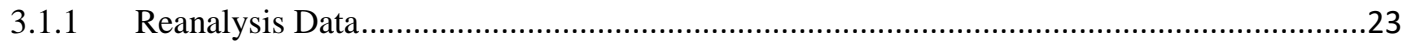

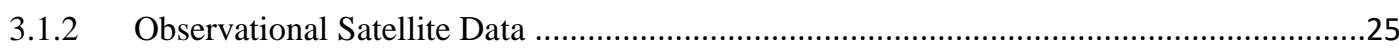

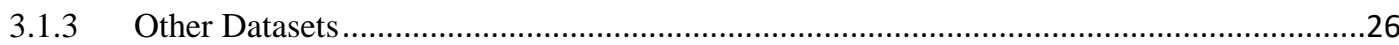

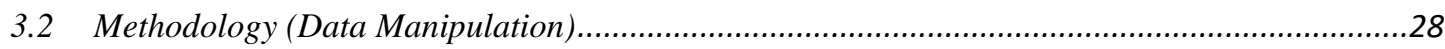




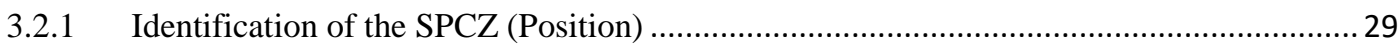

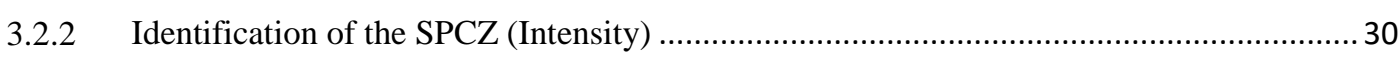

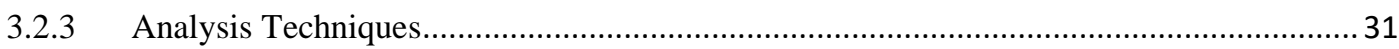

\section{Chapter 4 Results..................................................................................................................33}

4.1 Inter-comparison of Reanalysis and Satellite Products ..................................................... 33

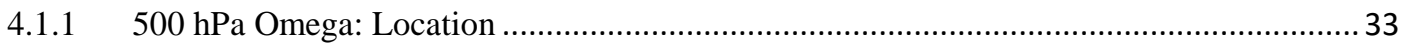

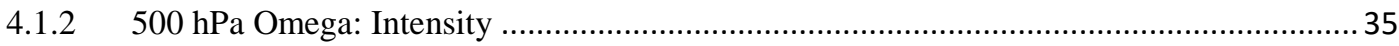

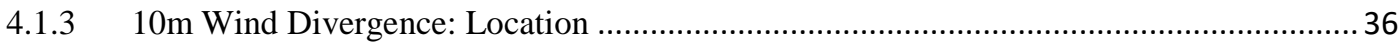

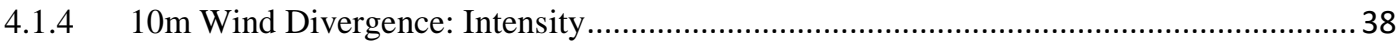

4.2 Comparison of Twentieth Century Reanalysis Products....................................................... 39

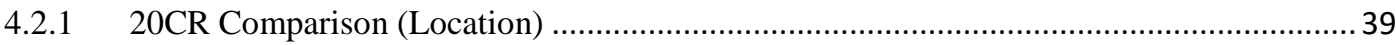

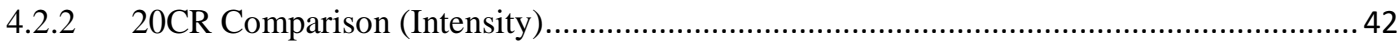

4.3 Interactions with ENSO and IPO and Twentieth Century Trends ....................................... 43

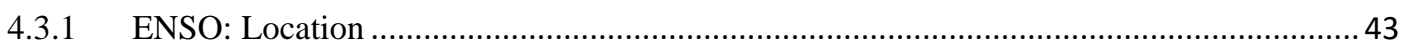

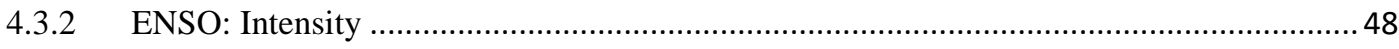

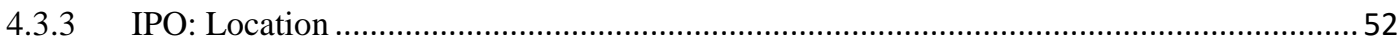

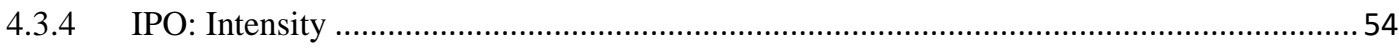

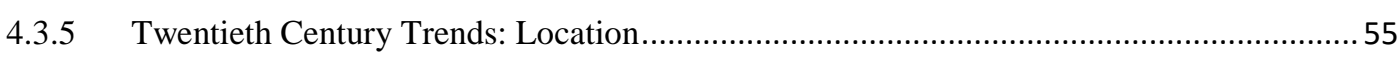

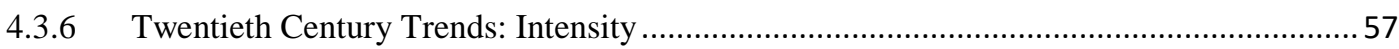

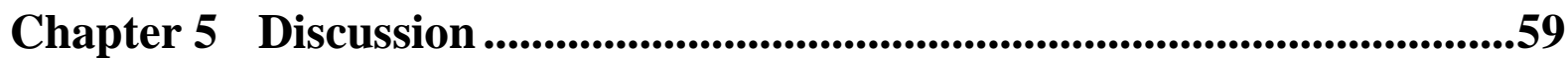

5.1 Inter-comparison of Reanalysis and Satellite Products ..........................................................5

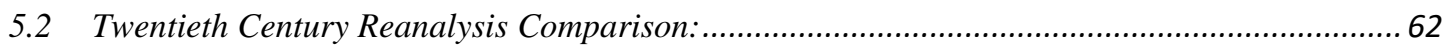

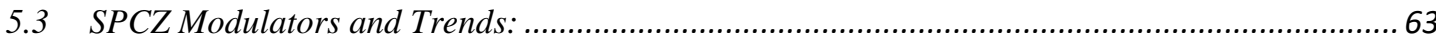

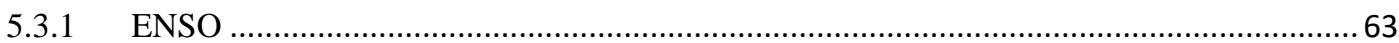

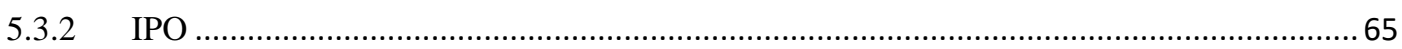

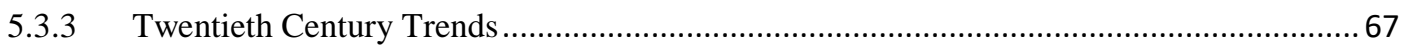

Chapter 6 Conclusions and Future Work .............................................................669

Bibliography: .................................................................................................................................71

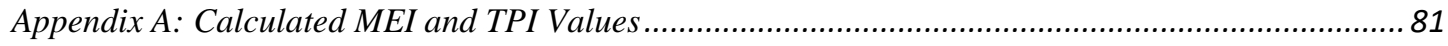

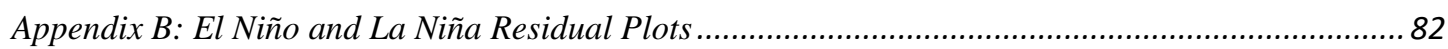




\section{List of Figures}

Figure 1.1 Average position of SPCZ and ITCZ in southwest Pacific.....................1

Figure 2.1 The lifecycle of an MJO event as it propagates eastward along the

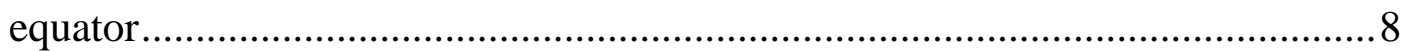

Figure 2.2 Plot demonstrating where the SPCZ is likely to be located during different phases of the MJO

Figure 2.3 Atmospheric and oceanic characteristics of El Niño and La Niña conditions..... .13

Figure 2.4 SST anomalies during positive and negative IPO phases ...................... 16

Figure 2.5 Mean SPCZ location in relation to IPO and ENSO phase .19

Figure 3.1 The unfiltered correlation between the IPO and SST from HadISST2.1. and the three TPI regions

Figure 3.2 Base map showing SPCZ region analysed for this study ......................28

Figure 3.3 Plot showing smoothed and unsmoothed SPCZ position .......................30

Figure 3.4 Comparison of the greatest magnitude of the SPCZ from the 20CRv2c $500 \mathrm{hPa}$ omega fields using different methods

Figure 4.1 The mean DJF location of the SPCZ from 1979-2011 for all reanalysis (omega field) and satellite products .34

Figure 4.2 The mean DJF intensity of SPCZ from 1979-2011 for all reanalysis (omega field) and satellite products

Figure 4.3 The mean DJF location of the SPCZ from 1979-2011 for all reanalysis (divergence field) and satellite product .37

Figure 4.4 Plot showing anomalous divergence in SPCZ region .38

Figure 4.5 The mean DJF intensity of the SPCZ from 1979-2011 for all reanalysis (divergence field) and satellite products .38

Figure 4.6 Comparison of mean DJF SPCZ position between 20CRv2 and 20CRv2c

Figure 4.7 Comparison of mean DJF SPCZ intensity between 20CRv2 and 20CRv2c

Figure 4.8 The mean DJF SPCZ position based on ENSO phase from 1908-2011... 
Figure 4.9 EOF1 pattern of SPCZ position variability for 1908-2011

Figure 4.10 Time series of EOF1 of SPCZ position and MEI from 1908-2011 46

Figure 4.11 Correlation map of SST anomalies and time series of EOF1 of SPCZ position for 1908-2011.

Figure 4.12 Regression map of SST anomalies and time series of EOF1 of SPCZ position for $1908-2011$.

Figure 4.13 The mean DJF SPCZ intensity based on ENSO phase from 1908-2011.

Figure 4.14 EOF1 pattern of variance for 1908-2011 mean SPCZ intensity 49

Figure 4.15 Time series of EOF1 of SPCZ intensity and MEI from 1908-2011 ......50

Figure 4.16 Correlation map of SST anomalies and time series of EOF1 of SPCZ intensity for 1908-2011 51

Figure 4.17 Regression map of SST anomalies and EOF1 of SPCZ intensity for $1908-2011$

Figure 4.18 The mean DJF SPCZ location relative to twentieth century IPO cycles.

Figure 4.19 Time series of EOF1 of SPCZ position and the TPI from 1908-1998...

Figure 4.20 The mean DJF SPCZ intensity relative to twentieth century IPO cycles

Figure 4.21 Time series of EOF1 of SPCZ intensity and the TPI from 1908-1998...

Figure 4.22 The mean DJF SPCZ position through time from 1908-2011 ...............56

Figure 4.23 Position of the SPCZ from 20CRv2c at $150^{\circ} \mathrm{E}$ for $1908-2011 \ldots \ldots \ldots \ldots . . .56$

Figure 4.24 The mean DJF SPCZ intensity through 1908-2011 .............................58 


\section{List of Tables}

Table 3.1 Details of stations where weather observations were added between 20CRv2 and 20CRv2c .24

Table 4.1 20CRv2c temporal correlations with OLR, GPCP, and ERA Interim for 1979-2011 DJF period .35

Table 4.2 20CRv2c temporal correlations with OLR, GPCP, and ERA Interim for

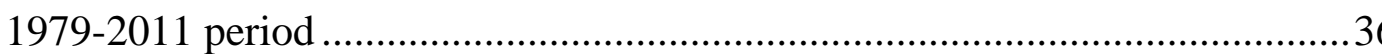

Table 4.3 P values for the "western section" and the "eastern section" where the SPCZ position appears different between 20CRv2 and 20CRv2c .41

Table 4.4 Representation of $\mathrm{p}$ values and trend of SPCZ position from 1908-2011 by longitude. .57 


\section{List of Acronyms}

SPCZ - South Pacific Convergence Zone

ENSO - El Niño-Southern Oscillation

IPO - Interdecadal Pacific Oscillation

PDO - Pacific Decadal Oscillation

MJO - Madden-Julian Oscillation

20CR - Twentieth Century Reanalysis

20CRv2 - Twentieth Century Reanalysis version 2

20CRv2c - Twentieth Century Reanalysis version 2c

NCEP/NCAR1 - National Centers for Environmental Prediction - National Center for Atmospheric Research Reanalysis 1

ECMWF - European Centre for Medium-Range Weather Forecasts

ERA Interim - ECMWF Interim Reanalysis

GPCP - Global Precipitation Climatology Project

TRMM - Tropical Rainfall Measuring Mission

NOAA - National Oceanic and Atmospheric Administration

NIWA - National Institute of Water and Atmosphere

WPWP - West Pacific Warm Pool

SACZ - South Atlantic Convergence Zone

SICZ - South Indian Convergence Zone

ITCZ - Intertropical Convergence Zone 
SSTs - sea surface temperatures

SO - Southern Oscillation

EOF - empirical orthogonal function

OLR - outgoing longwave radiation

PV - potential vorticity

SLP - sea level pressure

CMIP3 - Coupled Model Inter-comparison Project phase 3

CMIP5 - Coupled Model Inter-comparison Project phase 5

GCMs - General Circulation Models

NWP - numerical weather prediction

ISPD - International Surface Pressure Databank

ACRE - Atmospheric Circulation Reconstructions over the Earth

NASA - National Aeronautical Space Agency

JAXA - Japan Aerospace Exploration Agency

MEI - Multivariate ENSO Index

TPI - Tripole index

ERSST - Extended Reconstructed Sea Surface Temperature

ICOADS - International Comprehesive Ocean-Atmosphere Dataset

DJF - December to February

IDL - International Date Line

SEN - strong El Nino

WEN - weak El Nino

SLN - strong La Nina 
WLN - weak La Nina 



\section{Chapter 1 Introduction}

\subsection{General Introduction to the South Pacific Convergence Zone}

The South Pacific Convergence Zone (SPCZ) is the most extensive band of convection and precipitation in the Southern Hemisphere, extending from the tropical West Pacific Warm Pool (WPWP) south-eastward toward French Polynesia (Figure 1.1) (Folland et al., 2002; Vincent, 1994). The SPCZ is most developed in the austral summer (December-February) and consists of two distinct components, a zonally-oriented tropical component in the west, and a diagonally oriented sub-tropical component to the east (Haffke \& Magnusdottir, 2013; Niznik et al., 2015).

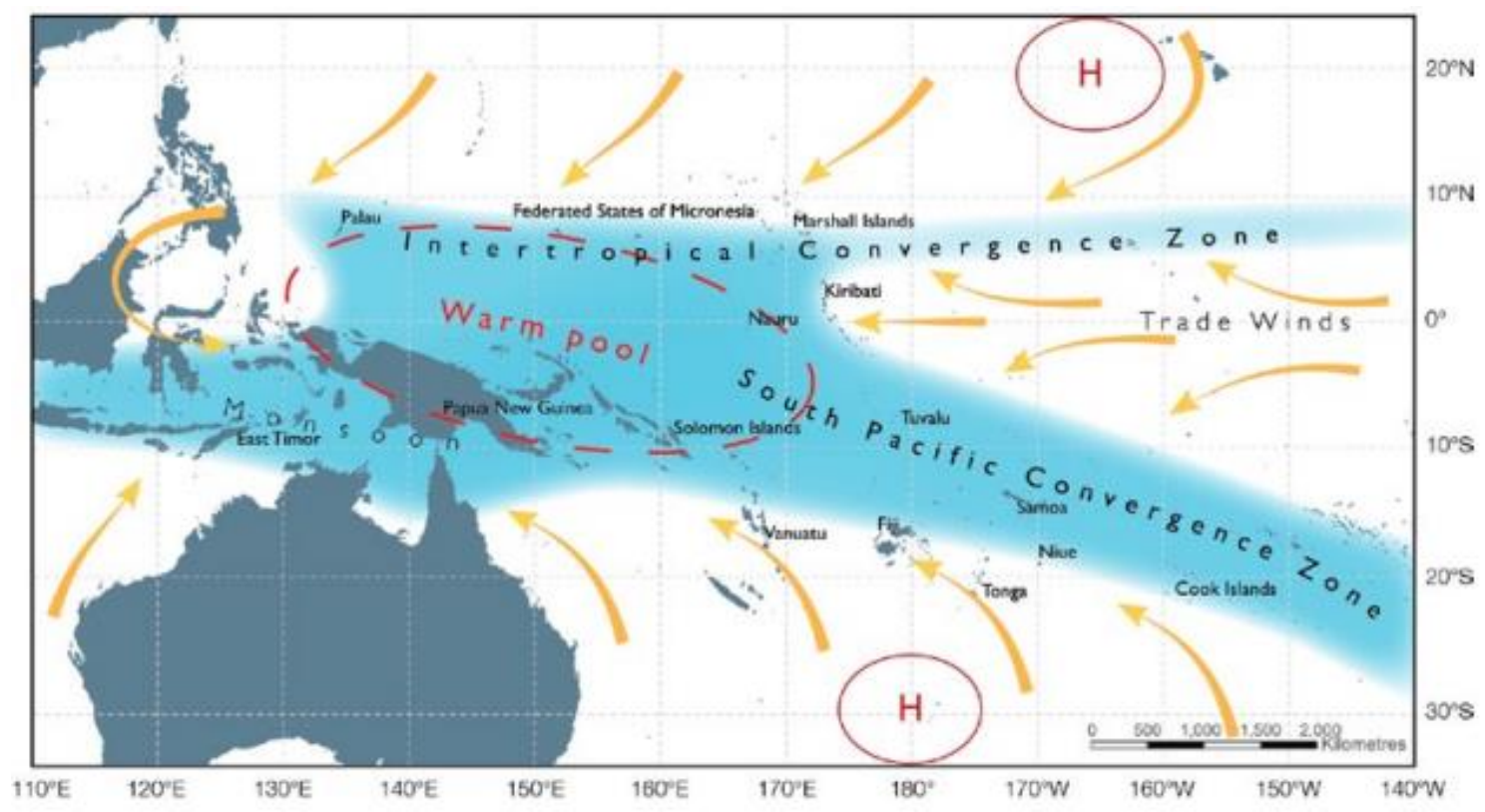

Figure 1.1 Map showing the average position of SPCZ and Intertropical Convergence Zone shaded in blue. The yellow arrows show surface winds. The WPWP resides within the dashed red oval. Source:(Australian Bureau of Meterology and CSIRO)

The SPCZ responds to different climate modes on various timescales. It is influenced by the Madden-Julian Oscillation (MJO) on intraseasonal timescales (e.g. Matthews et al., 1996), the El Niño-Southern Oscillation (ENSO) on inter-annual timescales (e.g.

Borlace et al., 2014), and the Inter-decadal Pacific Oscillation (IPO) on decadal 
timescales (e.g. Folland et al., 2002). It also modulates the formation and distribution of tropical cyclones in the Southwest Pacific, with tropical cyclone genesis favoured within $10^{\circ} \mathrm{S}$ of the SPCZ location (Diamond et al., 2013; Vincent et al., 2011).

The SPCZ plays a key role in the climate of isolated South Pacific nations, being a major control on rainfall distribution (Cai et al., 2012; Lorrey et al., 2012; Niznik et al., 2015; Vincent et al., 2011). Strong rainfall gradients at the edges of the SPCZ mean that any short- or long-term changes in position of the convection zone can lead to dramatic changes in climatic and hydrological conditions for small island nations in the Southwest Pacific (Cai et al., 2012; Vincent et al., 2011). Floods and droughts which are influenced by variation of the SPCZ about its mean position can cause severe socioeconomic impacts, such as damage to agricultural crops and civil infrastructure, as a result of heavy rainfall induced flooding (Lorrey et al., 2012). These impacts mean that understanding past and present variability of the SPCZ is extremely important in assessing how future changes could affect vulnerable South Pacific nations.

\subsection{Study Aims and Objectives}

This study uses the representation of the SPCZ in reanalysis and satellite products to test the performance of the Twentieth Century Reanalysis (20CR) product. This reanalysis will then be used to perform various analysis to investigate SPCZ behaviour extending back to the early twentieth century.

The three key objectives are to:

1. Assess whether the depiction of the SPCZ in the 20CR version 2c (20CRv2c) product is reliable for evaluating different metrics of SPCZ convective activity. This will be accomplished via inter-comparison with other reanalysis and observational satellite products, with analysis being performed for the 1979-2011 period.

2. Investigate whether there are any significant differences in the representation of the SPCZ between the 20CR Version 2 (20CRv2) and 20CRV2c products. This analysis will be performed for the 1908-2011 period.

3. Use 20CRv2c to investigate the effect of inter-annual and decadal variability on the SPCZ, with particular focus on ENSO, the IPO, and twentieth century trends. This analysis will also be performed for the 1908-2011 period. 


\subsection{Thesis Structure}

This thesis contains six chapters, detailing all the information necessary to provide a robust understanding of SPCZ history and the key findings.

- Chapter 1 (this chapter) provides an introduction to this study by outlining its relevance. It then details the aims and objectives of the research, before explaining the structure of the thesis.

- Chapter 2 provides a detailed background of the thesis via a comprehensive review of the current understanding of the SPCZ, describing the mechanics that control the SPCZ, the modulators of the SPCZ, its control on tropical cyclone genesis, and the potential influences of climate change on the SPCZ.

- Chapter 3 describes the various datasets that are used in this study, before detailing the methodologies which are utilised to carry out the research.

- Chapter 4 outlines the results that were found during the analysis that was carried out for this study.

- Chapter 5 provides a discussion of the results in conjunction with the understanding of the SPCZ in current literature.

- Chapter 6 concludes the thesis by highlighting the keys findings that were made, along with suggestions of potential future work related to this study. 


\section{Chapter 2 Background}

Chapter 2 of this thesis provides a brief review of the current understanding of the SPCZ. An outline of the mechanics leading to the formation of the SPCZ will be discussed in section 2.1. This will be followed by an overview of three SPCZ modulators - the MJO, ENSO, and the IPO. The relationship between the SPCZ and tropical cyclones is examined, followed by a brief overview of how the SPCZ might respond to climate change.

\subsection{Mechanisms Controlling the SPCZ}

The SPCZ is one of three diagonally-orientated convergence zones that are present in the Southern Hemisphere during the Austral summer (Van Der Wiel et al., 2015b; Widlansky et al., 2011). The other two sub-equatorial convergence zones are the South Atlantic Convergence Zone (SACZ), and the much smaller South Indian Convergence Zone (SICZ) (Van Der Wiel et al., 2015a). What makes these three convergence zones unique is that the Northern Hemisphere does not contain any such diagonally oriented convergence zones in the subtropics - instead there is the zonally-aligned Intertropical Convergence Zone (ITCZ), which is located just north of the equator (Van Der Wiel et al., 2015b).

After it was first reported in surface observations by Bergeron (1930), the peculiar diagonal SPCZ was first observed early in the early "satellite era" (Hubert, 1961; Streten \& Troup, 1973). The SPCZ is often split into two portions: a section that is mostly orientated in a zonal fashion in the west (between $150^{\circ} \mathrm{E}$ and $165^{\circ} \mathrm{W}$ ) and a component that is more meridionally orientated (i.e. diagonal) to the east (Brown et al., 2011; Widlansky et al., 2011). The zonal component is a tropical convergence zone associated with warm sea surface temperatures (SSTs) of theWPWP, while the diagonal component displays tropical, subtropical, and extra tropical characteristics (Brown et al., 2011). The mechanisms controlling the SPCZ have long been a focus of research, in an attempt to understand its unusual diagonal orientation. The following section will review the evolution in understanding of SPCZ mechanics since it was first observed. 
Analysing three years of five-day averaged satellite data, Streten and Troup (1973) used maximum cloud brightness to observe the three Southern Hemisphere convergence zones. They noted that these bands extending from the tropics into the mid-latitudes all showed evidence of being related to the hemispheric longwave circulation patterns, and hence are associated with tropical-extratropical interactions. The SPCZ and SACZ are the largest and most permanent of these features, however, they are more variable in location and intensity when compared to the SICZ (Streten \& Troup, 1973; Widlansky et al., 2011).

Trenberth (1976) was the first to coin the term SPCZ in a study looking at spatial and temporal variations of the Southern Oscillation. The study noted the mixed characteristics of the SPCZ, and noted that even the subtropical component maintained convergence zone characteristics between the south-easterlies ahead of migrating anticyclones in the southwest Pacific, and the moist north-easterlies on the western edge of the South Pacific High (Trenberth, 1976). The eastern component often has frontal characteristics related to the subtropical jet-stream, and can lead to cyclogenesis within the SPCZ associated with systems moving towards the southeast (Trenberth, 1976). However, the SPCZ tends to form a "graveyard" for fronts within troughs between the migrating anticyclones moving from the southwest (Trenberth, 1976). The research also highlighted the relationship between the Southern Oscillation (SO) and the SPCZ, which has been the focus of numerous studies since, and will be discussed in section 2.2.2.

Since these early studies, there has been a range of research investigating the position and orientation of the SPCZ, with theories largely focussing on tropical-mid latitude interactions caused by synoptic scale disturbances and propagating tropospheric waves (e.g. Matthews, 2012; Van Der Wiel et al., 2015a; Widlansky et al., 2011). These studies have looked at how synoptic scale disturbances interact with the longer term mean climatological state in the SPCZ region. Transient Rossby waves emanating from the Subtropical jet near Australia are refracted towards the upper tropospheric westerly duct over the eastern equatorial Pacific (Matthews, 2012; Van Der Wiel et al., 2015a). These waves slow down and accumulate in the SPCZ region while stretching into a north-west/south-east orientation, and can trigger deep convection when they pass over the warm waters of the tropical south-west Pacific (Matthews, 2012; Van Der Wiel et al., 2015a; Widlansky et al., 2011). However, Rossby waves can only propagate when 
the mean upper tropospheric state is westerly, so if the westerly duct is not present, the triggering of convection is less likely (Matthews, 2012). This helps explain why convection in the SPCZ is most pronounced during the Austral summer, when the westerly duct is in place over the equatorial Pacific (Matthews, 2012).

The impact of Southern Hemisphere continental landmasses on the distribution of Pacific Ocean SSTs, and hence SPCZ location, has also been investigated using model simulations. For example, Kiladis et al. (1989) modelled the SPCZ after removing South America and Australia, and the results were compared to a control run in which the continents were in position. Climatological mean SSTs were used in both cases. It was found that the removal of South America had no strong effect on the SPCZ position, and that while the tropical western component was weakened with the removal of Australia, the spatial form remained similar (Kiladis et al., 1989). These results suggested that the orientation of the SPCZ is more reliant on tropical - mid-latitude interactions rather than Southern Hemisphere land and SST distribution (Kiladis et al., 1989).

The influence of the south-east Pacific high on controlling the eastern margin of the SPCZ has also been examined (e.g. Lintner \& Neelin, 2008; Takahashi \& Battisti, 2007). Takahashi and Battisti (2007) suggest that the interaction of the subtropical westerlies with the Andes causes subsidence in the south-east Pacific, resulting in the subtropical high pressure system observed in that area. The western edge of this dry zone sets the eastern margin of the SPCZ, and the north-west/south-east tilt seen is due to the orientation of the south-easterly trade winds in that region (Takahashi \& Battisti, 2007). Lintner and Neelin (2008) propose that variation in trade wind intensity control the eastern edge of the SPCZ, with a decrease in the trade winds associated with an eastward expansion of convection and precipitation, as is seen during El Niño events.

\subsection{Modulators of the SPCZ}

The position and intensity of the SPCZ is strongly influenced by different climate phenomena on various timescales. There are three main modulators that cause SPCZ variability: The MJO influences the SPCZ on intraseasonal timescales, ENSO on interannual timescales, and IPO on decadal timescales. This section provides a brief background on these phenomena, followed by a discussion on how each contributes to variation of the SPCZ. 


\subsubsection{The Madden Julian Oscillation and the SPCZ}

\section{The Madden Julian Oscillation:}

The MJO is the leading component of intraseasonal variability in the tropical atmosphere, and displays large scale atmospheric circulation and convection while propagating eastward at $\sim 5 \mathrm{~ms}^{-1}$ (Madden \& Julian, 1994; Roundy, 2008; Yoneyama et al., 2013; Zhang, 2005). The lifecycle of the MJO is typically in the order of 30-60 days, a timescale which describes a large portion of variability in the tropical circulation (Krishnamurti et al., 2013). Although the MJO is defined as a planetary-scale disturbance in circulation and convection with associated global weather and climate impacts, its rainfall signature is most prominent in the Indian and western Pacific Oceans, where warm SSTs help maintain convection (Fauchereau et al., 2016; Hendon et al., 1999; Yoneyama et al., 2013; Zhang, 2005). The MJO is most pronounced during the late austral spring, summer, and early fall, however it exhibits both strong annual and seasonal variability in its intensity (Hendon et al., 1999; Zhang, 2005).

The MJO is observed in the Indian and western Pacific Oceans as an eastward-moving centre of strong convection and precipitation, otherwise known as the "active phase", which is bordered to the east and west by regions of weaker convection ("suppressed phases") (Zhang, 2005). The two phases are linked by zonal overturning circulations, which extend through the entire troposphere (Figure 2.1). The lower troposphere contains anomalous westerly winds, in, and to the west of the strong convective centre, with anomalously strong easterly winds to the east (Zhang, 2005). The situation is reversed in the upper troposphere, with anomalous easterly winds to the west, and anomalous westerlies to the east (Zhang, 2005). The slow eastward movement at $\sim 5 \mathrm{~ms}^{-1}$ is one of the distinguishing features that separates the MJO from other equatorial propagating waves, however, this speed varies slightly between, and within individual events (Hendon \& Salby, 1994; Knutson et al., 1986; Weickmann et al., 1985). The convection associated with the MJO usually disappears as it moves into the eastern Pacific, however, indicators such as surface pressure and wind anomalies continue to move eastwards at speeds of up to $30-35 \mathrm{~ms}^{-1}$, significantly faster than propagation speeds in the Indian and western Pacific Oceans (Zhang, 2005). Fields such as divergence, water vapour, and temperature all show patterns consistent with the convection and winds associated with the MJO (Hendon \& Salby, 1994; Zhang, 2005). These fields show zonal asymmetry and vertical westward tilt in relation to the centre of 
strong convection, creating favourable conditions for new convection to the east of the existing main centre, and unfavourable conditions to the west (Zhang, 2005). This results in the eastward propagation of the strong convective centre.

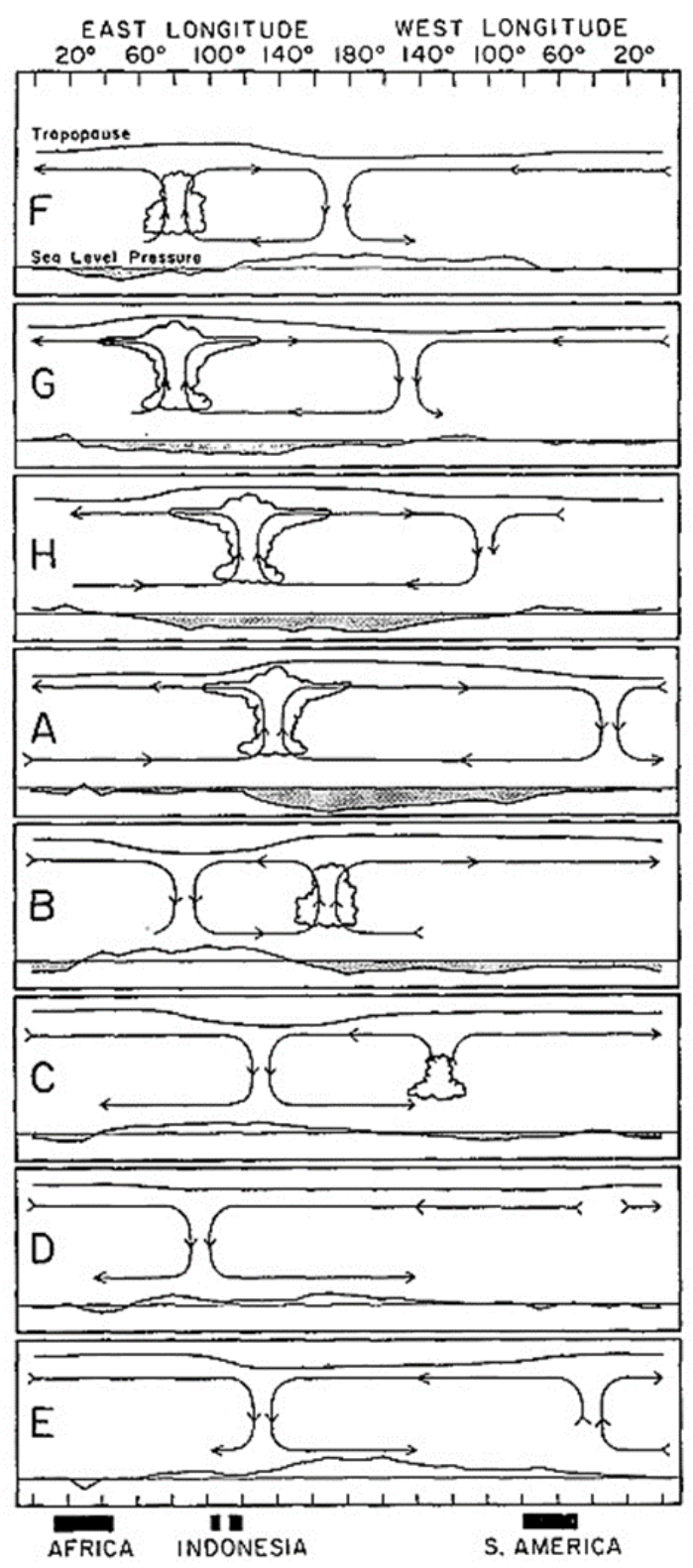

Figure 2.1 The lifecycle of an MJO event as it propagates eastward along the equator. The cloud symbols represent areas of convection and arrows represent the zonal circulation. The curved lines above and below the circulation represents raised and lowered areas of tropospheric and sea level pressures. Source: Zhang (2005).

The MJO interacts with tropical weather and climate on multiple scales, from the formation of individual convective clouds, to the global scale propagation and organisation of convection (Hirons et al., 2013). It is known to influence rainfall variability in many regions, including the Pacific Islands and the monsoon regions of Australia and Asia (Zhang, 2005). It is also seen to interact with ENSO, as convective activity moves eastwards with the warm SST anomalies in the eastern Pacific Ocean 
associated with El Niño events (Hirons et al., 2013; Zhang, 2005). The MJO has proved difficult to forecast beyond a few weeks, but there have been recent advancements in accurately predicting the MJO signal through an entire integration period, via modified convective parametrisation based on relative humidity rather than moisture convergence (e.g.Hirons et al., 2013).

In an attempt to monitor and predict the MJO in real time, Wheeler and Hendon (2004) used a pair of empirical orthogonal functions (EOFs) to develop a seasonally independent index. The data used were near equatorially averaged $200 \mathrm{hPa}$ and $850 \mathrm{hPa}$ zonal winds, along with outgoing longwave radiation (OLR) data. The equatorial area studied was broken down longitudinally to represent where the active phase of the MJO was located, such that: the western hemisphere and Africa are represented by phases 8 and 1, the Indian Ocean is represented by phase 2 and 3, the Maritime Continent is represented by phases 4 and 5, and the Western Pacific is represented by phases 6 and 7 . These phases will be referred to in the following section when discussing the influence of the MJO on SPCZ activity.

\section{Interactions with the SPCZ}

The relationship between the MJO and the SPCZ has been well-documented since the 1980’s. Various studies (e.g.Lau \& Chan, 1985, 1988; Vincent et al., 1991; Weickmann et al., 1985) noticed an austral summer spectral peak in OLR in the zonal SPCZ region at around 50 days, which falls within the life cycle of an MJO event. These studies also showed intense convective episodes in the SPCZ (phases 6 and 7) occurring out of phase with Indian Ocean (phases 2 and 3) episodes on MJO time scales (Vincent, 1994). These early studies could not definitively say that their findings were a result of MJO cycles, however they did show the eastward propagation of enhanced convection and circulation anomalies, along with out of phase convection between the Western Pacific and Indian Ocean (Vincent, 1994).

Matthews et al. (1996) presented a hypothesis of how the MJO affects convection within the SPCZ, which is forced by MJO related enhanced convection over the Indonesian region leading to an upper tropospheric anticyclone. There is a large potential vorticity (PV) gradient associated with the subtropical jet which is advected equatorward on the eastern edge of the anticyclone, causing an upper atmospheric trough. Strong ascent develops on the eastern side of the trough as a result of strong 
horizontal temperature gradients, which can force convection if the process occurs over an area such as the SPCZ, which is susceptible to intense convection. Matthews et al. (1996) used an atmospheric model in an attempt to corroborate this hypothesis, and found that the model response to atmospheric heating and convection in the Indonesian region was to cause ascent in the SPCZ region due to advection of high PV air.

Matthews (2012) found the presence of two SPCZ modes: an enhanced mode and a shifted mode, related to propagating synoptic wave trains from the subtropical jet to the westerly duct. The variability of the SPCZ is dependent on where these wave trains originate, which is strongly modulated by ENSO and the MJO (Matthews, 2012). The study found that anomalous convection between the eastern Indian Ocean and the western Pacific associated with La Niña or MJO phases 3-6 significantly increased the likelihood of a westward shift in the SPCZ, due to an expanded westerly duct. This results in propagating synoptic waves to refracting towards the equator further westward than normal (Matthews, 2012). A shifted SPCZ however, is much less likely to occur when strong convection in the central Pacific associated with El Niño or MJO phases 78 is present (Matthews, 2012).

Expanding on this explanation of the MJO-SPCZ relationship, Haffke and Magnusdottir (2013) investigated the spatial expression of the SPCZ during each of the MJO phases of Wheeler and Hendon (2004). Their analysis was for the November-April period from 1980-2011 and only considered days that showed a strong MJO signal. The results are shown below in Figure 2.2. 

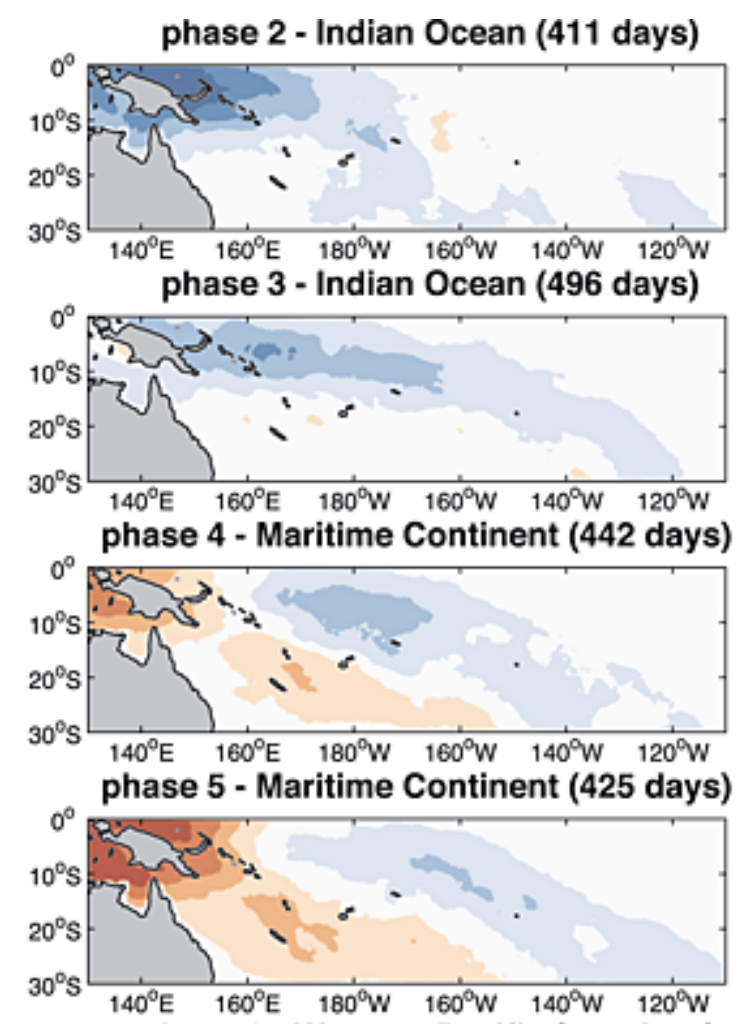

phase 6 - Western Pacific (443 days)
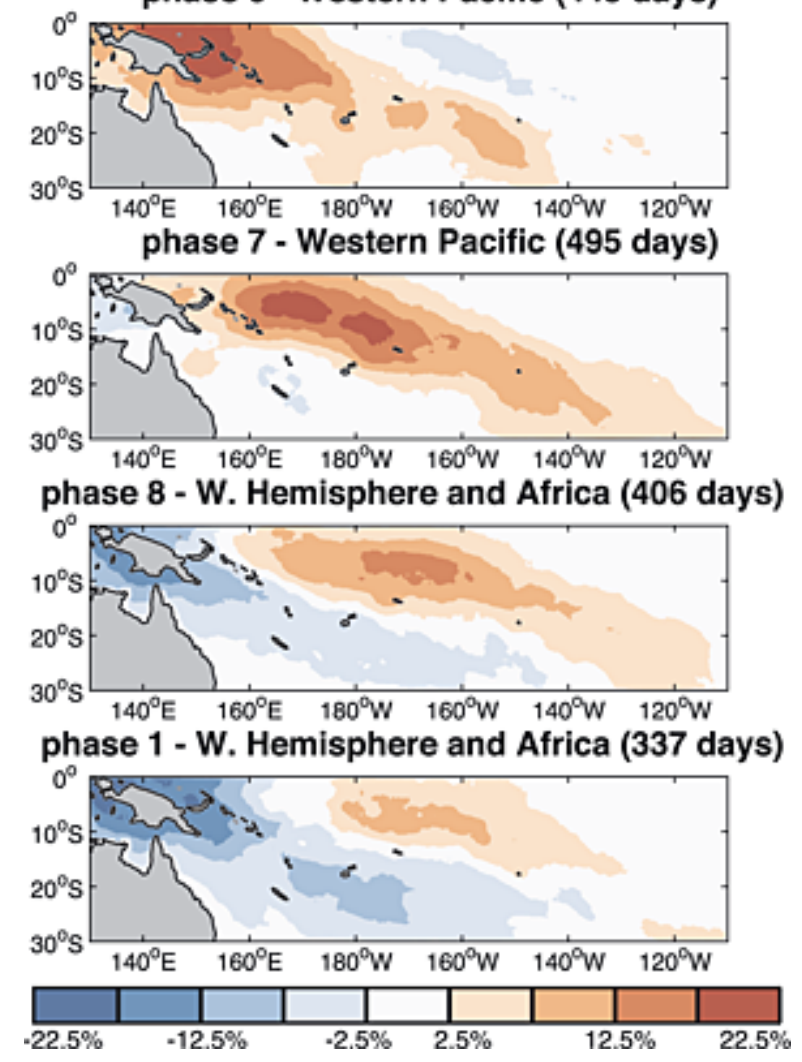

Figure 2.2 Plot demonstrating where the SPCZ is likely to be located during different phases of the MJO. It shows a SPCZ fraction of time present anomalies with respect to the average seasonal evolution. Orange and red indicate where the SPCZ is located more often than its mean position, while blue indicates where it is located less frequently in comparison to its mean position. Source: Haffke \& Magnusdottir, 2013.

Haffke and Magnusdottir (2013) show that the SPCZ is suppressed during phases 2 and 3 of the MJO when enhanced convection is located over the Indian Ocean. When the 
MJO is located over the Maritime Continent during MJO phases 4 and 5, SPCZ activity is enhanced north of Australia, as well as into the subtropics between around $160^{\circ} \mathrm{E}-$ $160^{\circ} \mathrm{W}$. The location of the SPCZ in these phases could also be considered a southwestward shift (Haffke \& Magnusdottir, 2013). SPCZ activity is enhanced and expands equatorward and eastward during phases 6 and 7 (western Pacific) of the MJO. Finally, SPCZ activity weakens and moves equatorward and eastward when the MJO is located over the Western Hemisphere and Africa (phase 7 and 8).

\subsubsection{The EI Niño Southern Oscillation and SPCZ}

\section{The El Niño Southern Oscillation}

ENSO describes the irregular, inter-annual oscillation of SSTs and sea level pressure (SLP) in tropical Pacific Ocean (Latif et al., 1998; Wang et al., 2017). The term "El Niño" ("the boy Christ-child" in Spanish) originally referred to the anomalously warm water that appeared around Christmas time every few years off the coasts of Peru and Ecuador, negatively affecting fisheries in the area (Trenberth, 1997). This term has now evolved to refer to the irregular eastern-central Pacific warming of the equatorial ocean SSTs that represent the warm phase of the ENSO phenomenon (Trenberth, 1997; Wang \& Fiedler, 2006). The cold phase is referred to as "La Niña" ("the girl” in Spanish) which consists of eastern-central Pacific cooling of tropical SSTs (Trenberth, 1997). The Southern Oscillation alludes to the inter-annual seesaw of SLP in the tropical Pacific, and was first described in the 1920's by Walker (1928), whilst conducting studies on global pressure variations in relation to the Indian monsoon intensity (Latif et al., 1998; Wang et al., 2017). This variation in SLP across the tropical Pacific Ocean is driven by the periodic strengthening and weakening of the trade winds (Wang et al., 2017).

A study by Bjerknes (1969) coined the term the "Walker Circulation" in reference to the equatorial zonal circulation that exists across the Pacific Basin (Julian \& Chervin, 1978). Bjerknes postulated that when cold water in the eastern equatorial Pacific was well-established, the air above would be too cold and heavy to rise with the ascending branch of the Hadley circulation. Instead, the air would flow westwards towards the WPWP by which point it would be sufficiently heated to undergo largescale ascent (Bjerknes, 1969). This upper level air would then flow eastwards before cooling and descending back to the surface over the eastern Pacific (Wang et al., 2017). Bjerknes (1969) was the first study indicating that the ocean and atmosphere in the tropical 
Pacific were closely coupled, and that El Niño and the Southern Oscillation were actually two different expressions of the same phenomenon (Wang et al., 2017). The idea that ENSO is driven by a positive ocean-atmosphere feedback involving the Walker Circulation is now the widely recognised theory (Wang et al., 2017).

The described state of the tropical Pacific Ocean manifests itself in easterly trade winds and a zonal SST gradient, with cold upwelling water off the South American coast and very warm SSTs in the west near Indonesia (Collins et al., 2010; McPhaden et al., 2006). This is the so called "normal" state of the tropical Pacific Ocean, with La Niña intensifying the mean climatological state (Wang et al., 2017). El Niño will form when a warm SST anomaly develops over the central or eastern tropical Pacific Ocean reducing the zonal SST gradient, leading to a weakening of the Walker Circulation and subsequent breakdown in the trade winds (Wang et al., 2017). A comparison between the two phases can be seen in Figure 2.3. During El Niño events, low SLP and high SST anomalies are observed in the eastern equatorial Pacific, along with high SLP and low SST anomalies in the off-equatorial western Pacific (Wang \& Fiedler, 2006). This breakdown in the background state of the equatorial Pacific region drives atmospheric circulation changes, with major convection and rainfall shifting eastwards from the WPWP towards the central and eastern Pacific Ocean (Latif et al., 1994). The change in location of major convection not only causes climate anomalies in the immediate region of the Pacific, but is also known to have global impacts via atmospheric and oceanic teleconnections (Latif et al., 1994; Liu \& Alexander, 2007).
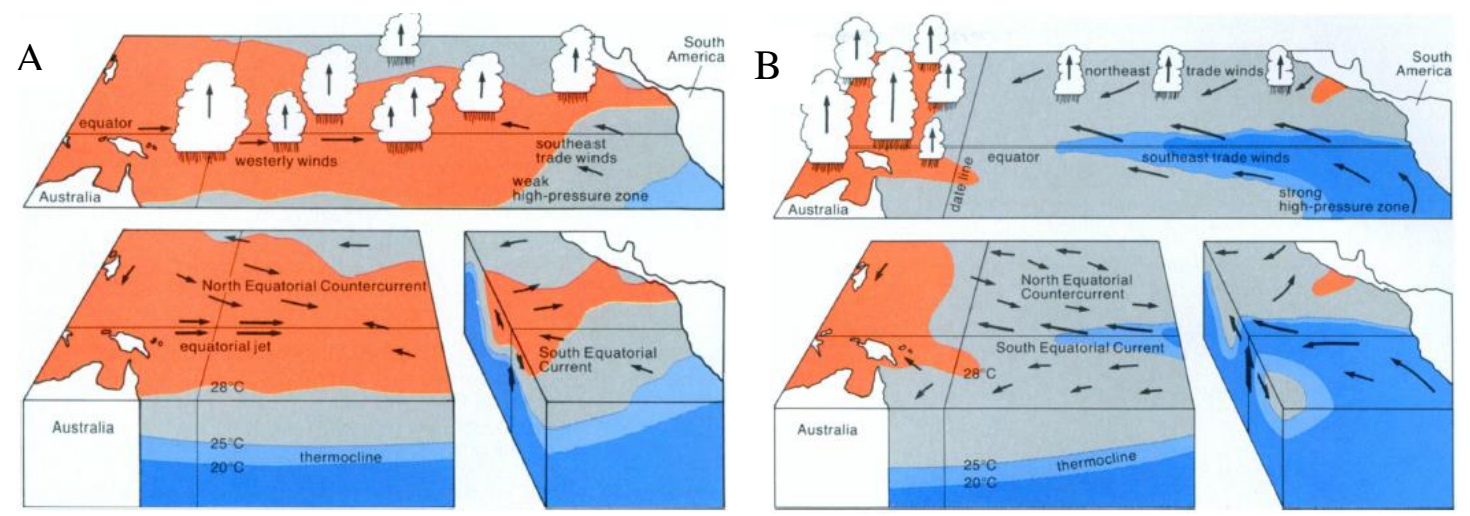

Figure 2.3 Diagrams showing varying atmosphere (top) and oceanic (bottom) characteristics of A) El Niño B) La Niña conditions during ENSO phases. The atmospheric parts of the diagram show how areas of convection (clouds) and trade winds (black arrows) change between El Niño and La Niña conditions. The oceanic parts of the diagram indicate how oceanic currents (black arrows) and the thermocline varies between El Niño and La Niña events. Orange (blue) shading represents warmer (colder) than usual ocean temperatures. Source: (Philander, 1989).

In the South American region during El Niño conditions, anomalous heavy rainfall generally occurs along the northern Peru and southern Ecuador coasts, along with south- 
eastern South America, while precipitation is largely below average in the tropical Andes and north-eastern South America (Sulca et al., 2017). Over North America, above average precipitation generally occurs in the southern and western areas, particularly in winter. Precipitation is also often above average over eastern North America (Whan \& Zwiers, 2017). Drier than average conditions tend to occur from the Great Lakes across to western Canada, as well the Ohio Valley to south-eastern Canada (Whan \& Zwiers, 2017). In the western Pacific, drier than average conditions and droughts are common over large parts of northern and eastern Australia, particularly in spring. The monsoon trough is also often weaker and displaced equatorward in the Austral summer during El Niño events, leading to lower than average wet season rainfall, particularly in the north-east of tropical Australia (Evans \& Allan, 1992; Hamada et al., 2002; Power et al., 2006; Risbey et al., 2009). A similar situation occurs over Indonesia, with a late onset of the summer monsoon and generally lower rainfall amounts, particularly in eastern regions (Hamada et al., 2002).

ENSO also has a strong impact on the Indian Monsoon variability. The majority of El Niño events often lead to below average rainfall and droughts in India, while La Niña events often coincide with above average rainfall and flooding over India (Kripalani \& Kulkarni, 1997; Kumar et al., 1995). The relationship between ENSO and the Indian monsoon is not a simple one, because although all severe droughts have occurred during El Niño events, not all El Niño events have caused severe droughts (Kumar et al., 2006).

\section{Interactions with the SPCZ}

Numerous studies have shown that the position of the SPCZ varies on inter-annual timescales with ENSO (Borlace et al., 2014; Brown et al., 2011; Folland et al., 2002; Trenberth, 1976; Vincent et al., 2011). During El Niño events, the SPCZ tends to move north-east of its climatological mean position, while in La Niña conditions there is generally a shift to the south-west of the mean position (Borlace et al., 2014; Brown et al., 2011; Folland et al., 2002; Kidwell et al., 2016; Trenberth, 1976; Vincent et al., 2011). Observations have shown that the SPCZ generally maintains its diagonal orientation across the subtropics despite its change of location (Vincent et al., 2011). The movement of the SPCZ occurs as a result of ENSO forced changes of the tropical Pacific Ocean and atmosphere. During La Niña conditions, increased trade winds and cooler SSTs in the eastern and central Pacific Ocean (Collins et al., 2010; McPhaden et 
al., 2006; Wang et al., 2017) push SPCZ associated convection south-west of the climatological mean position. Conversely, during El Niño conditions, a breakdown of the trade winds is caused by warm SST anomalies in the eastern and central Pacific Ocean resulting in a reduced zonal SST gradient and weakened Walker Circulation (Wang et al., 2017). This movement of warm SSTs allows the SPCZ associated convection to occur further north and east of its mean position.

There have been three El Niño events observed (the strong events of 1982/83 and 1997/98, as well as the moderate event of 1991/92) in which the SPCZ has undergone an extreme equatorward swing and become orientated in a near-zonal fashion (Borlace et al., 2014; Brown et al., 2011; Kidwell et al., 2016; Vincent et al., 2011). Borlace et al. (2014) attribute this extreme zonal swing of the SPCZ to strong warming in eastern equatorial Pacific Ocean reducing the zonal SST gradient across the equatorial Pacific Ocean. This warming shifts the main area of rainfall and convection east towards South America, leading to the northward shift of the eastern portion of the SPCZ (Borlace et al., 2014; Kidwell et al., 2016). At the same time as this northward shift, the cold SST anomalies and reduced convection in the western equatorial Pacific lead to the western end of the SPCZ being located slightly south of its climatological mean position, producing the overall zonal orientation of the SPCZ across the equatorial Pacific Ocean (Borlace et al., 2014; Kidwell et al., 2016; Vincent et al., 2011).

\subsubsection{Inter-decadal Pacific Oscillation and SPCZ}

\section{The Inter-decadal Pacific Oscillation}

The IPO is a multi-decadal fluctuation of Pacific SSTs, with an expression similar to that of ENSO (Parker et al., 2007). It is similar, and often compared to, the Pacific Decadal Oscillation (PDO), however the PDO is defined only for the North Pacific, while the IPO is defined over the entire Pacific basin (Newman et al., 2016; Parker et al., 2007). With the south-west Pacific region being the focus of this particular study, this decadal scale pattern of variability will be referred to as the IPO herein.

The positive phase of the IPO is expressed as warmer than average SSTs over the central and eastern Pacific Ocean, while cooler than average SSTs occur over the north and south-west Pacific Ocean (similar to SST anomalies seen during El Niño) (Henley et al., 2015). The opposite sign exists during the negative phase of the IPO (similar to SST anomalies seen during La Niña) (Figure 2.4). There have been two full IPO cycles 
recorded in the last century: negative (cool) IPO conditions were evident from the late 1800's to 1924 and from 1947-1976, while positive (warm) IPO conditions occurred from 1925-1946 and 1977 until the late 1990s (Mantua \& Hare, 2002). The IPO has wide ranging climatic and ecological repercussions, including: impacts on North Pacific Salmon fisheries productivity (Mantua et al., 1997), modulation of ENSO related rainfall in Australia (Power et al., 1999), influence on north-east Asian surface temperature anomalies (Minobe, 2000), anomalies in North American surface temperatures (Mantua \& Hare, 2002) and precipitation (Cayan et al., 1998), among others. It has also been shown to be an important modulator of globally averaged surface air temperatures, with decades showing rapid warming (e.g. the 1970s) being associated with positive IPO conditions, whereas periods showing a relative hiatus in warming (e.g. the early 2000s) are associated with negative IPO conditions (Henley et al., 2015; Meehl et al., 2013).
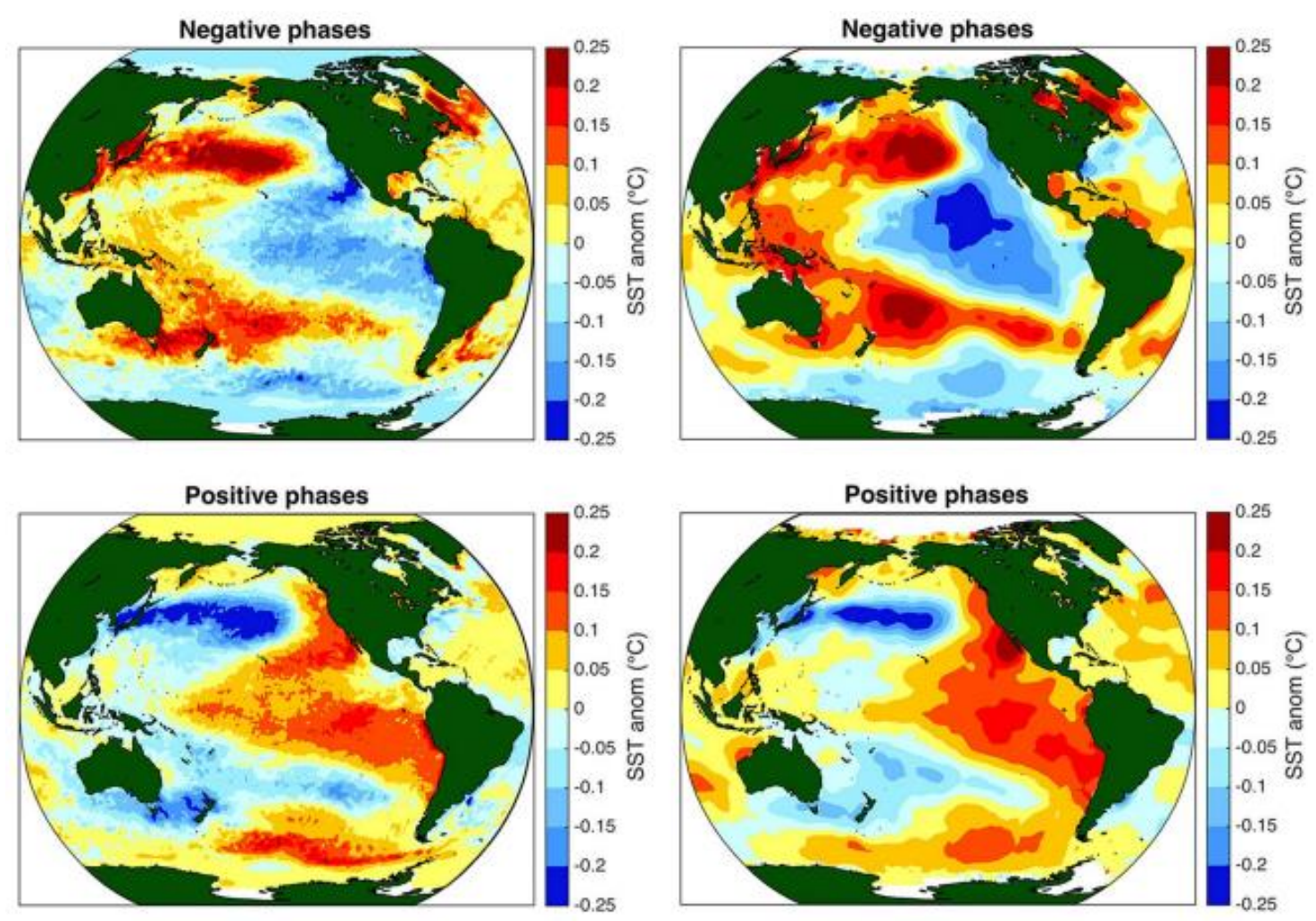

Figure 2.4 Composites of SST anomalies during IPO positive and negative phases for HadISST2.1 (left) for 18702007 and ERSSTv3b (right) for 1870-2013 (Henley et al., 2015).

The existence of low frequency, decadal modulation of Pacific Ocean SSTs was first recognised in studies during the 1990s (e.g. Ebbesmeyer et al., 1991; Mantua et al., 1997; Miller et al., 1994; Trenberth, 1990). A study by Mantua et al. (1997) was the first to introduce the term "PDO" during research into North Pacific salmon production. 
The basis of the study was on the varying success of Pacific Northwest and Alaskan salmon fisheries during the second half of the twentieth century. During large parts of the 1980s and 1990s, salmon fisheries in the Pacific Northwest struggled and Alaskan salmon fishery production thrived, while the reverse of this situation occurred during the 1960s and early 1970s (Mantua et al., 1997). The study identified the PDO as the leading EOF of monthly SST anomalies in the North Pacific (Newman et al., 2016).

Following this realisation, there have been numerous attempts to prescribe mechanisms to this oscillation, particularly the PDO. Here the mechanisms affecting both the PDO and IPO will be discussed, in the knowledge that PDO forcings also strongly influence the Pacific wide effects.

Originally, it was thought that the IPO pattern was possibly its own physical mode of Pacific SST variability, due to low simultaneous correlation between the PDO and SST anomalies in the eastern equatorial Pacific (Newman et al., 2016). Furthermore, modelling studies by Latif and Barnett $(1994,1996)$ suggested that decadal variability could arise in the North Pacific due to coupled ocean-atmosphere feedbacks. However, the idea of the IPO being its own physical mode of variability has since been challenged, with numerous physical processes seemingly responsible for the decadal pattern of variability in Pacific Ocean SSTs (Henley et al., 2015; Newman et al., 2016). One of the main processes involves teleconnections from the tropics via atmospheric and oceanic waves (Henley et al., 2015; Newman et al., 2016). For example, an El Niño event causes a perturbation in the tropical circulation which is manifested in the North Pacific Ocean by the deepening of the Aleutian Low, with the resultant oceanic response forcing the Pacific into a positive IPO pattern (Newman et al., 2016). This North Pacific Ocean incorporation of low frequency ENSO variations caused Newman et al. (2003) to first challenge the idea of the IPO as its own physical mode of variability.

Stochastic forcing is also thought to play a part in the expression of the IPO, with large scale atmospheric fluctuations possibly explaining a considerable amount of variability in the North Pacific Ocean (Alexander, 2010; Frankignoul \& Reynolds, 1983; Newman et al., 2016). Alexander (2010) suggests that fluctuations in the Aleutian Low is the leading cause of North Pacific SLP variability. This idea implies that a strong Aleutian Low could help drive positive IPO conditions without the need of tropical influence, 
having internal atmospheric fluctuations as the main driver (Alexander, 2010; Newman et al., 2016).

Ocean dynamics also contribute to the IPO pattern. Schneider and Cornuelle (2005) suggested that anomalies in the Kuroshio Current, along with ENSO variability and SLP fluctuations of the Aleutian low, was a component in helping force the decadal SST pattern in the Pacific. The "re-emergence mechanism" (Alexander \& Deser, 1995) also helps modulate Pacific Ocean SSTs, where warm ocean temperature anomalies that form during summer are mixed downwards, and become trapped under the summer thermocline, before being mixed back to the surface during the following autumn (Newman et al., 2016). The theory was first introduced by Namias and Born (1970, 1974), and has been shown to occur over the North Pacific Ocean, helping to force IPO SST pattern over consecutive winters (Newman et al., 2016). Changes in oceanic gyres also create IPO related SST variability, particularly in the western Pacific. This occurs via westward propagating Rossby waves which take three to ten years to cross the Pacific Ocean, leading to largely decadal variability in SSTs (Newman et al., 2016).

The current consensus suggests that rather than one process causing the IPO pattern, the decadal modulation of Pacific Ocean SSTs is most likely a combination of all the mechanisms mentioned above (Newman et al., 2016). However, regardless of the causal mechanisms, the climatic and societal impacts of the IPO mean it is important to understand (Henley et al., 2015; Newman et al., 2016).

\section{Interactions with the SPCZ}

Many climatic impacts of the IPO are similar to that of ENSO, except they are on longer timescales and of lower amplitude (Latif \& Barnett, 1996; Mantua \& Hare, 2002; Mantua et al., 1997). Folland et al. (2002) used surface wind convergence and noted a north-east (south-west) movement of the SPCZ during positive (negative) IPO phases, however it was more significant when the ENSO phase was incorporated into the analysis. They found that the greatest movement of the SPCZ occurred when the IPO and ENSO phases were working together. For example, when El Niño conditions occur during a positive IPO phase, the SPCZ moved maximally north-east, with the furthest south-west displacement occurring when La Niña conditions coincided with a negative IPO phase (Folland et al., 2002). The movement was less significant when ENSO and the IPO opposed each other (Figure 2.5). Salinger et al. (2014) and Kidwell et al. (2016) 
note similar SPCZ displacement in relation to the IPO. The SPCZ was east of its mean position during the period 1978-1999 (positive IPO) and west of the mean position for the period 1945-1977 (negative IPO). It appears to have moved westward since 1999 with a switch to negative IPO (Kidwell et al., 2016; Salinger et al., 2014). Kidwell et al. (2016) also noted that the SPCZ area seems to decrease in size during negative IPO events when compared to positive IPO events.

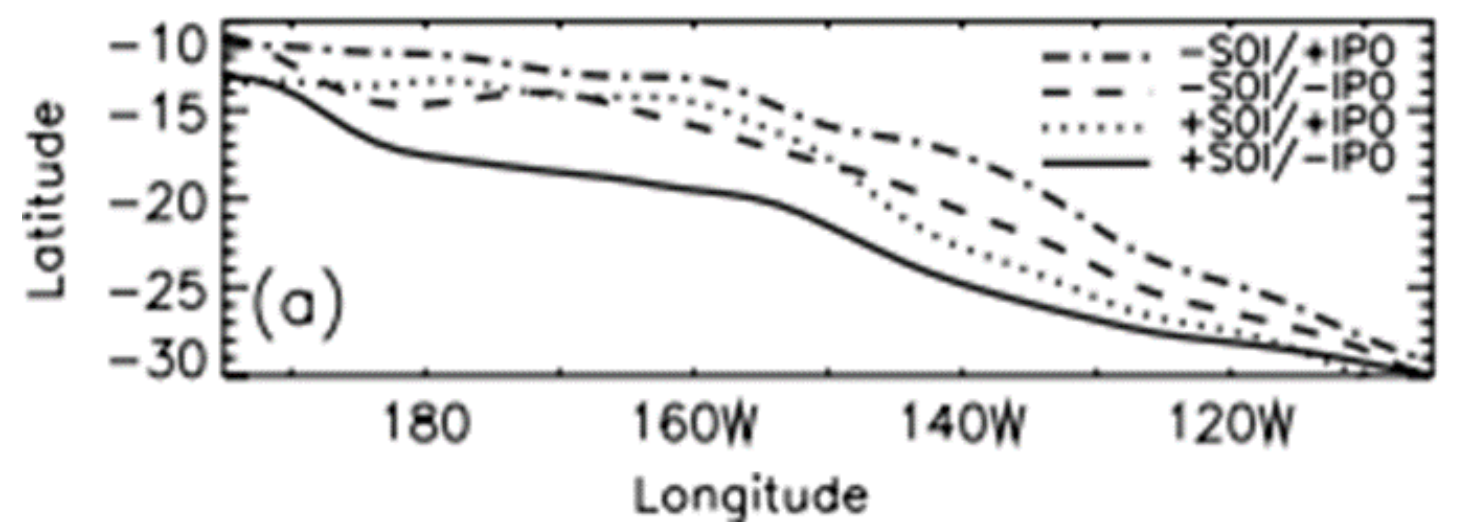

Figure 2.5 Mean SPCZ location in relation to IPO and ENSO phase. Figure modified from Folland et al., (2002).

Using oxygen isotopes from coral cores collected in Tonga and Fiji, Zhang (2007) constructed an IPO index in the region back to 1650 . This index was shown to closely correlate with IPO and SPCZ indices, and effectively extends knowledge of decadal variability in the South Pacific back 250 years prior to instrumental records (Zhang, 2007). This study suggests that the north-east movement of the SPCZ during the positive IPO phase, and south-west movement during the negative IPO phase remains consistent prior to the beginning of instrumental records (Zhang, 2007). However, in a similar study using a coral core from Rarotonga, Linsley et al. (2004) found evidence that the twentieth century spatial pattern of the IPO has varied in the South Pacific region over the past 300 years, particularly in the mid-1800s. It is suggested that this difference is likely due to trade wind variations and the position of the SPCZ, and implies that the IPO-SPCZ relationship might not be consistent prior to instrumental records (Linsley et al., 2004).

\subsection{Tropical Cyclones and the SPCZ}

\subsubsection{Tropical Cyclone Formation}

The conditions accompanying tropical cyclone development are relatively well understood, although they are complex and variable in time and space (Briegel \& Frank, 
1997; Frank \& Roundy, 2006). Early studies investigating favourable conditions for tropical cyclone development from Gray and Brody (1967) and Gray (1975) identified several key environmental conditions that influence genesis: SSTs above $26.5^{\circ} \mathrm{C}$ along with a deep oceanic mixed layer; deep instability through the troposphere; high humidity in the middle of the troposphere; no greater than moderate vertical wind shear; high low-level vorticity; and a location far enough from the equator to allow influence from the Coriolis effect. Briegel and Frank (1997) state that the first three parameters, in conjunction with favourable Coriolis conditions exist over significant parts of the tropical oceans over large time periods, whilst vertical wind shear and low-level vorticity conditions vary markedly on much smaller temporal and spatial scales. This theory implies that tropical cyclone development will occur in areas where locally weak wind shear and strong low level vorticity exist over an area of ocean exhibiting environmentally favourable conditions (Briegel \& Frank, 1997; Frank \& Roundy, 2006). An observational study by Zehr (1992) also noted that tropical cyclones usually develop when an area containing pre-existing deep convection and large-scale uplift coincide with cyclonic low-level vorticity and anticyclonic upper-level vorticity.

While the climatological parameters present during the formation of a tropical cyclone are relatively well understood, the mechanisms that produce these circulations are still uncertain (Camargo et al., 2007; Frank \& Roundy, 2006). Frank and Roundy (2006) state that the majority of tropical cyclones develop within the vicinity of the intertropical convergence zone (ITCZ), particularly when there is the existence of a monsoon trough with westerly flow on the equatorward side of the trough axis. The initial phase of genesis is the formation of a mesoscale vortex within an area of tropical convection, which can form in two ways: The spontaneous breakdown of the monsoon trough within the ITCZ if it remains unperturbed for a sufficient length of time; or external perturbations that can accelerate formation of tropical cyclones within preferred portions of the ITCZ (Briegel \& Frank, 1997; Frank \& Roundy, 2006). Genesis most probably occurs due a combination of these two factors (Frank \& Roundy, 2006). Once a mesoscale vortex is of sufficient maturity, it can sustain itself through interaction with warm ocean waters in the absence of further external perturbations (Briegel \& Frank, 1997). These external forces can come in a variety of forms, with Briegel and Frank (1997) showing that north-west Pacific typhoons tend to form when a mid-latitude trough interacts with the monsoon trough. 


\subsubsection{Influence of the SPCZ on Tropical Cyclones}

The majority of early work investigating tropical cyclone genesis in the south-west Pacific region largely revolved around their relationship with ENSO (e.g.Basher \& Zheng, 1995; Hastings, 1990; Revell \& Goulter, 1986). Many of these studies noted distinct spatial shifts in where tropical cyclones originated, with a north-eastward shift during El Niño conditions and a south-west displacement during La Niña conditions (Basher \& Zheng, 1995; Kuleshov et al., 2008). This trend is similar to the displacement of the SPCZ during El Niño and La Niña conditions noted in section 2.2.2, suggesting a strong relationship between the location of the SPCZ and tropical cyclone genesis (Vincent et al., 2011).

It has long been known that the SPCZ region (particularly the tropical component) is favoured for tropical cyclone development, after which they generally propagate to the south-east (Streten \& Troup, 1973; Vincent, 1994). However, it was only a more recent study by Vincent et al. (2011) that specifically looked into why tropical cyclone genesis was favoured in the SPCZ region. The study found that tropical cyclone Genesis was preferred within $10^{\circ} \mathrm{S}$ of the SPCZ location, due to: favourable cyclonic vorticity of low-level winds, sufficient deep convection, and low wind shear within this region (Vincent et al., 2011). Conversely, anti-cyclonic vorticity of low level winds helps to prevent tropical cyclone genesis to the north and east of the SPCZ (Vincent et al., 2011). They also demonstrated that tropical cyclone development is only likely to occur in the far south-west Pacific Ocean during most SPCZ conditions, however the region of genesis and tropical cyclone activity can extend further east towards French Polynesia during zonal swings of the SPCZ such as those of 1982/1983, 1991/1992, and 1997/1998 (Diamond et al., 2012; Sinclair, 2002; Vincent et al., 2011).

\subsection{The SPCZ and Climate Change}

Trying to predict how the SPCZ might react in the future to climate change is a difficult task, not only because it relies on the response of ENSO and the IPO, but also because models currently have difficulty in representing the SPCZ accurately (Brown et al., 2013; Evans et al., 2016; Niznik et al., 2015).

Studies attempting to simulate the SPCZ using the Coupled Model Inter-comparison Project phase 3 (CMIP3) and phase 5 (CMIP5) experiments found that the representation of the SPCZ in both projects was much too zonal (Brown et al., 2013; 
Brown et al., 2012; Niznik et al., 2015). This misrepresentation of the SPCZ is caused by SST biases, especially a systematic "cold tongue" bias that exists along the equator (Evans et al., 2016). In an attempt to overcome this issue, studies (e.g. Evans et al., 2016; Nguyen et al., 2012) have forced models with bias corrected SSTs from CMIP3 General Circulation Models (GCMs). This resulted in much more realistic precipitation patterns in the SPCZ region (Evans et al., 2016).

Modelled future changes of the SPCZ have produced varying results. Some suggest no major changes to the mean SPCZ location (Brown et al., 2012; Evans et al., 2016). Another study using bias corrected models by Widlansky et al. (2013) estimated that moderate future warming $\left(1-2^{\circ} \mathrm{C}\right)$ would lead to diminished precipitation in the SPCZ, while stronger warming (greater than $3^{\circ} \mathrm{C}$ ) would lead to increased precipitation. A study by Cai et al. (2012) also indicated no major change in future SPCZ location, however, it did suggest an increase in zonal SPCZ events in response to a predicted increase in extreme El Niño events. While the response of the SPCZ to climate change remains uncertain, attempts to model the SPCZ are of much importance, due to the potential future impact even small displacements could have on vulnerable Pacific Island nations (Cai et al., 2014; Cai et al., 2012; Evans et al., 2016). 


\section{Chapter 3 Data and Methodology}

Chapter 3 of this thesis provides an outline of the data used, and methodology employed to carry out this study. Section 3.1 gives a description of the various datasets that were used, as well as providing information on where to access this data. Section 3.2 then briefly details the methodologies that were implemented in order to carry out the research needed to complete this thesis.

\subsection{Data}

The initial aim of this study was to assess how realistically the 20CR products (Compo et al., 2011) depict the SPCZ over the course of the past century. To achieve this end, two 20CR products - 20CRv2 and 20CRv2c were assessed alongside a suite of other reanalysis and observational satellite products. The reanalysis products used for comparison were: the National Centers for Environmental Prediction - National Center for Atmospheric Research Reanalysis 1 (NCEP/NCAR1) (Kalnay et al., 1996), and the European Centre for Medium-Range Weather Forecasts (ECMWF) Interim Reanalysis (ERA Interim) (Dee et al., 2011). The satellite products used for comparison were: the Global Precipitation Climatology Project (GPCP) (Adler et al., 2003), the Tropical Rainfall Measuring Mission (TRMM) (Huffman et al., 2007), and the Outgoing Longwave Radiation (OLR) dataset from the National Oceanic and Atmospheric Administration (NOAA) (Liebmann \& Smith, 1996).

\subsubsection{Reanalysis Data}

\section{Twentieth Century Reanalysis}

The 20CR project was implemented to provide a global reanalysis dataset that spanned the entire twentieth century, while assimilating only physical surface observations (Compo et al., 2011). It originated out of the need for a long term reanalysis dataset that was able to quantify uncertainties of twentieth century climate model simulations (Compo et al., 2011). 20CRv2c runs from 1851-2012 (20CRv2 spans 1871-2012) at $2^{\circ}$ by $2^{\circ}$ latitude/longitude spatial resolution, and at 6 hourly time periods (Compo et al., 2011; Wang et al., 2013). 
Many reanalyses (e.g. NCEP/NCAR1, ERA Interim, and others) assimilate all usable available observations, including, but not limited to; surface observations, upper air data, and satellite observations (Compo et al., 2011). The 20CR product assimilates only surface observations, thereby avoiding artificial jumps and trends seen in some other reanalysis products that are associated with the changing nature of the observational record (e.g. the introduction of satellite data in the 1970s). The 20CR uses an ensemble of numerical weather prediction (NWP) model forecasts to obtain a first guess field of the state of the atmosphere (Compo et al., 2011; Wang et al., 2013). The advantage of this approach is that it allows for a coherent and consistent estimate of the atmospheric state, with the ability to produce a quality dataset extending further back in time beyond the satellite era. However, surface conditions do not uniquely represent the state of the full atmosphere, especially beyond the upper troposphere, meaning this approach is inherently limited. The 20CR datasets are available for download at https://www.esrl.noaa.gov/psd/data/20thC_Rean/, and for a detailed description of the 20CR project, see Compo et al. (2011) and references therein.

Data from five stations in the South Pacific were added to the International Surface Pressure Databank (ISPD) between 20CRv2 (ISPD version 2) and 20CRv2c (ISPD version 3) (Table 3.1). The analysis performed in this study should help determine if these extra observations, provided as a contribution from the National Institute of Water and Atmosphere (NIWA) to the Atmospheric Circulation Reconstructions over the Earth (ACRE) initiative, have helped improve the depiction of the SPCZ between the two products (A. Lorrey, personal communication, November 22, 2017).

Table 3.1 Details of stations where weather observations were added between 20CRv2 and 20CRv2c. Data supplied by Andrew Lorrey from National Institute of Water and Atmosphere (NIWA).

\begin{tabular}{|l|l|l|r|r|r|}
\hline Station Name & Lat & Lon & Time Period Start & Time Period End & ISPD Version \\
\hline Rarotonga Radio Station & $21.19^{\circ} \mathrm{S}$ & $158.81^{\circ} \mathrm{W}$ & $1 / 05 / 1934$ & $31 / 05 / 1950$ & 3 \\
\hline Penrhyn & $9^{\circ} \mathrm{S}$ & $158.05^{\circ} \mathrm{W}$ & $13 / 01 / 1937$ & $31 / 08 / 1996$ & 3 \\
\hline Pukapuka & $10.88^{\circ} \mathrm{S}$ & $165.82^{\circ} \mathrm{W}$ & $1 / 11 / 1929$ & $18 / 07 / 2000$ & 3 \\
\hline Rarotonga Aero & $21.18^{\circ} \mathrm{S}$ & $159.8^{\circ} \mathrm{W}$ & $1 / 06 / 1948$ & $30 / 09 / 2010$ & 3 \\
\hline Raro Avarua & $21.2^{\circ} \mathrm{S}$ & $159.78^{\circ} \mathrm{W}$ & $1 / 02 / 1929$ & $31 / 12 / 1933$ & 3 \\
\hline
\end{tabular}

\section{ERA Interim Reanalysis}

The ERA Interim Reanalysis product was until recently the most current reanalysis from the ECMWF (Dee et al., 2011). The ERA Interim Reanalysis was established partly to help prepare for the development of the ERA-20C project, and assimilates available satellite and physical observations (Dee et al., 2011). It runs from 1979- 
present using a horizontal spatial resolution of approximately $80 \mathrm{~km}$, producing surface and upper air parameters at three and six hourly intervals respectively (Dee et al., 2011). The ERA Interim dataset is available for download from https://www.ecmwf.int/en/forecasts/datasets/reanalysis-datasets/era-interim, and for a full description of the product, see Dee et al. (2011) and references therein.

\section{NCEP/NCAR Reanalysis 1}

The NCEP/NCAR1 reanalysis project arose from a perceived "jump" in many meteorological parameters that resulted from changes implemented in the Global Data Assimilation System run at NCEP (Kalnay et al., 1996). It was the first global reanalysis product available to the research community and its advent transformed research on the large-scale circulation of the atmosphere (J. Renwick, personal communication, November 28, 2017). The reanalysis runs from 1948-present, with data presented in a six hourly (four times daily) format and daily means, on a $2.5^{\circ}$ by $2.5^{\circ}$ latitude/longitude horizontal grid, with 17 vertical levels from the surface of the earth to the $10 \mathrm{hPa}$ level. Like ERA Interim, the reanalysis assimilates all available satellite and physical observations. The NCEP/NCAR1 Reanalysis data is provided by the NOAA/OAR/ESRL PSD, Boulder, Colorado, USA, from their website at https://www.esrl.noaa.gov/psd/, and for a full description of the product, see Kalnay et al. (1996) and references therein.

\subsubsection{Observational Satellite Data}

\section{Global Precipitation Climatology Project (GPCP) Data: Version 2.3 merged data}

The GPCP originated out of the need for a consistent, globally complete analysis of precipitation over the earth's land surface and oceans (Adler et al., 2003). It achieves this via a merged analysis of surface rain gauge observations, and precipitation estimates from satellite infrared and microwave data (Adler et al., 2003). The GPCP dataset runs from 1979 to present, providing monthly estimates of global surface rainfall at $2.5^{\circ}$ by $2.5^{\circ}$ latitude/longitude horizontal resolution. For this study, version 2.3 of the GPCP was used. The data is provided by the NOAA/OAR/ESRL PSD, Boulder, Colorado, USA, from their website at http://www.esrl.noaa.gov/psd/, and for a full description of the product, see Adler et al. (2003) and references therein. 


\section{Tropical Rainfall Measuring Mission (TRMM): TRMM and other satellites product 3B42 (version7)}

The TRMM project is a joint U.S.-Japan mission from the Japan Aerospace Exploration Agency (JAXA) and the National Aeronautical Space Agency (NASA) (Huffman et al., 2007). It originated out of the need for a calibrated estimate of precipitation based on satellite and gauge data at fine temporal and spatial scales (Huffman et al., 2007). The TRMM project provides precipitation estimates from $50^{\circ}$ North to $50^{\circ}$ South at a $0.25^{\circ}$ by $0.25^{\circ}$ latitude/longitude horizontal resolution (Huffman et al., 2007). It ran from 1998-2015, and has since been superseded by the Global Precipitation Measurement Programme. For this study, the 3B42 Version 7 post-real-time research version was used, and data was provided by NASA, from their website at https://pmm.nasa.gov/data-access/downloads/trmm. For a full description of the TRMM project see Huffman et al. (2007) and references therein.

\section{Outgoing Longwave Radiation (OLR) Data}

OLR measurements are used to estimate the radiation budget of the Earth and identify areas of strong tropical convection, with the dataset being sourced from NOAA polar orbiting satellites (Gruber \& Krueger, 1984; Gruber \& Winston, 1978; Liebmann \& Smith, 1996). The OLR dataset runs from 1974 to present, with two estimates per day (daytime and night time orbits), and are archived onto a $2.5^{\circ}$ by $2.5^{\circ}$ latitude/longitude horizontal grid by the National Environmental Satellite Data and Information Service of NOAA (Liebmann \& Smith, 1996). Interpolated OLR data are provided by the NOAA/OAR/ESRL PSD, Boulder, Colorado, USA, from their website at http://www.esrl.noaa.gov/psd/.

\subsubsection{Other Datasets}

\section{Multivariate ENSO Index}

The Multivariate ENSO Index (MEI) (Wolter \& Timlin, 1993) is one of a number of indices used to monitor the state of ENSO. It is based on six observed variables from the tropical Pacific: surface air temperature, SSTs, SLP, meridional and zonal winds, and the total cloudiness of the sky. The MEI dataset contains overlapping bi-monthly MEI values for each year (e.g. Jan/Feb, Feb/Mar, Mar/Apr, etc.). For this study, all bimonthly values from November to April were averaged to create an Austral summer seasonal MEI value, a method similar to that used by Haffke and Magnusdottir (2013). 
This gave one MEI value for each summer season that could be analysed (Appendix A). The MEI data were acquired from NOAA/ESRL at https://www.esrl.noaa.gov/psd/enso/mei/table.html and https://www.esrl.noaa.gov/psd/enso/mei.ext/table.ext.html

Quintiles of this dataset were used to represent whether any given Austral summer season would be classified as El Niño, La Niña, or Neutral for this study. The $80^{\text {th }}-100^{\text {th }}$ percentile is used to represent a strong El Niño, the $60^{\text {th }}-80^{\text {th }}$ percentile to represent a weak El Niño, the $0-20^{\text {th }}$ percentile to represent a strong La Niña, and the $20^{\text {th }}-40^{\text {th }}$ percentile to represent a weak La Niña. The DJF seasons which fall in the $40^{\text {th }}-60^{\text {th }}$ percentile are treated as a neutral seasons. Whilst this is different to the way that ENSO events are normally classified, it provides a representative sample size for each chosen ENSO classification.

\section{Tripole Index for the IPO}

The Tripole Index (TPI) (Henley et al., 2015) for the IPO takes the difference between the average SST anomalies in the southwest and northwest Pacific, and the SST anomalies in the equatorial Pacific Ocean, producing an index to measure Pacific Ocean inter-decadal variability (Figure 3.1).

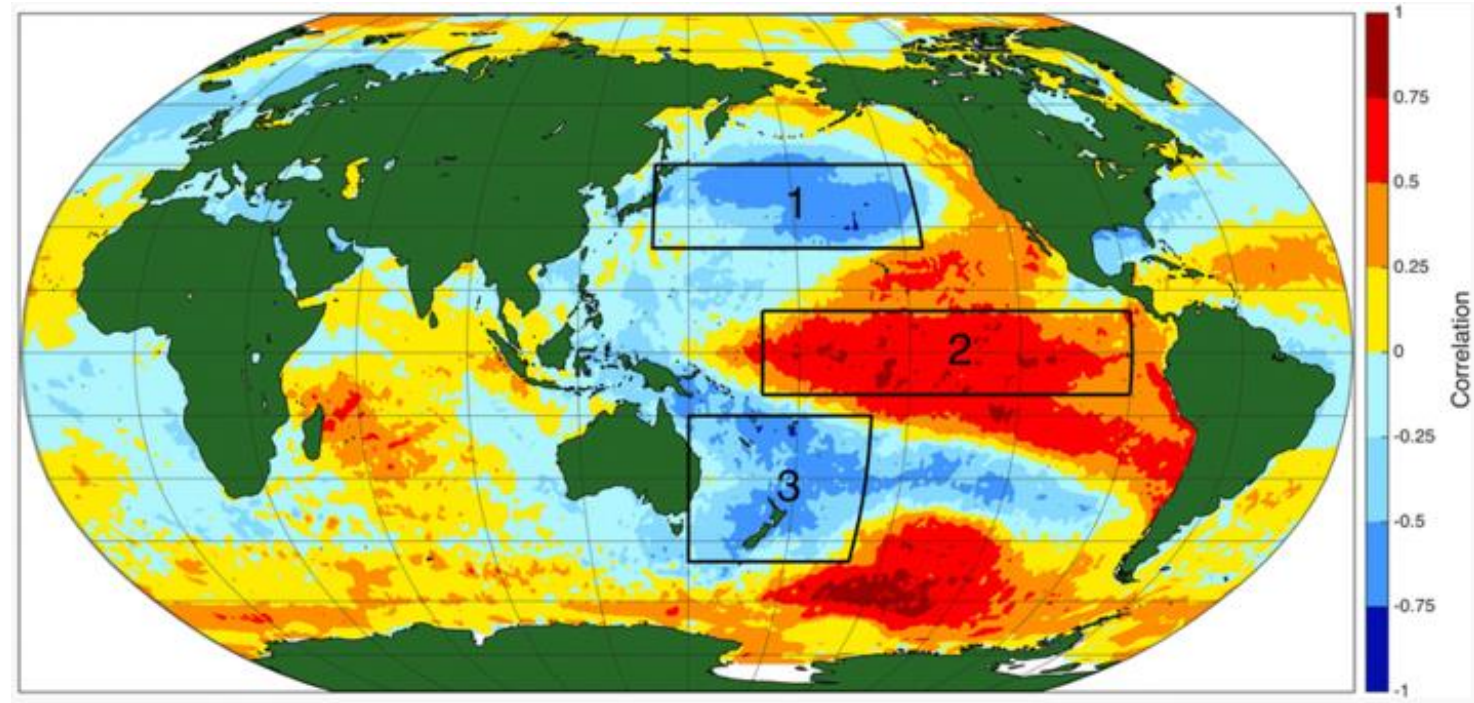

Figure 3.1 The unfiltered correlation between the IPO and SST from HadISST2.1. TPI regions are indicated by the black boxes, with the index calculated as the difference between the average SST anomalies from the central Pacific (box 2) and the Southwest and Northwest Pacific (boxes 3 and 1 respectively) (Henley et al., 2015)

For this study, the unfiltered TPI was used from the NOAA Extended Reconstructed Sea Surface Temperature (ERSST) version 5 (v5) dataset. This dataset contains monthly values from January 1870 to present and the dataset updates monthly. The monthly 
values from November to April were averaged to create an Austral summer season TPI. This left one TPI value for each Austral summer season from 1908/1909-2011/2012 to be used for IPO analysis in this study (Appendix A). The TPI data were current as of 21/3/2018 and were acquired from NOAA/ESRL at https://www.esrl.noaa.gov/psd/data/timeseries/IPOTPI/tpi.timeseries.ersstv5.data

\section{Extended Reconstructed Sea Surface Temperature (ERSST) v5}

The Extended Reconstructed Sea Surface Temperature (ERSST) (Huang et al., 2017) version 5 (v5) dataset is the newest monthly SST dataset provided from the International Comprehensive Ocean-Atmosphere Dataset (ICOADS). The ERSSTv5 dataset spans from 1854 to present on a $2^{\circ}$ by $2^{\circ}$ latitude/longitude horizontal grid, and uses new SST data from version 3.0 release from ICOADS. The ERSSTv5 data were acquired from NOAA/ESRL at https://www.esrl.noaa.gov/psd/data/gridded/data.noaa.ersst.v5.html.

\subsection{Methodology (Data Manipulation)}

All reanalysis and satellite observational data were downloaded into a NetCDF format and manipulated through the MATLAB programme. These global datasets were interpolated onto a $1.5^{\circ} \times 1.5^{\circ}$ horizontal grid covering the area from $150^{\circ} \mathrm{E}$ to $120^{\circ} \mathrm{W}$ in longitude and $0^{\circ}$ to $35^{\circ} \mathrm{S}$ in latitude, an area of the Southwest Pacific that includes both the tropical and subtropical components of the SPCZ (Figure 3.2).

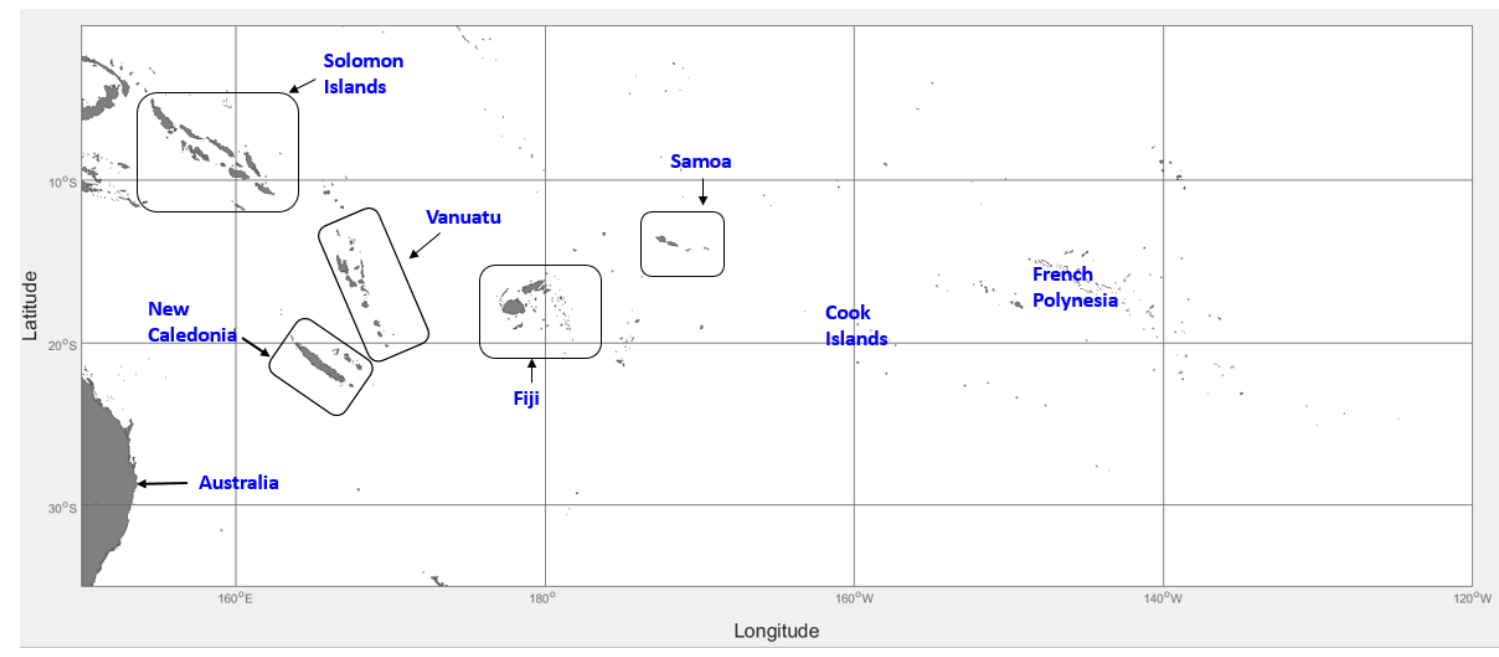

Figure 3.2 Base map showing the region that the SPCZ is analysed in for this study. The map covers an area of the Southwest Pacific from $150^{\circ} \mathrm{E}$ to $120^{\circ} \mathrm{W}$ in longitude and $0^{\circ}$ to $35^{\circ} \mathrm{S}$ in latitude.

The analysis for part one of this study is from 1979-2011, a period when all of the products overlap within the satellite era, with the exception of the TRMM dataset, in 
which data from 1998-2011 was used for this study. The analysis for part two and three of this study only used the 20CR products and covered the period from 1908-2011.

\subsubsection{Identification of the SPCZ (Position)}

There are various fields that have been used to identify the location of the SPCZ. These include, minima in near surface $(10 \mathrm{~m})$ wind divergence, OLR, and $500 \mathrm{hPa}$ vertical velocity (expressed as "omega", the time rate of change of pressure rather than height), and a maximum in precipitation (Brown et al., 2011). Minimum 10m wind divergence is used to represent maximum near surface wind convergence, and positive values of omega represent downward motion, so minimum downward motion represents maximum upward motion (convection). Both of these fields are representative of convergence zones. Minimum OLR represents maximum cloudiness, which indicates the strongest areas of convection in tropical regions, although this relationship is not as strong in subtropical regions (Van Der Wiel et al., 2015b). In this study, minimum 10m wind divergence (referred to as surface wind convergence herein) and $500 \mathrm{hPa}$ omega were used to indicate the position and intensity of the SPCZ when analysing the reanalysis products. The representation of the SPCZ in the reanalysis products can then be compared with minimum OLR and maximum precipitation from the observational satellite products.

Within the specified SPCZ area, monthly mean values for the aforementioned climate fields were used to calculate a December to February (DJF) mean position of the SPCZ. The mean Austral summer position of the SPCZ was then identified as a line of minimum $500 \mathrm{hPa}$ omega, $10 \mathrm{~m}$ wind divergence, OLR, and maximum precipitation. This approach is similar to Brown et al. (2011). For the reanalysis products, the latitude of minimum omega and wind divergence was located across each longitude within the SPCZ region, and a line was fitted between each point to represent the SPCZ location. The same method was applied to the observational satellite products, with a line of minimum OLR and maximum precipitation used to denote the position of the SPCZ.

Once the location of the SPCZ was identified, a 13-point low pass filter was run over the location points twice to show a smoothed depiction of the SPCZ. This is the same filter that is used in Chapter 3 of the Working Group 1 report of the IPCC $4^{\text {th }}$ Assessment. A comparison of the original versus smoothed depiction of the SPCZ can be seen in Figure 3.3. 


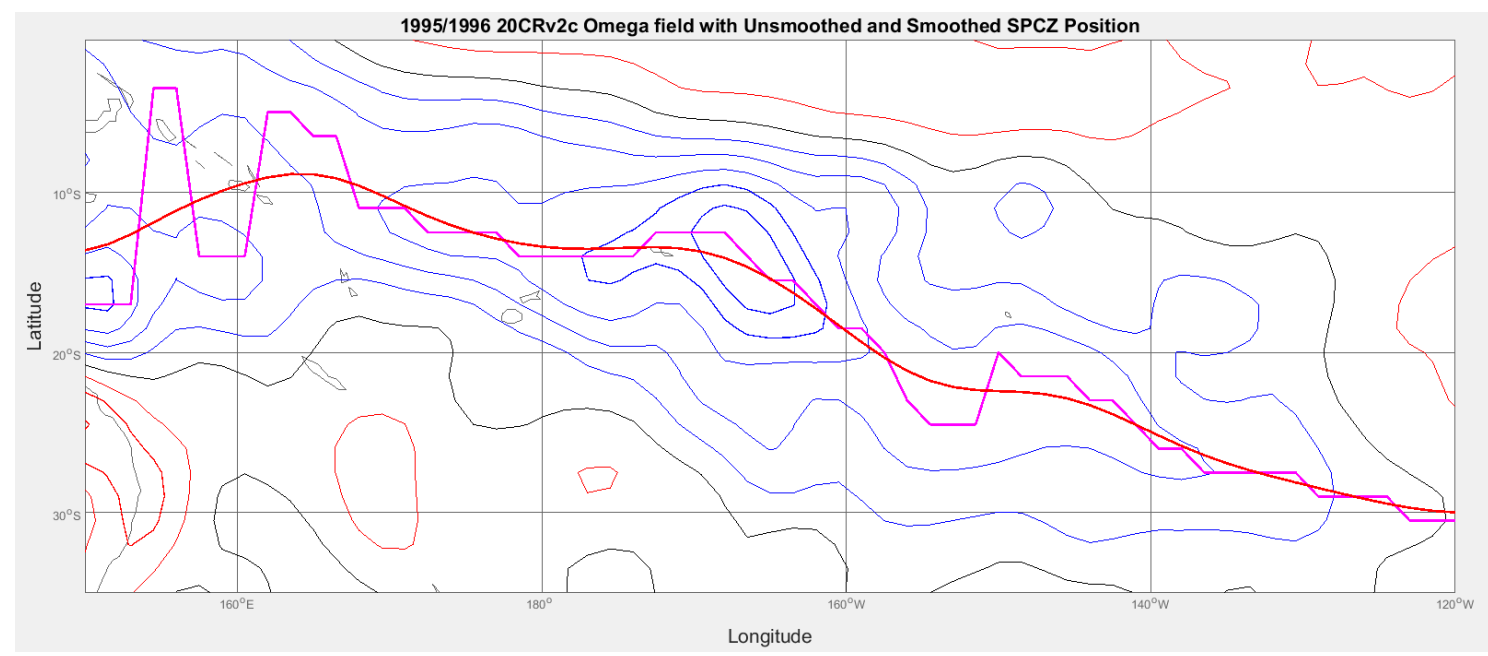

Figure 3.3 Contours are the DJF 1995/1996 average 500hPa omega fields (Pa/s, contour interval 0.02, black contour 0 , red contours above 0 , blue contours less than 0 . The pink line shows the latitude of minimum omega at each longitude, and the red line shows the filtered/smoothed version.

\subsubsection{Identification of the SPCZ (Intensity)}

In an effort to maintain consistency through this study, the method of finding the greatest intensity of the SPCZ was very similar to that employed to find the position of the SPCZ, which is described in section 3.2.1. The greatest intensity for each SPCZ metric was determined for each longitude, and the resulting line was smoothed twice using the 13-point low pass filter described in section 3.2.1. It must be stressed that the intensity values were not calculated from the smoothed line of the SPCZ position, as these values would not actually represent the greatest intensity across the longitudinal range. The differing intensity values that are achieved when comparing these two methods can be seen in Figure 3.4. When the SPCZ intensity is being investigated throughout this study, the values used are from the smoothed version of the maximum calculated magnitude data (yellow line in Figure 3.4). 


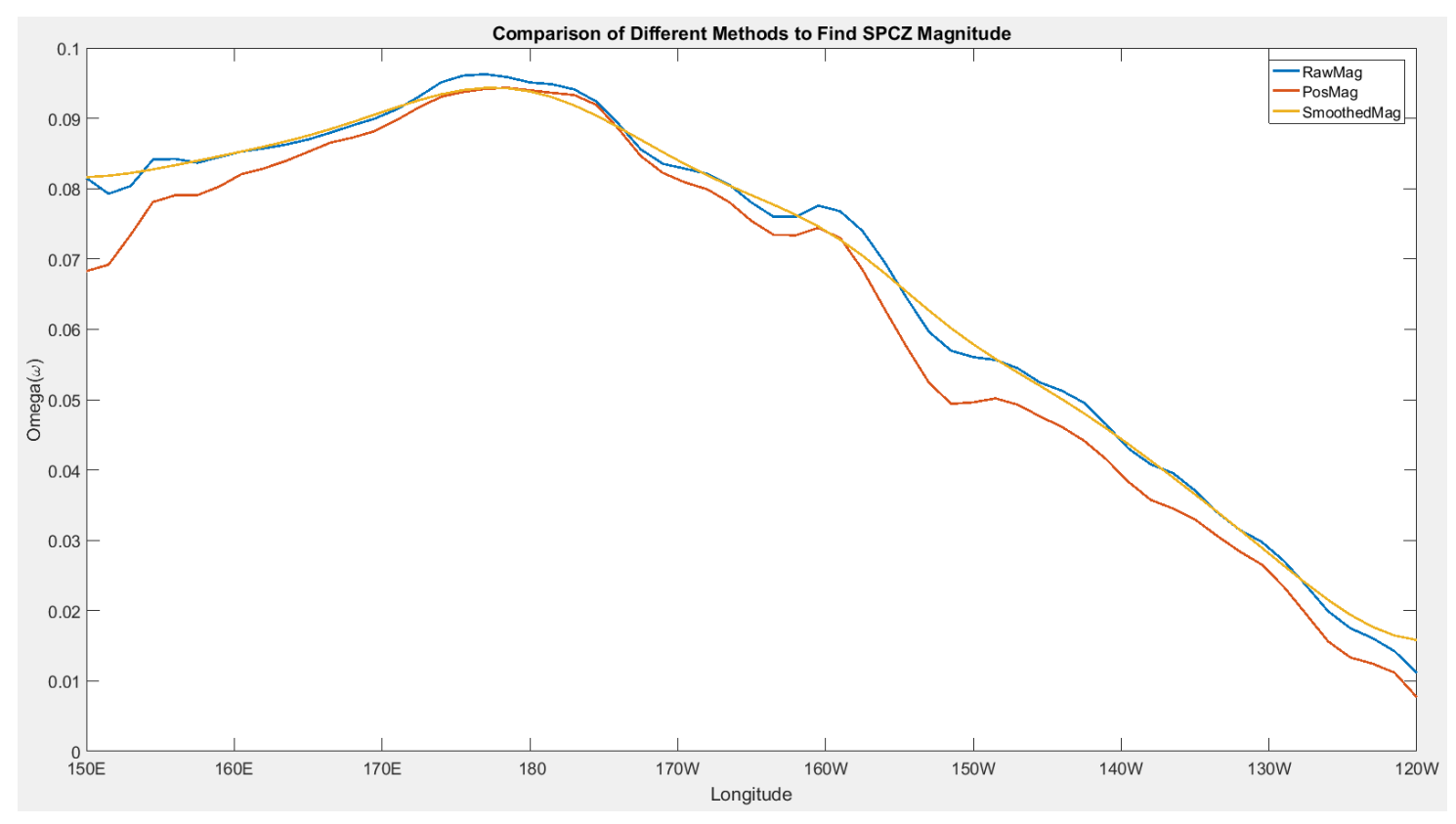

Figure 3.4 Comparison of the greatest magnitude of the SPCZ from the 20CRv2c 500hPa omega fields from 19792011 using different methods. The red line shows the magnitude if calculated off the smoothed line of the SPCZ position calculated as described in section 3.2.1. The blue line shows the maximum intensity calculated for each longitude across the SPCZ region, and the yellow line is the smoothed version of the blue line.

\subsubsection{Analysis Techniques}

Composite averages of SPCZ position and intensity were calculated according to the values of various time series: the MEI, the TPI, and for twenty-year periods through time ("bins"). The MEI time series data described in section 3.1.3 is used for the ENSO analysis, while the widely accepted IPO periods of the twentieth century from Mantua and Hare (2002) are used for IPO analysis. The twenty-year time periods starting at 1908 were chosen to give an evenly representative sample in order to analyse SPCZ trends through time.

Correlation analysis was performed to study the strength of spatial and temporal relationships of the SPCZ position and intensity. The correlation in longitude of average SPCZ position (latitude point) was calculated to show the spatial correlation, while the correlation in time for each longitude was calculated in order to investigate similarity in inter-annual variability between products.

In order to investigate the dominant modes of variability of SPCZ position and intensity, this study utilised EOF analysis (Wilks, 2011). From this analysis, correlation and regression maps were created with the ERSSTv5 SST dataset (dataset explained in section 3.1.3). This allowed visualisation of the SST anomaly expression in the Southwest Pacific area to determine whether the variability of the SPCZ was related to physical climate modes. 
A student's t-test was used to investigate whether there was a statistically significant difference between the representation of the SPCZ between 20CRv2 and 20CRv2c. Linear trend regression analysis was also performed at points across the longitudinal expanse of the analysed SPCZ region to determine whether there was an evident southward movement of the SPCZ through the twentieth and early twenty-first century.

The specific time periods and products used for each part of the analysis will be outlined in the results section (Chapter 4). 


\section{Chapter 4 Results}

Chapter 4 of this thesis will feature results from the research that has been carried out for this study. Section 4.1 will compare the location and intensity of the SPCZ across all of the reanalysis and satellite products from 1979-2011, before section 4.2 looks at the comparison between 20CRv2 and v2c from 1908 to 2011. In section 4.3, 20CRv2c will be used to investigate the effect of inter-annual and decadal variability on the SPCZ, with focus on ENSO, the IPO, and twentieth century trends. This analysis will also be performed for the 1908-2011 period.

\subsection{Inter-comparison of Reanalysis and Satellite Products}

In order to assess the efficacy of the two 20CR products in capturing SPCZ location and intensity, their depiction of the southwest Pacific tropical-subtropical convergence was compared with a suite of reanalysis and observational satellite products for the 19792011 period (described in section 3.1). Using the reanalyses, this was performed using mean DJF minimum 500hPa omega, and minimum 10m wind divergence fields, both of which are regularly used to identify areas of convergence and convection (e.g. Brown et al., 2011). TRMM and GPCP use maximum rainfall to represent the SPCZ, while the OLR dataset uses minimum in outgoing longwave radiation.

\subsubsection{0 hPa Omega: Location}

The mean DJF location of the SPCZ in the reanalyses from 1979-2011 was examined using the $500 \mathrm{hPa}$ omega field, and it was evident that all of the products analysed showed good agreement, especially west of $160^{\circ} \mathrm{W}$. There is some divergence between the products to the east of this line, particularly when looking at OLR (shown in pink) which lies south of the other products, and the NCEP/NCAR1 reanalysis (shown in red) which lies to the north (Figure 4.1). 


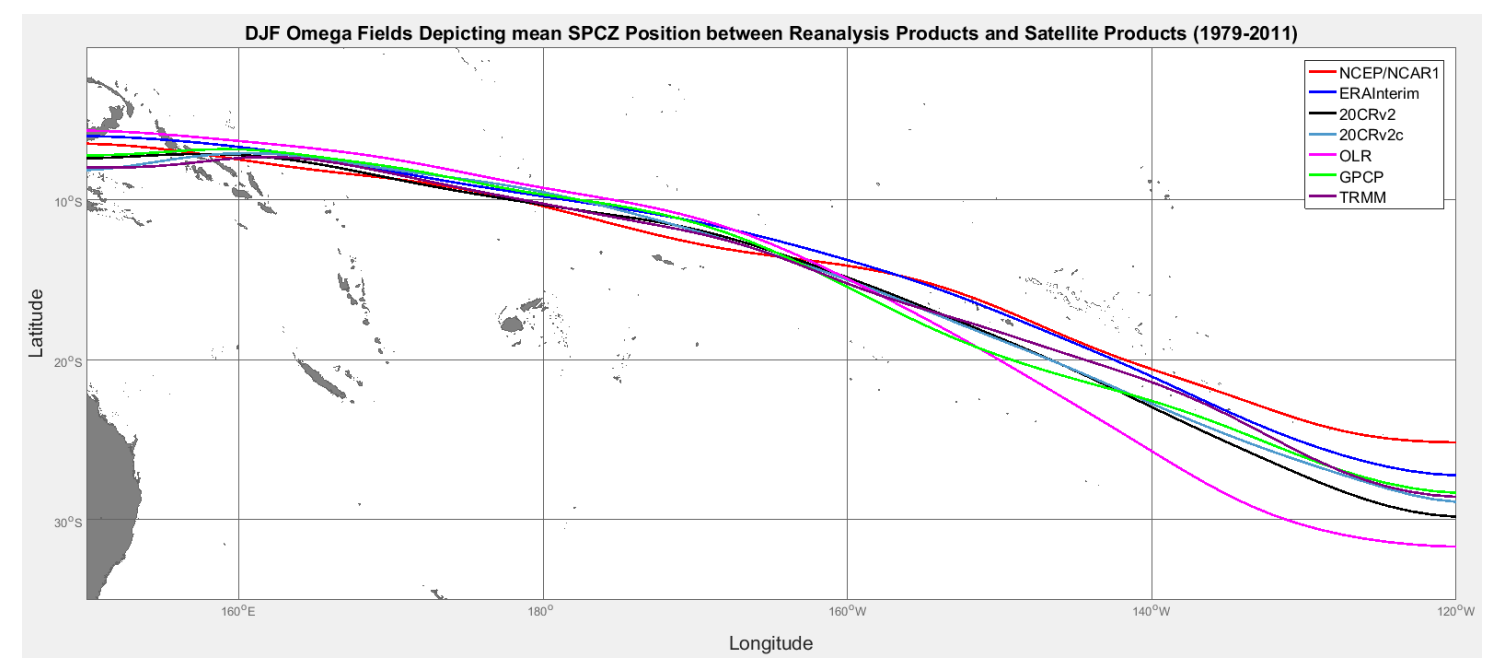

Figure 4.1 The mean DJF location of the SPCZ from 1979-2011 between the analysed products. Analysis was using the $500 \mathrm{hPa}$ omega field (from the reanalyses) during the austral summer period. NCEP/NCAR1 is shown by the red line, ERA Interim by the dark blue line, 20CRv2 by the black line, 20CRv2c by the light blue line, OLR by the pink line, GPCP by the green line, and TRMM by the purple line.

The NCEP/NCAR1 reanalysis shows a southernmost SPCZ position out of all the products between $150^{\circ} \mathrm{E}$ and $\sim 165^{\circ} \mathrm{W}$, and the northernmost to the east of $\sim 160^{\circ} \mathrm{W}$. This indicates the NCEP/NCAR1 reanalysis represents the SPCZ in the most zonal orientation of all the reanalyses. NCEP/NCAR1 is the oldest reanalysis product used in the study, and the zonal orientation issue is mentioned in various studies (e.g. Brown et al., 2013; Brown et al., 2012; Niznik et al., 2015). The OLR field is in good agreement with the other products west of $\sim 150^{\circ} \mathrm{W}$, but diverges to the south of the other products in the eastern part of the analysis domain. A possible explanation for this departure could be that the close relationship between OLR and precipitation in the tropics breaks down once the SPCZ becomes more subtropical in the eastern part of the analysis domain (see Van Der Wiel et al., 2015b).

The location of the SPCZ in the two 20CR products showed good agreement with all other analysed products. This can be seen in Figure 4.1, and is also corroborated by very significant spatial correlations $(\mathrm{r} \geq 0.99, \mathrm{n}=61$, d.f. $=59, \mathrm{p}<0.01)$ between $20 \mathrm{CR}$ and all other reanalysis and satellite products. There are weaker, but still highly significant time series correlations $(\mathrm{r}=0.6-0.9, \mathrm{n}=61$, d.f. $=59, \mathrm{p}<0.01)$ at each longitude between 20CRv2c and the ERA Interim, GPCP, and OLR products across the longitudinal range of the SPCZ area for the 1979-2011 period (Table 4.1). This demonstrates that the inter-annual variation of the position of the SPCZ is similar between these products across the SPCZ area. 
Table 4.1 20CRv2c temporal correlations with OLR (top), GPCP (middle), and ERA Interim (bottom). Correlations are for SPCZ position at each longitude across longitudinal range for the mean 1979-2011 DJF period.

\begin{tabular}{|l|r|r|r|r|r|r|r|r|r|r|r|r|r|r|r|r|r|r|r|r|}
\hline \multicolumn{10}{|c|}{ 20CRv2 Interannual Position Correlation with OLR, GPCP, and ERA Interim } \\
\hline & $150^{\circ} \mathrm{E}$ & $156^{\circ} \mathrm{E}$ & $162^{\circ} \mathrm{E}$ & $168^{\circ} \mathrm{E}$ & $174^{\circ} \mathrm{E}$ & 180.00 & $174^{\circ} \mathrm{W}$ & $168^{\circ} \mathrm{W}$ & $162^{\circ} \mathrm{W}$ & $156^{\circ} \mathrm{W}$ & $150^{\circ} \mathrm{W}$ & $144^{\circ} \mathrm{W}$ & $138^{\circ} \mathrm{W}$ & $132^{\circ} \mathrm{W}$ & $126^{\circ} \mathrm{W}$ & $120^{\circ} \mathrm{W}$ \\
\hline OLR & 0.70 & 0.80 & 0.84 & 0.88 & 0.90 & 0.89 & 0.85 & 0.86 & 0.85 & 0.80 & 0.78 & 0.71 & 0.75 & 0.81 & 0.84 & 0.87 \\
\hline GPCP & 0.80 & 0.84 & 0.75 & 0.82 & 0.93 & 0.86 & 0.85 & 0.89 & 0.85 & 0.67 & 0.68 & 0.79 & 0.83 & 0.80 & 0.87 & 0.90 \\
\hline ERA & 0.64 & 0.80 & 0.84 & 0.86 & 0.89 & 0.90 & 0.92 & 0.92 & 0.89 & 0.76 & 0.75 & 0.82 & 0.80 & 0.83 & 0.90 & 0.92 \\
\hline
\end{tabular}

\subsubsection{0 hPa Omega: Intensity}

Looking at the 1979-2011 SPCZ intensity plots, it is evident that all products show the greatest intensity from the International Date Line (IDL) westward, and convective intensity diminishes rapidly east of $180^{\circ}$ (Figure 4.2). The ERA Interim reanalysis and OLR field indicate the SPCZ is represented most strongly on the western boundary of the analysis domain $\left(150^{\circ} \mathrm{E}\right)$, whereas the other products suggest the intensity is greatest between the IDL and $170^{\circ} \mathrm{E}$.
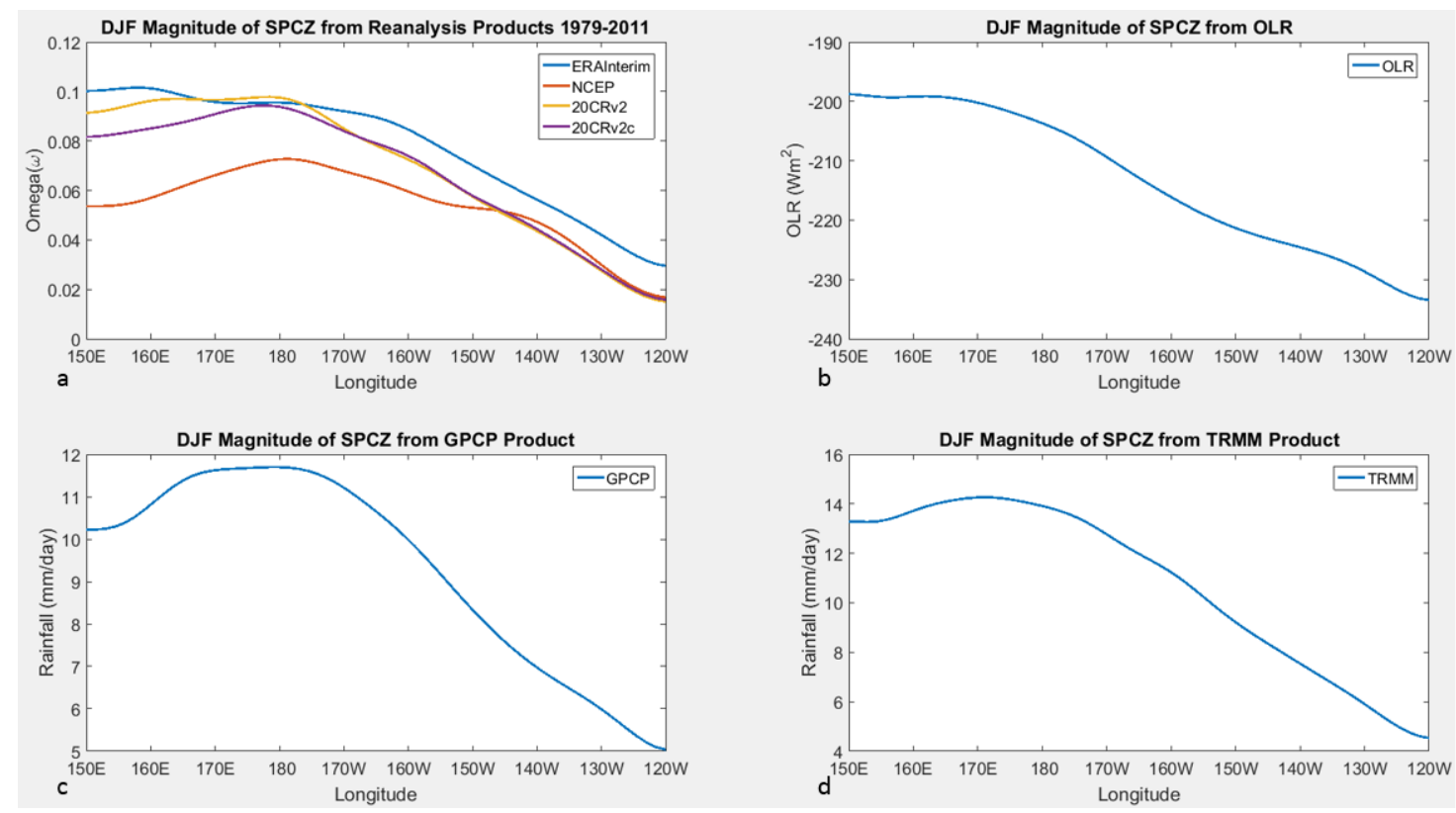

Figure 4.2 The mean DJF intensity of SPCZ for (a) $500 \mathrm{hPa}$ omega field of the four reanalysis products (b) OLR (note that OLR is depicted in negative values. This was done in order to produce a plot consistent the other satellite and reanalysis products) (c) GPCP and (d) TRMM. In plot (a) ERA Interim is shown by the blue line, NCEP/NCAR1 by the orange line, $20 \mathrm{CRv} 2 \mathrm{c}$ by the yellow line, and 20CRv2c by the purple line.

The most notable pattern seen in Figure 4.2 is how much weaker in intensity the SPCZ is in the far eastern portion of the analysis domain compared to the highest intensity in the west. This is to be expected, as convection is strongest in the tropical component of the SPCZ, and diminishes towards the east in the subtropical component. It is also evident that the NCEP/NCAR1 reanalysis product displays the SPCZ as noticeably weaker compared to the other three reanalyses, which are more closely aligned with each other. 
The two 20CR products show good agreement with the other analysed products when investigating SPCZ intensity (Figure 4.2), and according to spatial correlations ( $\mathrm{r} \geq$ $0.89, \mathrm{n}=61$, d.f. $=59, \mathrm{p}<0.01)$ between the $20 \mathrm{CR}$ and all other reanalysis and satellite products. Overall, the inter-annual variability of the SPCZ intensity at distinct longitudes also shows positive and significant cross-correlations when comparing 20CRv2c to the GPCP, ERA Interim, and OLR products (Table 4.2). The correlations are weaker in the far west of the SPCZ area (insignificant for 20CRv2c vs ERA Interim), but are better to the east of $\sim 170^{\circ} \mathrm{E}$. This demonstrates that the inter-annual variability of SPCZ intensity is similar between the reanalysis, in situ rainfall, and satellite products across the majority of the SPCZ area.

Table 4.2 20CRv2c temporal correlations with OLR (top), GPCP (middle), and ERA Interim (bottom). Correlations are for SPCZ intensity at each longitude across longitudinal range for the mean 1979-2011 DJF period.

\begin{tabular}{|l|r|r|r|r|r|r|r|r|r|r|r|r|r|r|r|r|r|r|r|}
\hline \multicolumn{110}{|c|}{ 20CRv2 Interannual Intensity Correlation with OLR, GPCP, and ERA Interim } \\
\hline & $150^{\circ} \mathrm{E}$ & $156^{\circ} \mathrm{E}$ & $162^{\circ} \mathrm{E}$ & $168^{\circ} \mathrm{E}$ & $174^{\circ} \mathrm{E}$ & 180.00 & $174^{\circ} \mathrm{W}$ & $168^{\circ} \mathrm{W}$ & $162^{\circ} \mathrm{W}$ & $156^{\circ} \mathrm{W}$ & $150^{\circ} \mathrm{W}$ & $144^{\circ} \mathrm{W}$ & $138^{\circ} \mathrm{W}$ & $132^{\circ} \mathrm{W}$ & $126^{\circ} \mathrm{W}$ & $120^{\circ} \mathrm{W}$ \\
\hline OLR & 0.17 & 0.34 & 0.37 & 0.41 & 0.57 & 0.73 & 0.79 & 0.76 & 0.75 & 0.68 & 0.73 & 0.80 & 0.83 & 0.73 & 0.62 & 0.64 \\
\hline GPCP & 0.30 & 0.38 & 0.47 & 0.55 & 0.63 & 0.71 & 0.75 & 0.68 & 0.65 & 0.64 & 0.81 & 0.89 & 0.85 & 0.68 & 0.61 & 0.64 \\
\hline ERA & 0.01 & 0.25 & 0.48 & 0.68 & 0.74 & 0.71 & 0.73 & 0.70 & 0.76 & 0.73 & 0.82 & 0.90 & 0.93 & 0.85 & 0.71 & 0.72 \\
\hline
\end{tabular}

These results stated above indicated that the performance of the 20CRv2c product in depicting both the position and intensity of the SPCZ (from the 500hPa vertical motion field) was sufficient to warrant its use in performing further analysis extending back to 1908.

\subsubsection{0m Wind Divergence: Location}

Looking at the mean DJF location of the SPCZ from 1979-2011 based on low level divergence (Figure 4.3) it is clear that this reanalysis field does not match the satellite products nearly as well as when using the omega reanalysis field. 


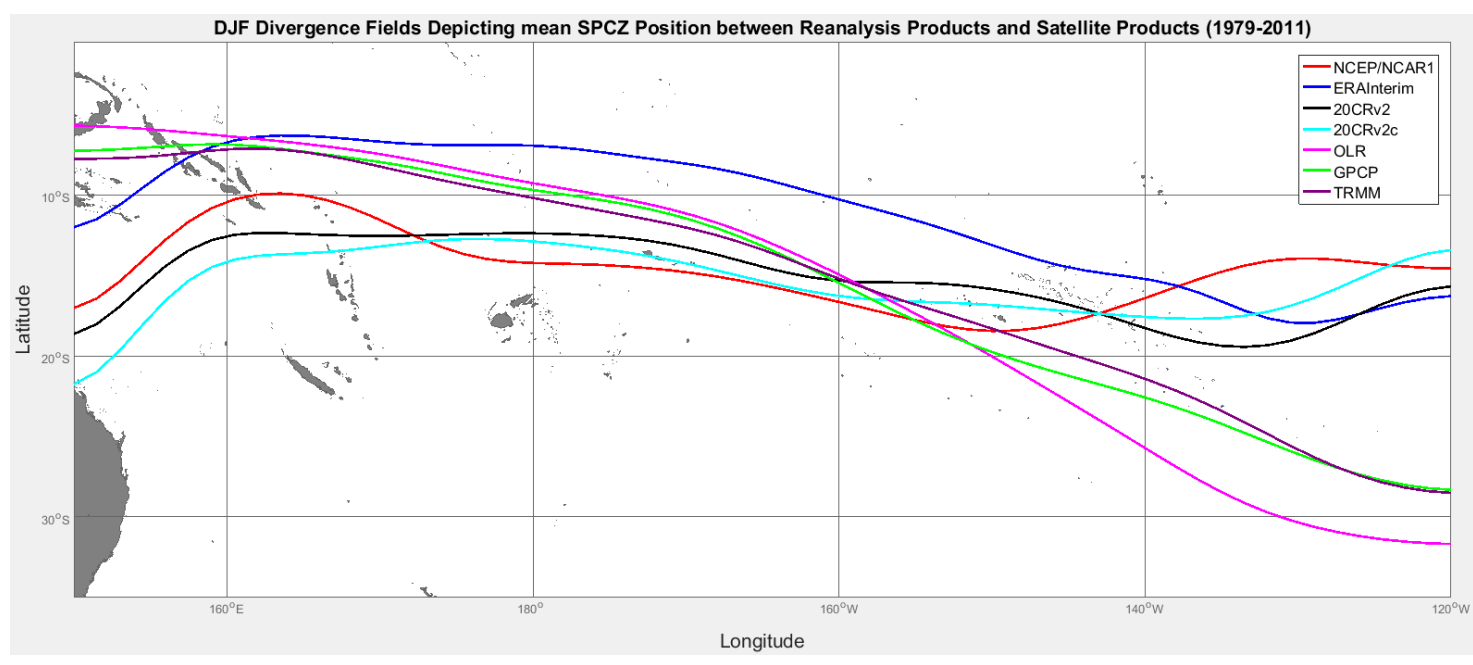

Figure 4.3 The mean DJF location of the SPCZ from 1979-2011 between the analysed products. Analysis was using the $10 \mathrm{~m}$ divergence field during the austral summer period. NCEP/NCAR1 is shown by the red line, ERA Interim by the dark blue line, 20CRv2 by the black line, 20CRv2c by the light blue line, OLR by the pink line, GPCP by the green line, and TRMM by the purple line.

The pattern that stands out with the divergence reanalysis product is the representation of the SPCZ as almost zonal. Two common traits can be observed; first, there is a southward dip for the SPCZ to the west of $160^{\circ} \mathrm{E}$, and second, there is a northward displacement of the SPCZ position east of $140^{\circ} \mathrm{W}$. The southward dip in the far west is likely related to the area of strong convergence that shows up over eastern Australia in most austral summer seasons (see example in Figure 4.4). In the far-east, areas of significant convergence also show up consistently between the equator and $10^{\circ} \mathrm{S}$ across the reanalyses. This leads to the representation of low level divergence as a proxy for the SPCZ in all four reanalysis products being significantly south of the satellite products in the west, and significantly north of the satellite products in the east. Overall, using the method of identifying the SPCZ, it can clearly be seen that using $500 \mathrm{hPa}$ omega field produces a more realistic depiction of the SPCZ, in comparison to the $10 \mathrm{~m}$ wind convergence field. 


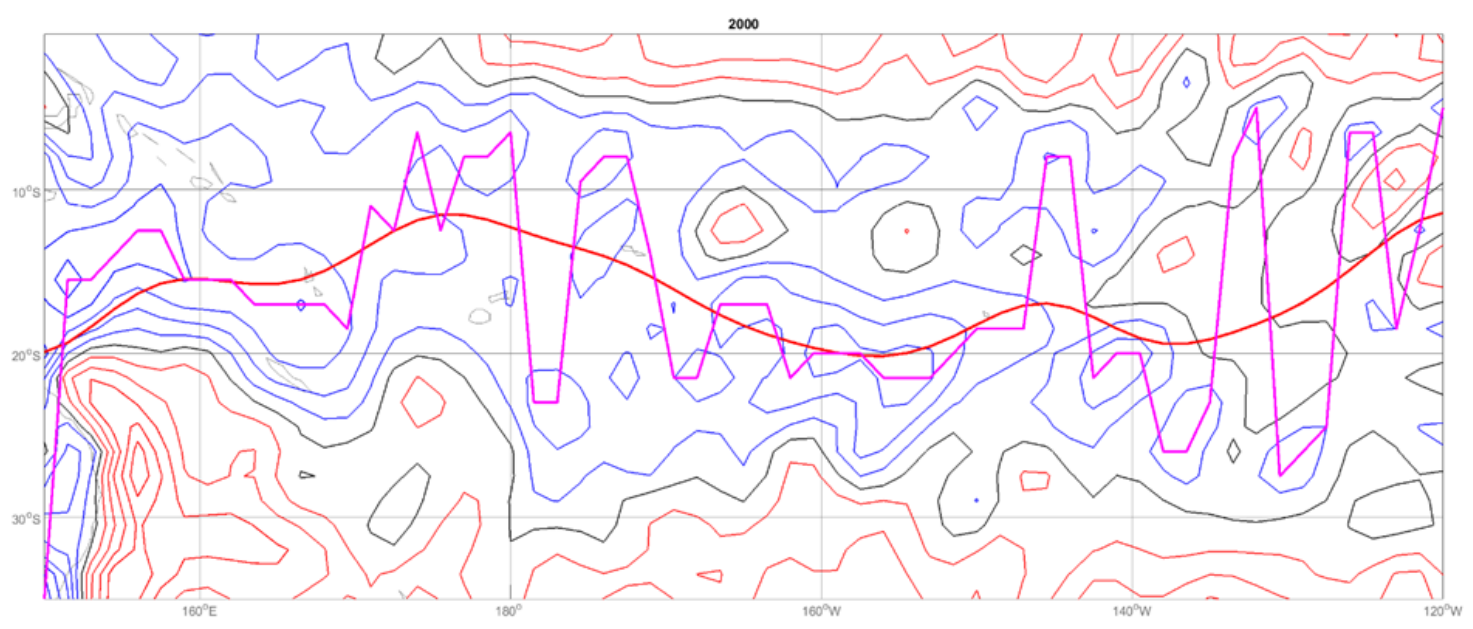

Figure 4.4 The SPCZ depicted from 10m divergence field for DJF from 2000/2001. The thick pink line connects the latitudinal points of minimum divergence (maximum convergence) across the longitudinal range. The thick red line is the depiction of the SPCZ once the 13 point low pass filter has been applied twice. Note the area of strong convergence over eastern Australia that influences the depiction of the SPCZ when using $10 \mathrm{~m}$ wind divergence.

\subsubsection{0m Wind Divergence: Intensity}

The intensity of the SPCZ depicted from 10m wind convergence (Figure 4.5) shows a different pattern to that shown in Figure 4.2. Rather than most reanalysis products showing a peak in intensity from $170^{\circ} \mathrm{E}$ to the IDL, all of them show the highest intensity in the far west of the plot (Figure 4.5a). While this is plausible, it is also the area where the SPCZ is inferred as having an unrealistic southward dip across all reanalysis products (Figure 4.3), which show it is related to the area of strong convergence over eastern Australia rather than the SPCZ itself.
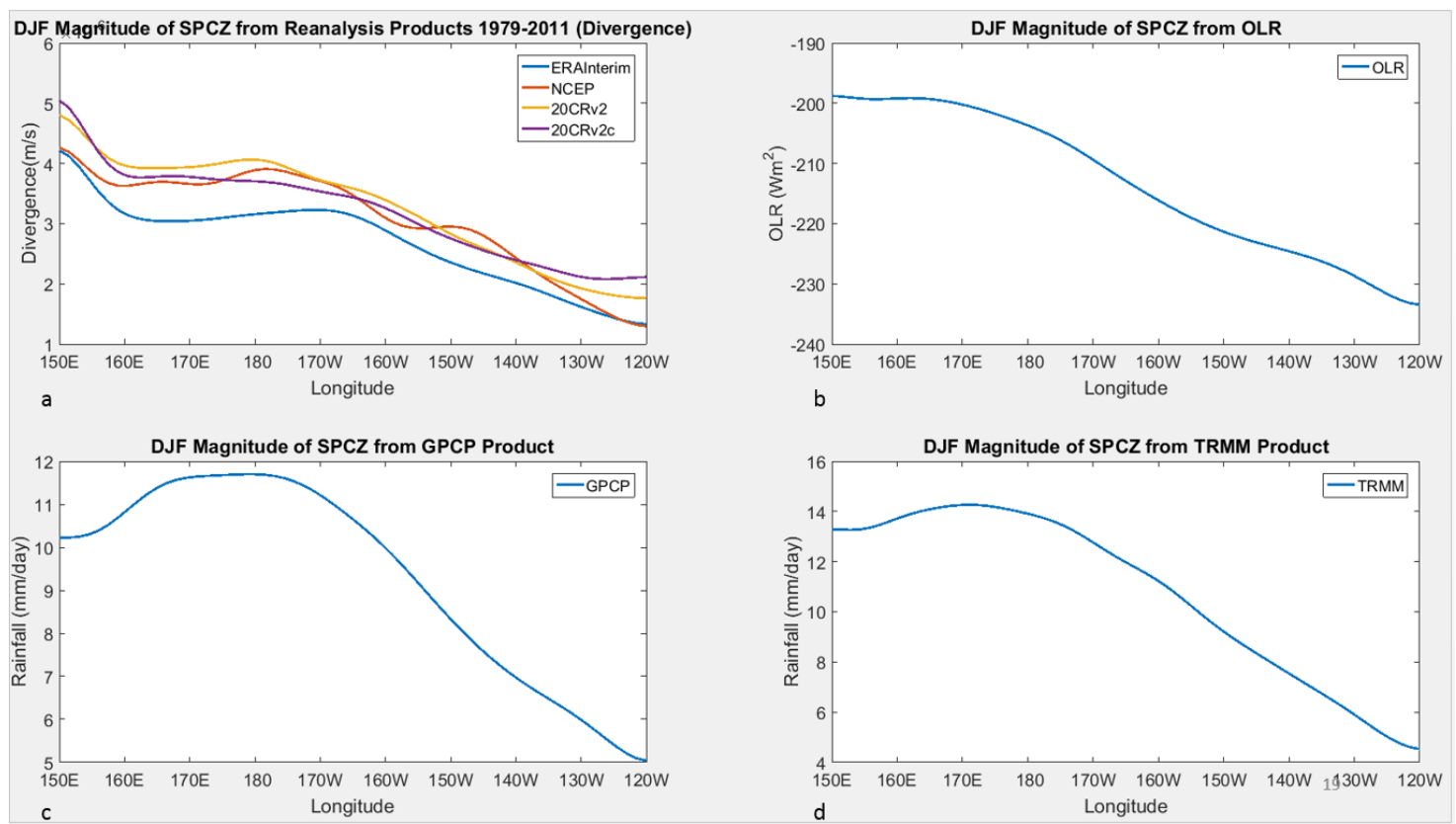

Figure 4.5 The DJF intensity of SPCZ for (a) 10m divergence fields for the four reanalysis products (b) OLR (c) GPCP and (d) TRMM. In plot (a) ERA Interim is shown by the blue line, NCEP/NCAR1 by the orange line, $20 \mathrm{CRv} 2 \mathrm{c}$ by the yellow line, and 20CRv2c by the purple line. 
Another notable feature is that the ERA Interim is the reanalysis product that depicts the SPCZ as the least intense whereas the other three show similar intensities across the longitudinal range. Looking at the 500hPa omega field, it was the NCEP/NCAR1 reanalysis that depicted the SPCZ as notably less intense than the other three (Figure 4.2).

There are obvious discrepancies between the satellite products and reanalysis products when using $10 \mathrm{~m}$ wind convergence to depict the SPCZ. Areas of strong convergence over eastern Australia and the central equatorial Pacific Ocean lead to an unrealistic positioning and intensity of the SPCZ in all four reanalysis products. In comparison, the position and intensity of the SPCZ appear more realistic, and in line with the observational satellite products when using the $500 \mathrm{hPa}$ omega field. This being the case, the remainder of this thesis will use the $500 \mathrm{hPa}$ omega field when using the reanalysis products to depict the SPCZ.

\subsection{Comparison of Twentieth Century Reanalysis Products}

Section 4.2 of this thesis investigates whether there has been an improvement in the 20CR product between v2 and v2c in the SPCZ region, by looking for any changes in the depiction of the SPCZ between the two products. Analysis for this part of the study was carried out using the mean DJF 500hPa omega field from only the 20CRv2 and 20CRv2c products, for the 1908-1957 and 1958-2011 periods, in an attempt to identify if increased data density has improved the performance of the 20CR between v2 and v2c.

\subsubsection{CR Comparison (Location)}

The comparison between 20CRv2 and 20CRv2c showed that the position of the SPCZ is very similar between the two products from 1958-2011, while there are slight differences between the two from 1908-1957 (Figure 4.6). Overall, the two products show a very similar SPCZ position across most of the longitudinal range studied for the 1958-2011 period, however, 20CRv2c does lie slightly to the south of 20CRv2 west of $160^{\circ} \mathrm{E}$, and slightly to the north, east of $\sim 145^{\circ} \mathrm{W}$ (Figure $4.6 \mathrm{~b}$ ). This closely related depiction of the SPCZ position is most likely a result of the underlying data being very similar between the two products for this time period. 

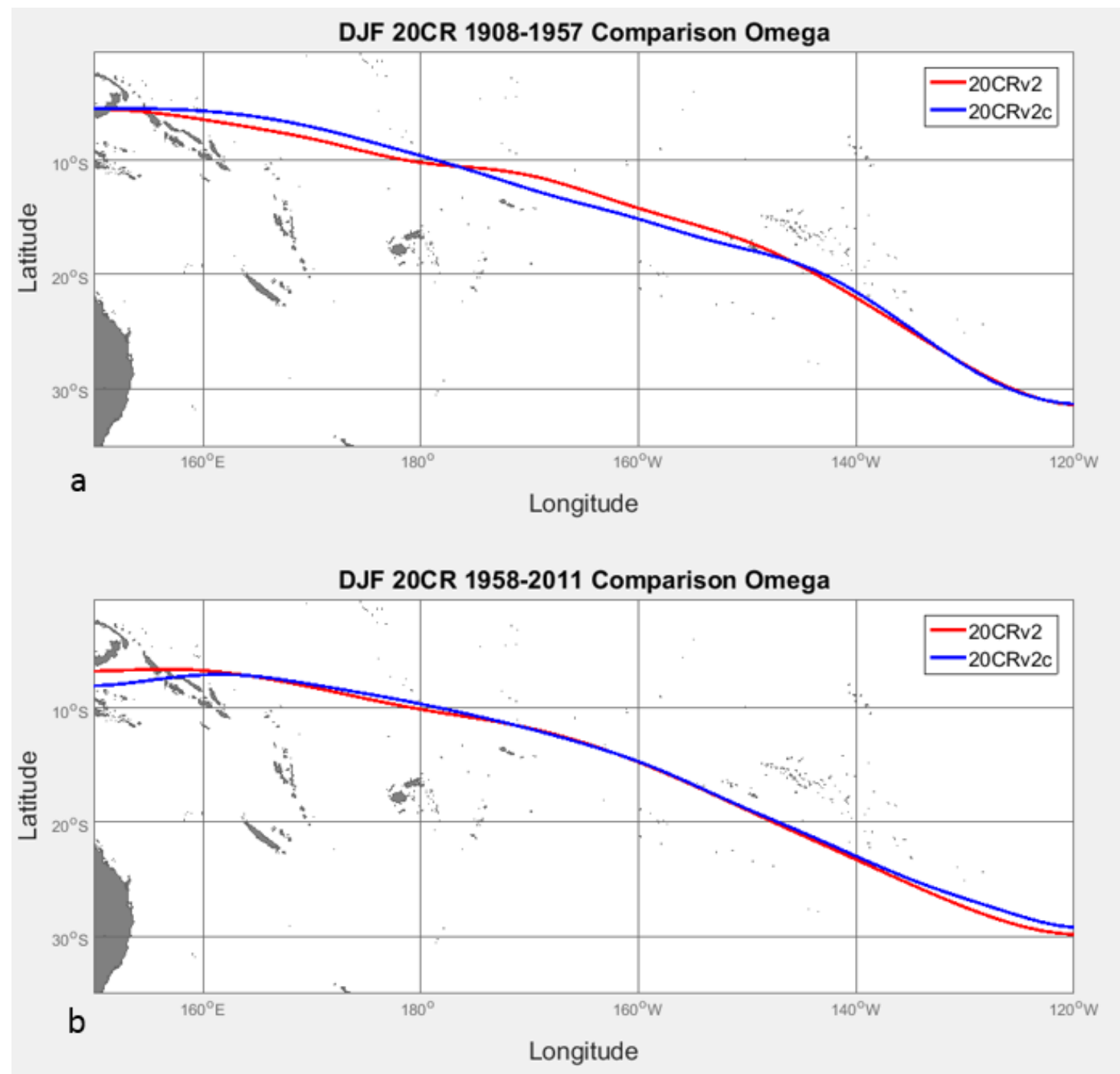

Figure 4.6 Comparison of mean DJF SPCZ position between 20CRv2 and 20CRv2c for 1908-1957 (a) and 19582011 (b). 20CRv2 is shown by the red line and 20CRv2c is shown by the blue line.

In the period from 1908-1957, there is discrepancy difference between the two products across most of the plot before they align in the far east of the region (Figure 4.6a). The SPCZ position is represented differently between 20CRv2 and 20CRv2c from $\sim 160^{\circ} \mathrm{E}$ to the IDL (the "western section"), and from the $\sim 170^{\circ} \mathrm{W}$ to $\sim 155^{\circ} \mathrm{W}$ (the "eastern section"). Looking at Figure 4.6a, it would be expected that there would be a statistically significant difference between the 20CRv2 and 20CRv2c in both the western section and the eastern section, and this was investigated by performing a two sample t-test (Table 4.3). 
Table 4.3 Comparison of P values for the "western section" and the "eastern section" where the SPCZ position appears different between 20CRv2 and 20CRv2c. P values in bold are significant at the $90 \%$ level.

\begin{tabular}{|l|r|r|r|r|r|r|r|r|r|r|r|}
\hline \multicolumn{8}{|c|}{ Western Section where 20CRv2 and 20CRv2c are Visually Different } \\
\hline Longitude & $162^{\circ} \mathrm{E}$ & $163.5^{\circ} \mathrm{E}$ & $165^{\circ} \mathrm{E}$ & $166.5^{\circ} \mathrm{E}$ & $168^{\circ} \mathrm{E}$ & $169.5^{\circ} \mathrm{E}$ & $171^{\circ} \mathrm{E}$ & $172.5^{\circ} \mathrm{E}$ & $174^{\circ} \mathrm{E}$ & $175.5^{\circ} \mathrm{E}$ & $177^{\circ} \mathrm{E}$ \\
\hline $\mathrm{P}$ Value & 0.109 & $\mathbf{0 . 0 9 8}$ & $\mathbf{0 . 0 9 5}$ & $\mathbf{0 . 0 9 9}$ & 0.107 & 0.118 & 0.130 & 0.143 & 0.158 & 0.180 & 0.219 \\
\hline \multicolumn{8}{|c|}{ Eastern Section where $20 \mathrm{CRv} 2$ and $20 \mathrm{CR} 2 \mathrm{C}$ are Visually Different } \\
\hline Longitude & $169.5^{\circ} \mathrm{W}$ & $168^{\circ} \mathrm{W}$ & $166.5^{\circ} \mathrm{W}$ & $165^{\circ} \mathrm{W}$ & $163.5^{\circ} \mathrm{W}$ & $163^{\circ} \mathrm{W}$ & $161.5^{\circ} \mathrm{W}$ & $160^{\circ} \mathrm{W}$ & $158.5^{\circ} \mathrm{W}$ & $157^{\circ} \mathrm{W}$ & $155.5^{\circ} \mathrm{W}$ \\
\hline P Value & 0.104 & $\mathbf{0 . 0 8 8}$ & $\mathbf{0 . 0 9 3}$ & 0.115 & 0.154 & 0.198 & 0.234 & 0.250 & 0.246 & 0.234 & 0.228 \\
\hline
\end{tabular}

Initially, this test was assessed at the $95 \%$ significance level, and it showed that no significant difference existed between 20CRv2 and 20CRv2c across the entire longitudinal range of the SPCZ area. However, at the $90 \%$ significance level, a statistically significant difference existed between the two products from $\sim 163^{\circ} \mathrm{E}$ to $\sim 167^{\circ} \mathrm{E}$, and from $\sim 168^{\circ} \mathrm{W}$ to $\sim 166^{\circ} \mathrm{W}$. This shows statistically significant differences were evident in parts of both the "eastern section" and "western section" of Figure 4.6a.

To further investigate any differences that might exist between 20CRv2 and 20CRv2c, the residual (20CRv2 minus 20CRv2c) omega fields were examined for four individual DJF periods. These were two Austral summer seasons prior to 1958 (La Niña from 1916/1917 and El Niño from 1930/1931), and two after 1958 (El Niño from 1982/83 and La Niña from 2010/2011). These years were chosen based on the highest and lowest MEI values from the two respective time periods, and the associated plots can be seen in appendix B. There appears to be a coherent difference in the omega field prior to 1958, especially during the 1930/1931 El Niño, with more vertical motion near the equator and less at $10^{\circ} \mathrm{S}$ for 20CRv2c, suggesting a northward movement of the SPCZ. The 1916/1917 La Niña shows less vertical motion in a diagonal area stretching from the northwest of the SPCZ area to around $160^{\circ} \mathrm{W}$ and $15^{\circ} \mathrm{S}$ to $20^{\circ} \mathrm{S}$ for $20 \mathrm{CRv} 2 \mathrm{c}$. This suggests a southward movement of the SPCZ between the products, however, the difference is not as coherent as during the 1930/1931 El Niño.

The difference between the two products appears less coherent for the post-1958 period. The 2010/2011 La Niña shows a slight difference between the products, however, there is no specific pattern visible. For the $1982 / 83 \mathrm{El} \mathrm{Niño,} \mathrm{there} \mathrm{is} \mathrm{suggestion} \mathrm{that} \mathrm{20CRv2c}$ shows less vertical motion near the equator west of $160^{\circ} \mathrm{W}$, with more around $10^{\circ} \mathrm{S}$, however, this pattern is not completely coherent. The general lack of coherent difference between 20CRv2 and 20CRv2c in the two chosen DJF seasons post 1958 indicates that both of the products are producing similar depictions of the atmospheric circulation in the SPCZ region for this recent, more data rich period. Conversely, more coherency in the residual omega fields prior to 1958 suggest that the two products are 
representing the atmospheric circulation differently for this older, more data sparse period.

The results stated above are important for this study, as the omega field and the representation of the SPCZ has changed between 20CRv2 and 20CRv2c. This suggests that the addition of extra stations in the Cook Islands between v2 and v2c has improved the performance of the 20CR product in the SPCZ region.

\subsubsection{CR Comparison (Intensity)}

The comparison of mean DJF SPCZ intensity indicated a slight difference between 20CRv2 and 20CRv2c in both periods investigated (Figure 4.7). Looking at the 19582011 period, the two products match very well east of $170^{\circ} \mathrm{W}$, but $20 \mathrm{CRv} 2$ shows slightly higher intensity to the west of this line (Figure 4.7b). However, while there is a slight difference in intensity (20CRv2 has higher intensity) in the western portion of the SPCZ, both of the products show quite a smooth, consistent line across the plot.

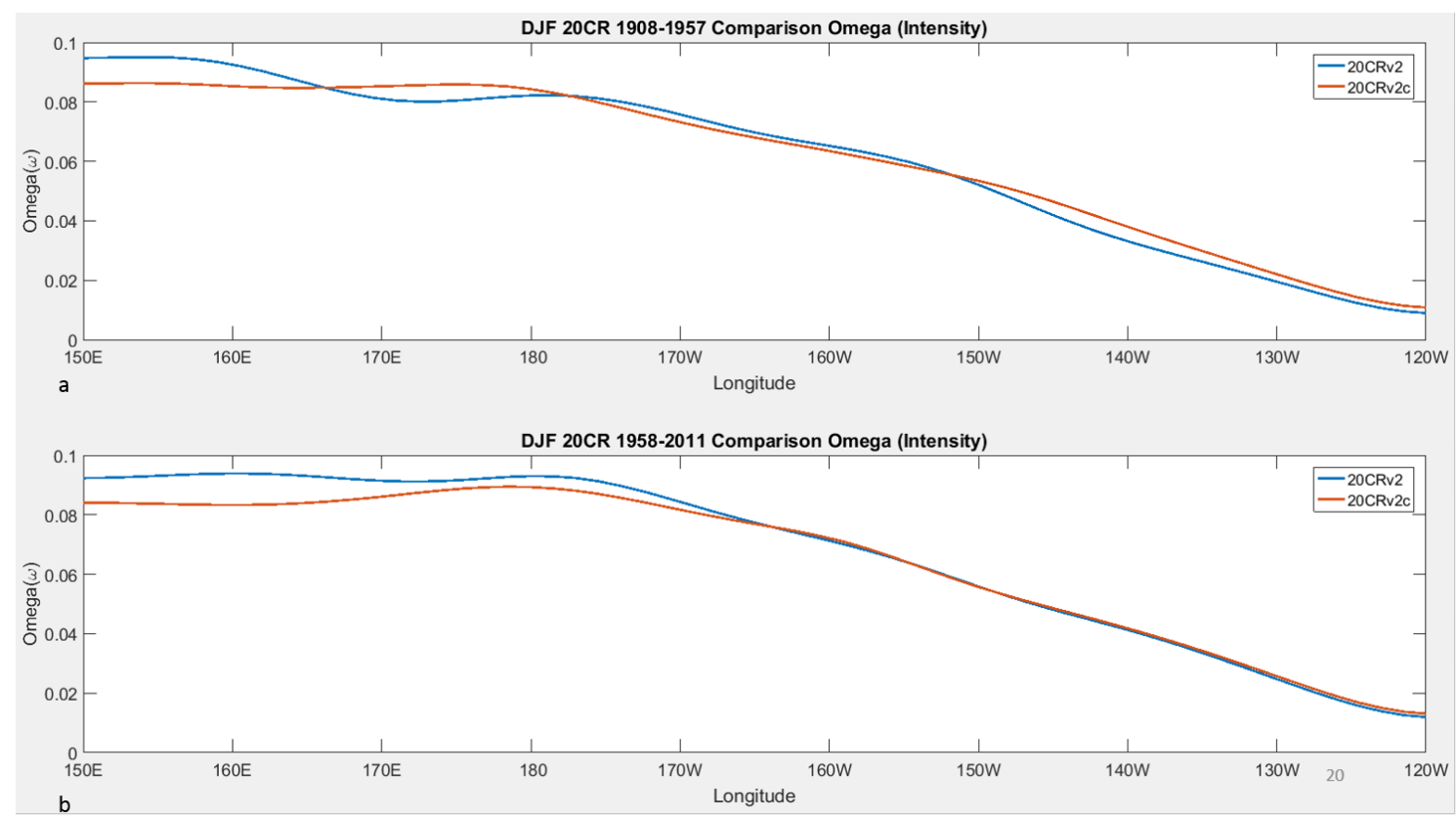

Figure 4.7 Comparison of mean DJF SPCZ intensity between 20CRv2 and 20CRv2c for 1908-1957 (a) and 19582011 (b). 20CRv2 is shown by the blue line and 20CRv2c by the orange line.

In comparison, the 1908-1957 period shows a similar smooth and consistent line across the plot for 20CRv2c, but not for 20CRv2. The representation of SPCZ intensity from 20CRv2 is wavier in appearance, consistently alternating between stronger and weaker than 20CRv2c across the longitudinal range (Figure 4.7a). This discrepancy between the two 20CR products from 1908-1957 helps substantiate the claim made in section 4.2.1 
that the extra data added during this time period has helped improve the depiction of the SPCZ in the 20CRv2c product.

\subsection{Interactions with ENSO and IPO and Twentieth Century Trends}

Section 4.3 of this thesis carries out analysis of the SPCZ, with ENSO and IPO relationships, as well as twentieth century trends investigated. The analysis is carried out for the 1908-2011 period using the mean DJF 500hPa omega field from 20CRv2c product.

\subsubsection{ENSO: Location}

The mean DJF position of the SPCZ in relation to ENSO phases shows a distinct north to south progression from what is defined for this study as strong (top 20\% from MEI index) El Niño (SEN) years to strong (bottom 20\% from MEI index) La Niña (SLN) years (Figure 4.8).

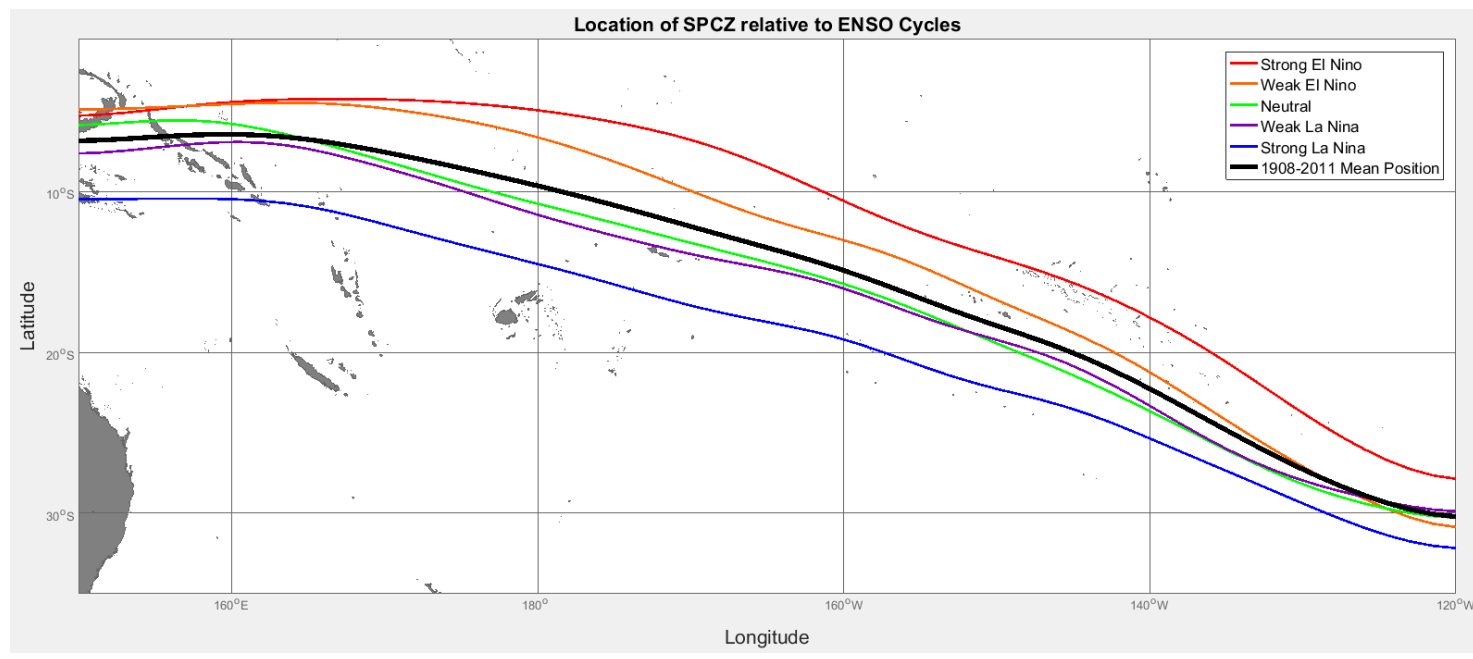

Figure 4.8 The mean DJF SPCZ position based on ENSO phase from 1908-2011. Strong El Niño years are shown by the red line, weak El Niño years by the orange line, neutral years by the green line, weak La Niña years by the purple line, and strong La Niña years by the dark blue line. The mean 1908-2011 SPCZ position is shown by the thick black line.

The mean position of the SPCZ for SEN years from 1908-2011 is much further north than all other ENSO phases, except in the very far west of the SPCZ area in which it lies slightly south of weak El Niño (WEN) years. It is also zonal from $150^{\circ} \mathrm{E}$ to the IDL, after which it begins to take on the diagonal orientation associated with the SPCZ. This leads to the most equatorward point of the mean SPCZ position being around $170^{\circ} \mathrm{E}$, rather than in the far west of the plot at $150^{\circ} \mathrm{E}$. The mean SPCZ position during WEN years shows a similar spatial pattern to that of SEN years. It is zonal west of $170^{\circ} \mathrm{E}$ before taking on the diagonal orientation into the subtropics, but its most equatorward 
position lies slightly further west (and south) than SEN years. The major difference between these two phases of ENSO is the magnitude of equatorward displacement, with greater displacement seen during SEN years.

The mean position of the SPCZ for strong La Niña (SLN) years is significantly further south than all other ENSO phases across the entire SPCZ region. The orientation of the SPCZ is zonal west of $160^{\circ} \mathrm{E}$ and diagonal to the east of this point. The position of the SPCZ during weak La Niña (WLN) years shows a similar pattern, but the magnitude of southward displacement is smaller. It is also zonal west of $160^{\circ} \mathrm{E}$, and the SPCZ position at $120^{\circ} \mathrm{W}$ is quite similar to that of Neutral and WEN years.

Despite the different way in which ENSO phases were defined for this study (see description in section 3.1.3), the spatial patterns of SPCZ positions in relation to ENSO phases are what would expect to be seen based on previous research (see section 2.2.2). Figure 4.8 also suggests that the deviation away from the mean 1908-2011 position is greater during El Niño years than La Niña years, with the magnitude of equatorward displacement during El Niño years being slightly greater than the southward displacement during La Niña years.

EOF analysis of the time series of SPCZ locations by year and longitude shows that the largest variability (55\%) is a northward (or southward) shift of the SPCZ across all longitudes with a peak of over $4^{\circ}$ latitude at around $140^{\circ} \mathrm{W}$. This pattern of SPCZ movement (Figure 4.9) was noted as most likely being related to ENSO, with related SST distribution and trade wind variation leading to northward and southward displacement of the SPCZ from its mean position. 


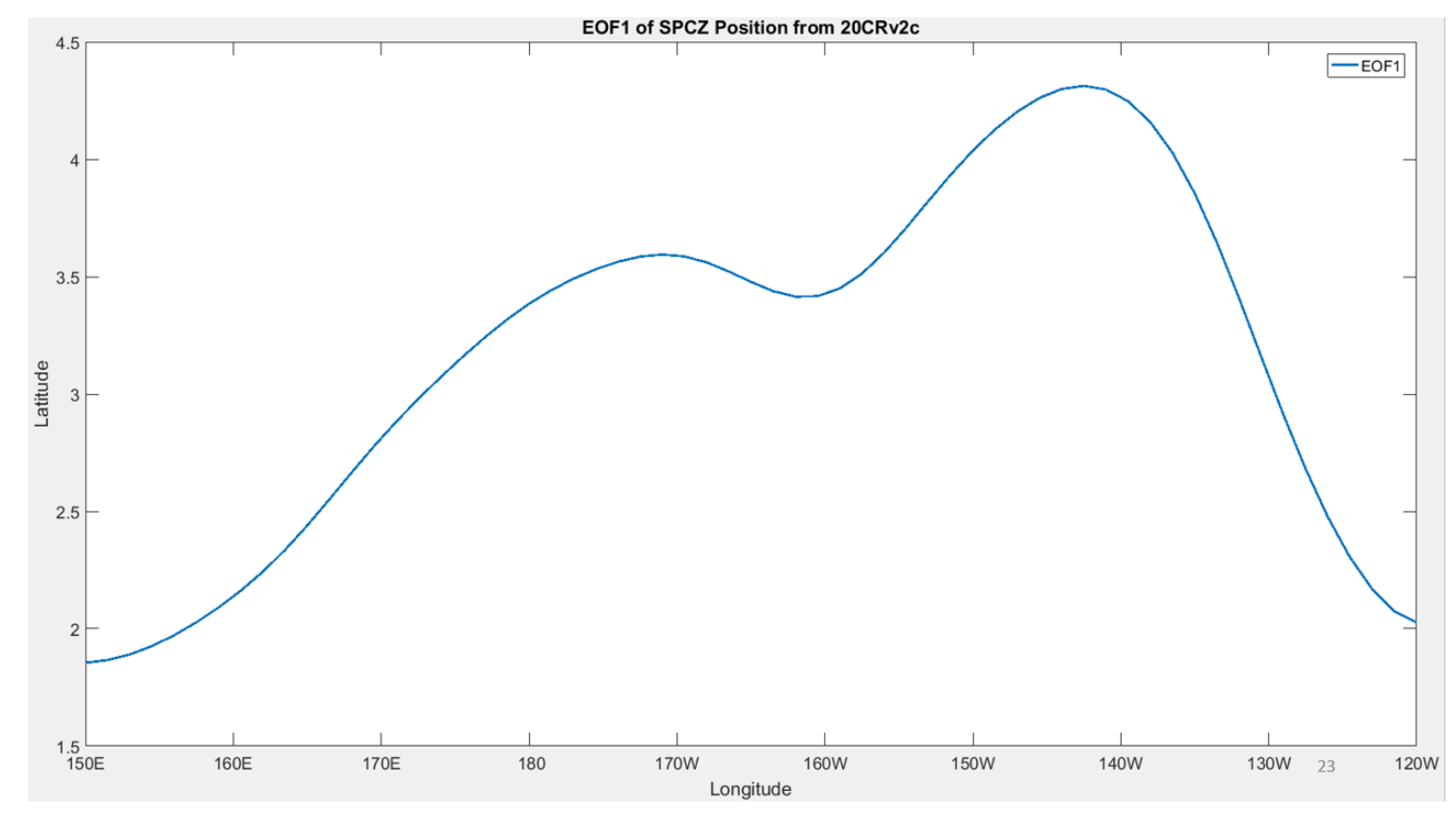

Figure 4.9 EOF1 pattern of variance from 20CRv2c 1908-2011 mean SPCZ position. This pattern accounts for 55\% of variability in SPCZ position.

A plot showing the time series of the first EOF of the SPCZ position with the MEI time series from 1908-2011 is shown in Figure 4.10. It is clear that the two time series are very similar, and a highly significant correlation coefficient $(\mathrm{r}=0.83, \mathrm{n}=104$, d.f. $=$ $102, \mathrm{p}<0.01)$ from 1908-2011. This correlation is maintained through time, also being $0.83(\mathrm{n}=50$, d.f. $=48, \mathrm{p}<0.01)$ from $1908-1957$ and $0.84(\mathrm{n}=54$, d.f. $=52, \mathrm{p}<0.01)$ from 1958-2011. This result demonstrated that there is a close relationship between ENSO phases and the leading pattern of variability in SPCZ position throughout the analysis period from 1908-2011. 


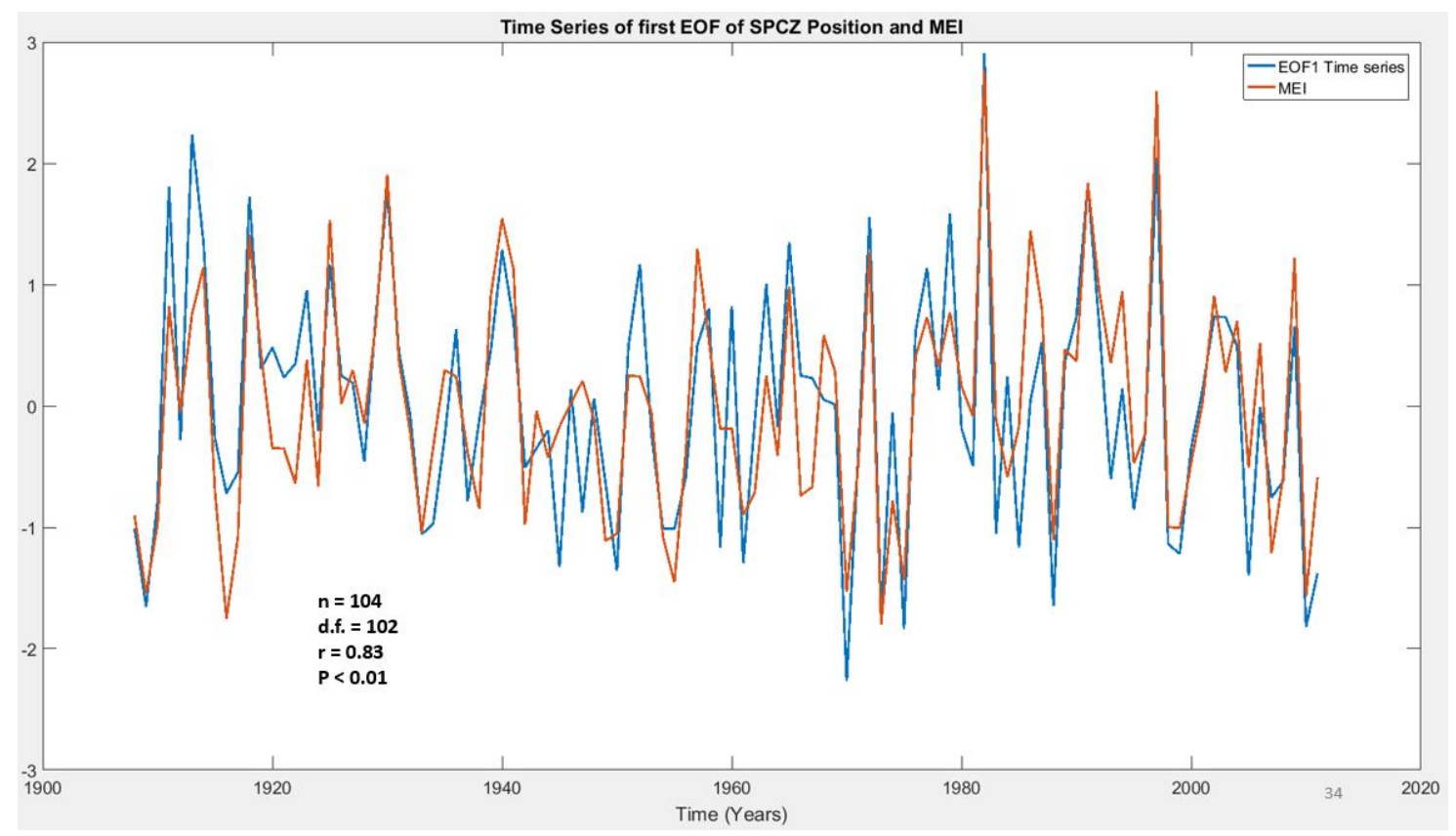

Figure 4.10 Time series of EOF1 of SPCZ position and MEI time series from 1908-2011. The EOF1 time series is shown by the blue line and the MEI time series is shown by the orange line.

To further corroborate this finding, a correlation map was plotted between the ERSSTv5 SST dataset and the first EOF of SPCZ position from 20CRv2c (Figure 4.11). Positive correlations exist over most of the tropical Pacific Ocean with a peak of 0.7 over the central Pacific Ocean (within the Niño 3.4 region), while negative correlations exist over the majority of the subtropical Pacific Ocean. The maximum negative correlation of 0.5 occurs in the far southwest corner of the SPCZ area. This demonstrates that when the SPCZ varies from its mean position in the EOF1 pattern (strongly correlated to ENSO) there is a strong positive correlation with SSTs near the equator in the central Pacific Ocean, with negative correlations in the subtropics. This relationship would be seen as a northward movement of the SPCZ coinciding with increased SSTs in the tropical Pacific Ocean and decreased SSTs over most of the subtropics, broadly consistent with El Niño conditions. 


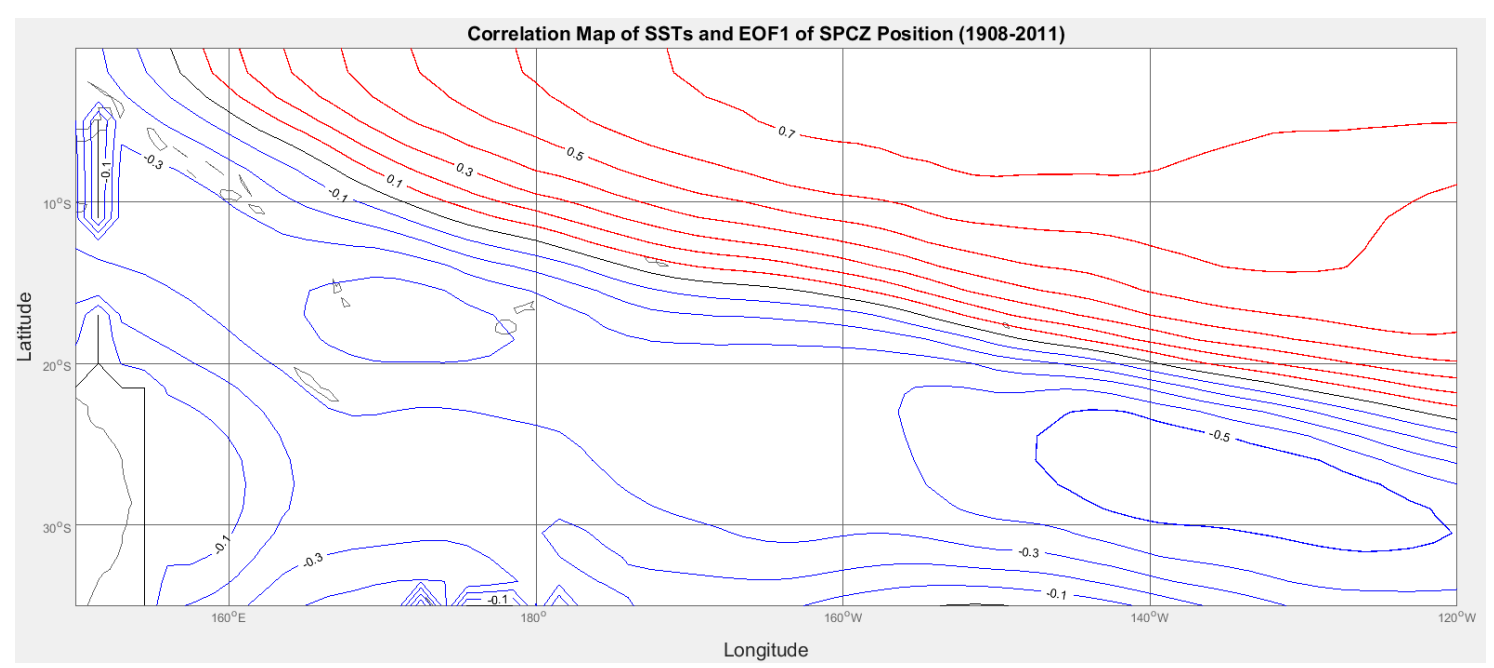

Figure 4.11 Correlation map of ERSSTv5 SST and the amplitude time series of EOF1 of SPCZ position from 20CRv2c for 1908-2011 period. Red contours represent positive correlations, blue contours represent negative correlations, and the black contour represents no correlation. Spacing of contours is 0.1 .

In order to visualise and show the amplitude of this SST anomaly pattern, a regression map of SSTs and EOF1 of the SPCZ position was created (Figure 4.12). Positive SST anomalies exist over the majority of the tropical Pacific Ocean within the SPCZ area, with a maximum amplitude of $0.9^{\circ} \mathrm{C}$ in the far northeast corner of the plot. Negative SST anomalies exist over most of the subtropical southwest Pacific Ocean, with a maximum amplitude of $-0.4^{\circ} \mathrm{C}$ in the far southwest of the plot. This pattern looks similar to the SST anomalies that would be expected during an El Niño event.

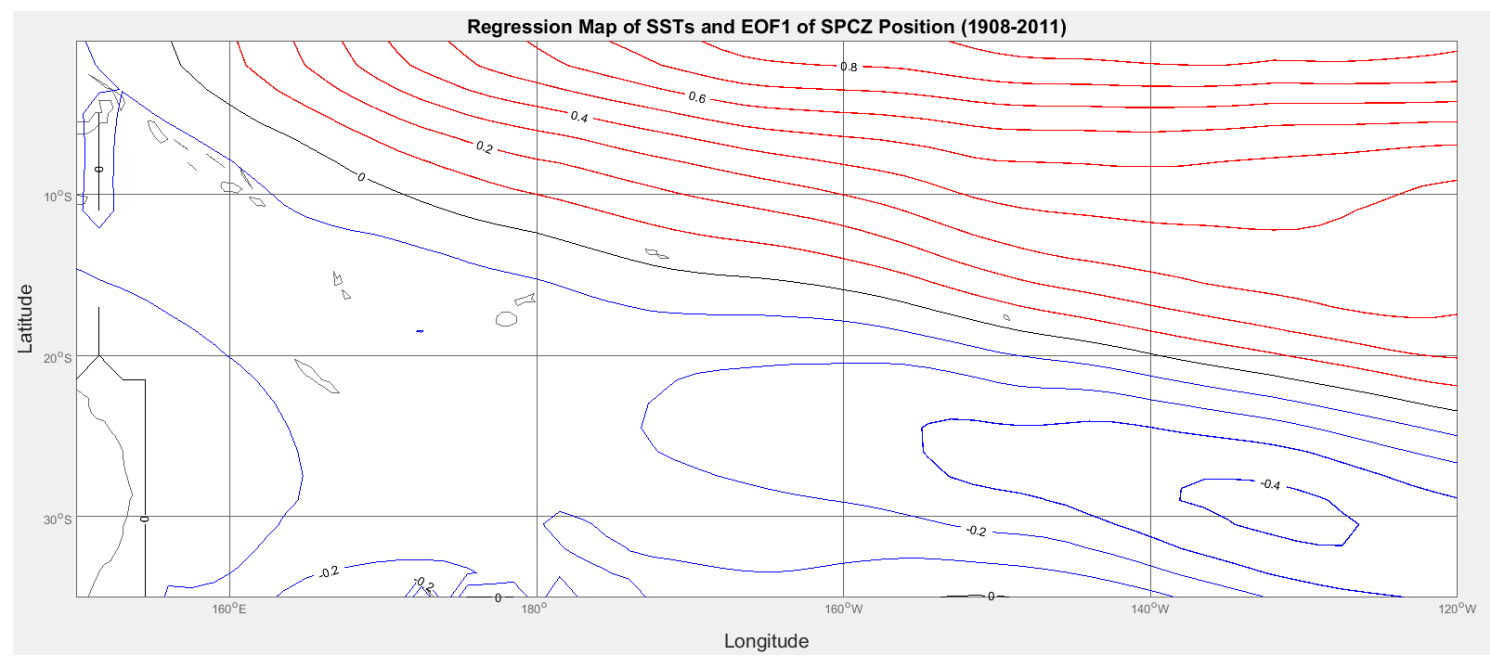

Figure 4.12 SST anomaly regression map from ERSSTv5 when plotted with EOF1 of SPCZ position from 20CRv2c for 1908-2011 period. Red contours represent positive SST anomalies, blue contours represent negative SST anomalies, and the black contour represents no SST anomaly. Spacing of contours is $0.1^{\circ} \mathrm{C}$. 


\subsubsection{ENSO: Intensity}

The pattern seen in the mean DJF SPCZ intensity plots in relation to ENSO phases (Figure 4.13) is not as well defined as the SPCZ position plots shown in Figure 4.8. However, the intensity of the SPCZ during SEN and WEN years stands out as having a different pattern to the other phases. SEN years have the weakest intensity of all phases at the far west of the plot, before increasing to a peak in intensity at the IDL. This peak is noticeably more intense than the peak of the other ENSO phases. The intensity quickly declines east of the IDL, however, at a consistently higher magnitude than the other ENSO phases to the eastern edge of the SPCZ area $\left(120^{\circ} \mathrm{W}\right)$.

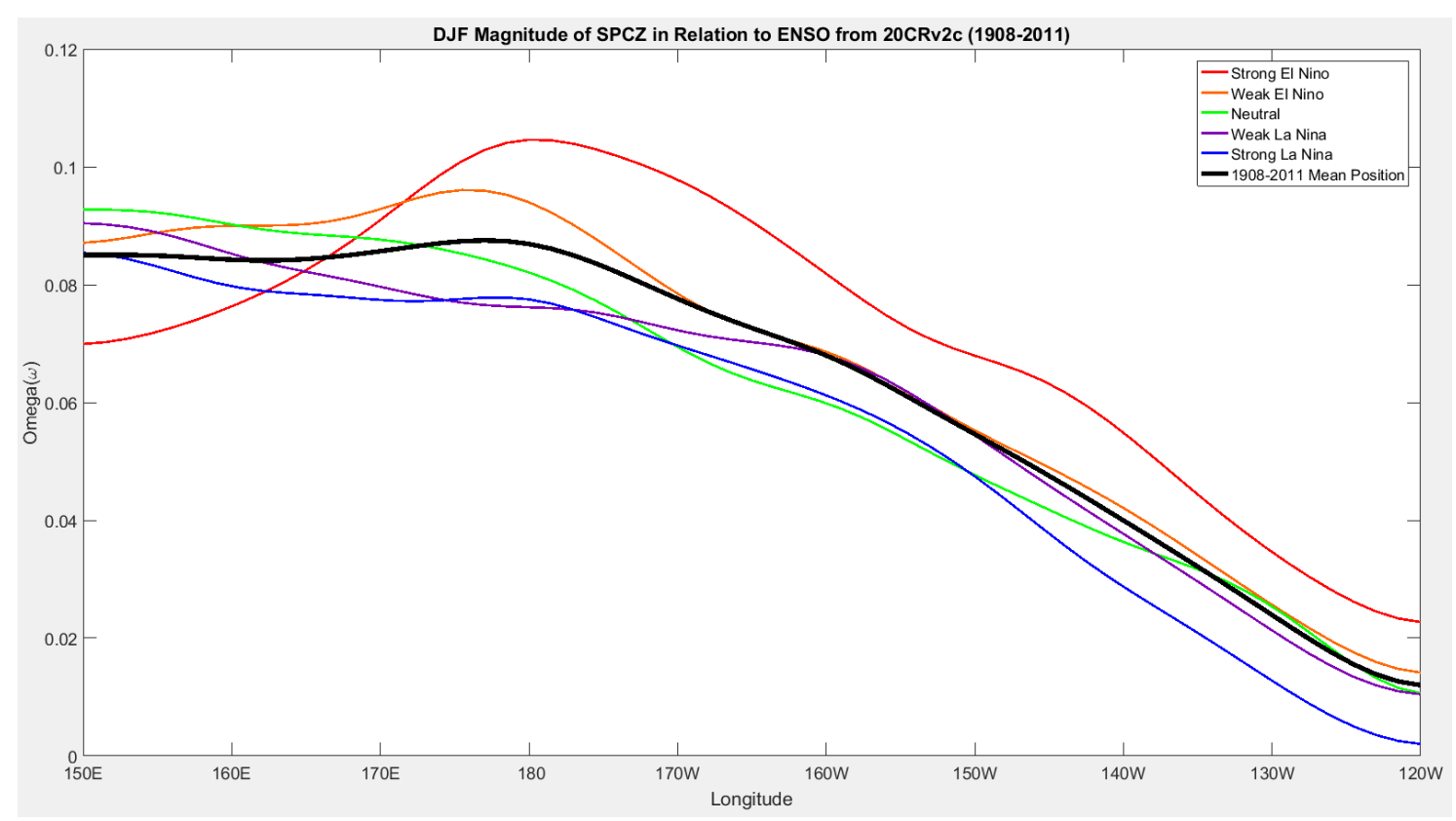

Figure 4.13 The mean DJF SPCZ intensity based on ENSO phase from 1908-2011. The mean strong El Niño intensity is shown by the red line, the mean weak El Niño intensity is shown by the orange line, the mean neutral intensity is shown by the green line, the mean weak La Niña intensity is shown by the purple line, and the mean strong La Niña intensity is shown by the blue line. The overall 1908-2011 mean intensity is shown by the black line.

The intensity of the SPCZ during WEN years shows a similar pattern to SEN years but of a lower magnitude. The maximum intensity occurs at $\sim 175^{\circ} \mathrm{E}$ before decreasing towards the eastern limit of the SPCZ area. The maximum intensity is not as high as during SEN years, however, it is still greater in magnitude than the other ENSO phases. The intensity is comparable to WLN years to the east of $160^{\circ} \mathrm{W}$, and also neutral years east of $135^{\circ} \mathrm{W}$.

The maximum intensity within the SPCZ occurs at the far western edge of plot $\left(150^{\circ} \mathrm{E}\right)$ for all periods that have been defined as neutral, WLN, and SLN. The rapid drop off in intensity occurs further east for neutral years $\left(\sim 175^{\circ} \mathrm{E}\right)$ than WLN or SLN years. This 
drop off occurs at the far western edge of the plot $\left(150^{\circ} \mathrm{E}\right)$ for both SLN years and WLN years. On average, SLN years show the lowest intensity of these three ENSO phases, however, the intensity of the three is comparable from near the IDL to $\sim 165^{\circ} \mathrm{W}$.

The intensity pattern of the SPCZ during El Niño years illustrates the eastward movement of the most intense convection towards the IDL during El Niño events (Figure 4.13), and is in line with previous studies looking at the relationship between the SPCZ and ENSO (see section 2.2.2).

EOF analysis shows that the largest variability (44.5\%) in SPCZ magnitude is a slight decrease (or increase) in the far west, and an increase (or decrease) east of $160^{\circ} \mathrm{E}$ (Figure 4.14). The largest variability of SPCZ magnitude occurs from near the IDL to $170^{\circ} \mathrm{W}$. This pattern once again stood out as most likely being related to ENSO, and would be seen as El Niño induced warm SST anomalies, and associated intense SPCZ convection moving eastward towards the IDL, with a slight decrease in SSTs and convection in the far west of the SPCZ region.

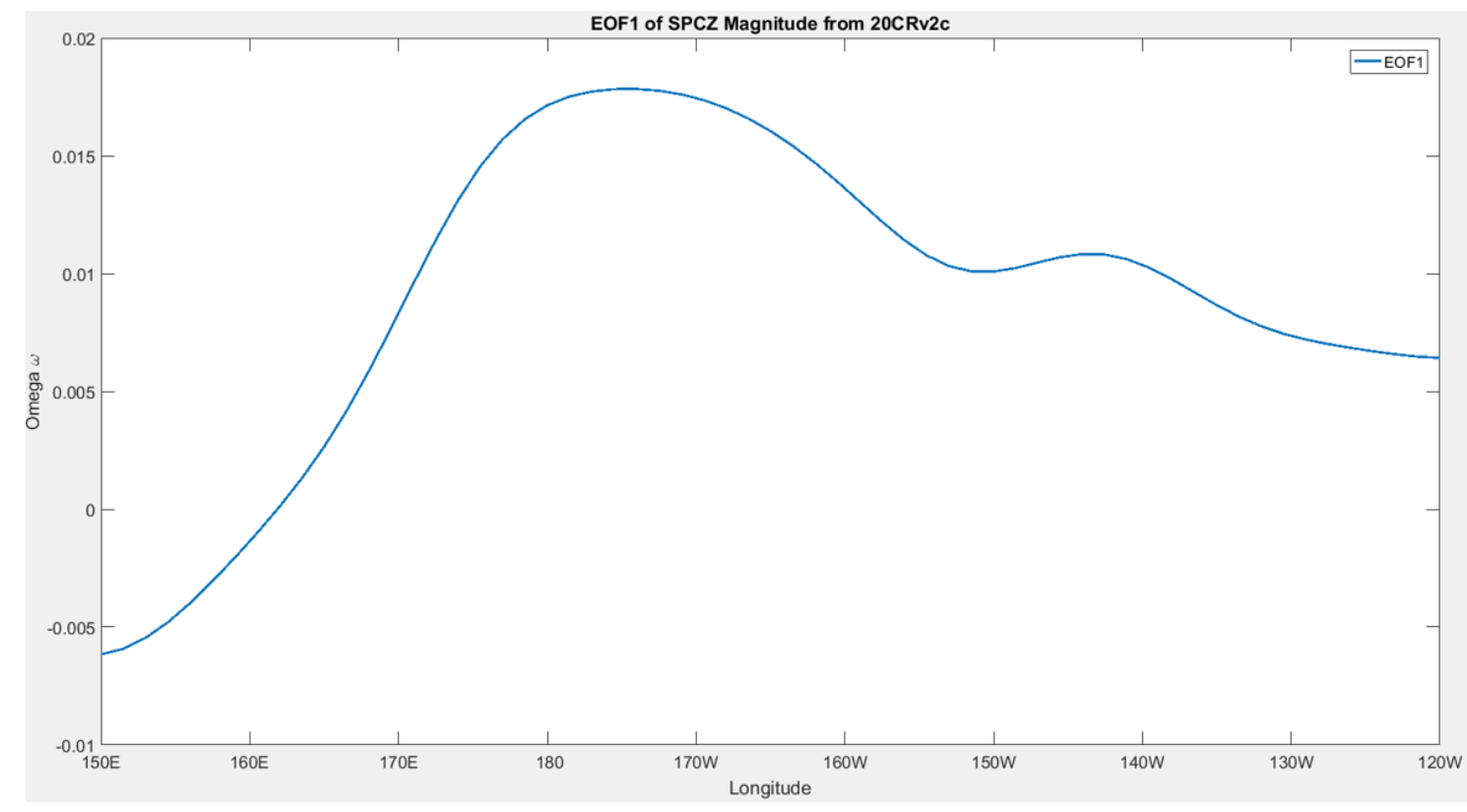

Figure 4.14 EOF1 pattern of variance from 20CRv2c 1908-2011 mean SPCZ intensity. This pattern accounts for $44.5 \%$ of variance seen in SPCZ intensity.

Looking at the time series of the first EOF of SPCZ intensity and the MEI time series plotted together, it was again evident that a notable relationship existed between the two variables (Figure 4.15). This was confirmed with a correlation coefficient of $0.69(\mathrm{n}=$ 104 , d.f. $=102, p<0.01)$ between the two time series. There is some difference in this relationship throughout the analysis period, with the correlation coefficient being 0.69 
$(\mathrm{n}=54$, d.f. $=52, \mathrm{p}<0.01)$ from 1958-2011, but reducing to $0.48(\mathrm{n}=50$, d.f. $=48, \mathrm{p}<$ 0.01) from 1908-1957. This result demonstrated there is a statistically significant relationship between ENSO phases and SPCZ intensity through the entire analysis period, although the correlation is slightly weaker in the first half of the twentieth century.

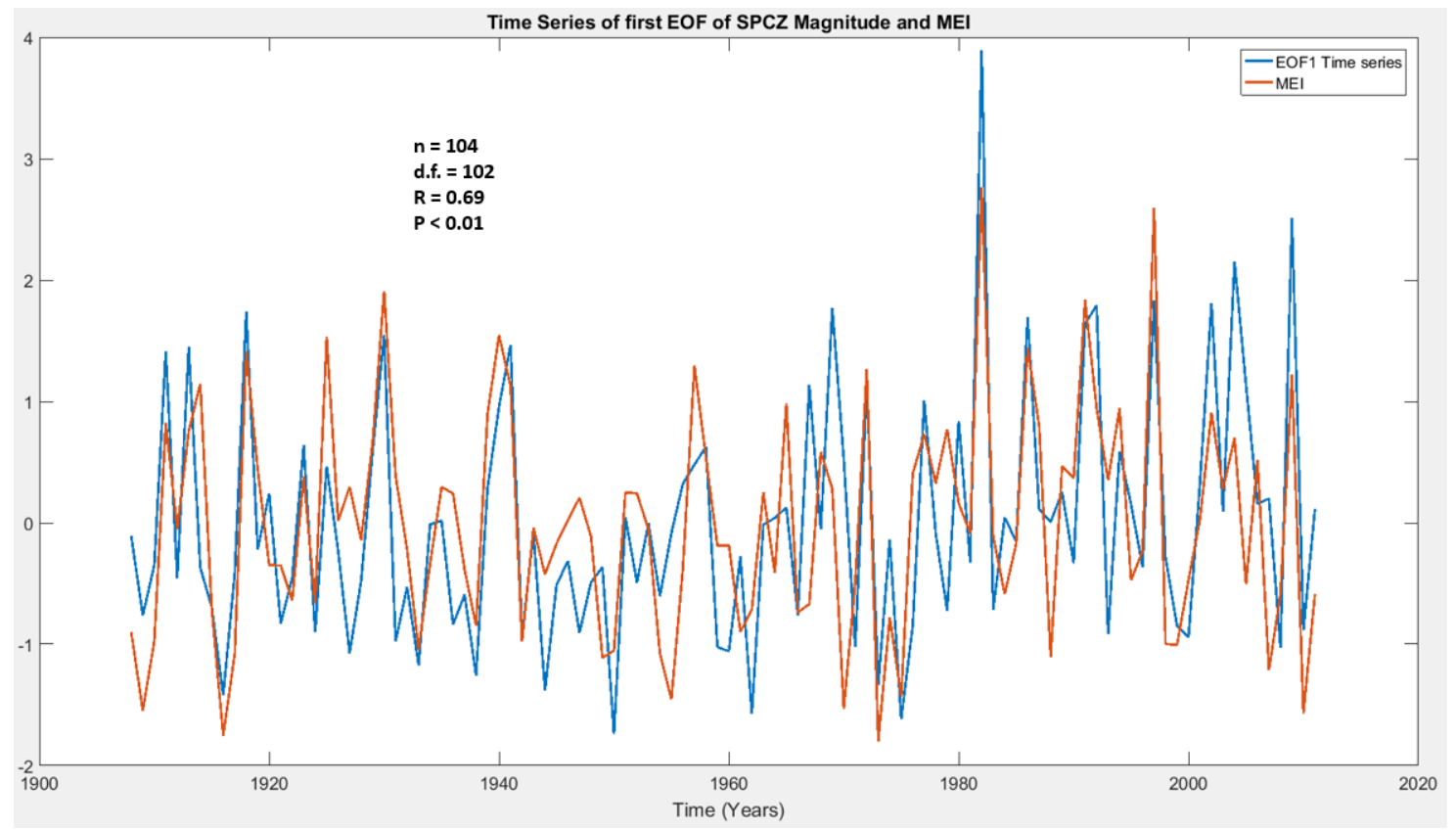

Figure 4.15 Time series of EOF1 of SPCZ intensity and MEI time series from 1908-2011. The EOF1 time series is shown by the blue line and the MEI time series is shown by the orange line.

In order to maintain consistency through the study, a correlation map was plotted between the ERSSTv5 SST dataset and the first EOF of SPCZ magnitude from 20CRv2c (Figure 4.16). Positive correlations again exist over most of the tropical Pacific Ocean with a peak of 0.6 in the central Pacific Ocean, and negative correlations largely exist in the subtropics (maximum amplitude of -0.3). 


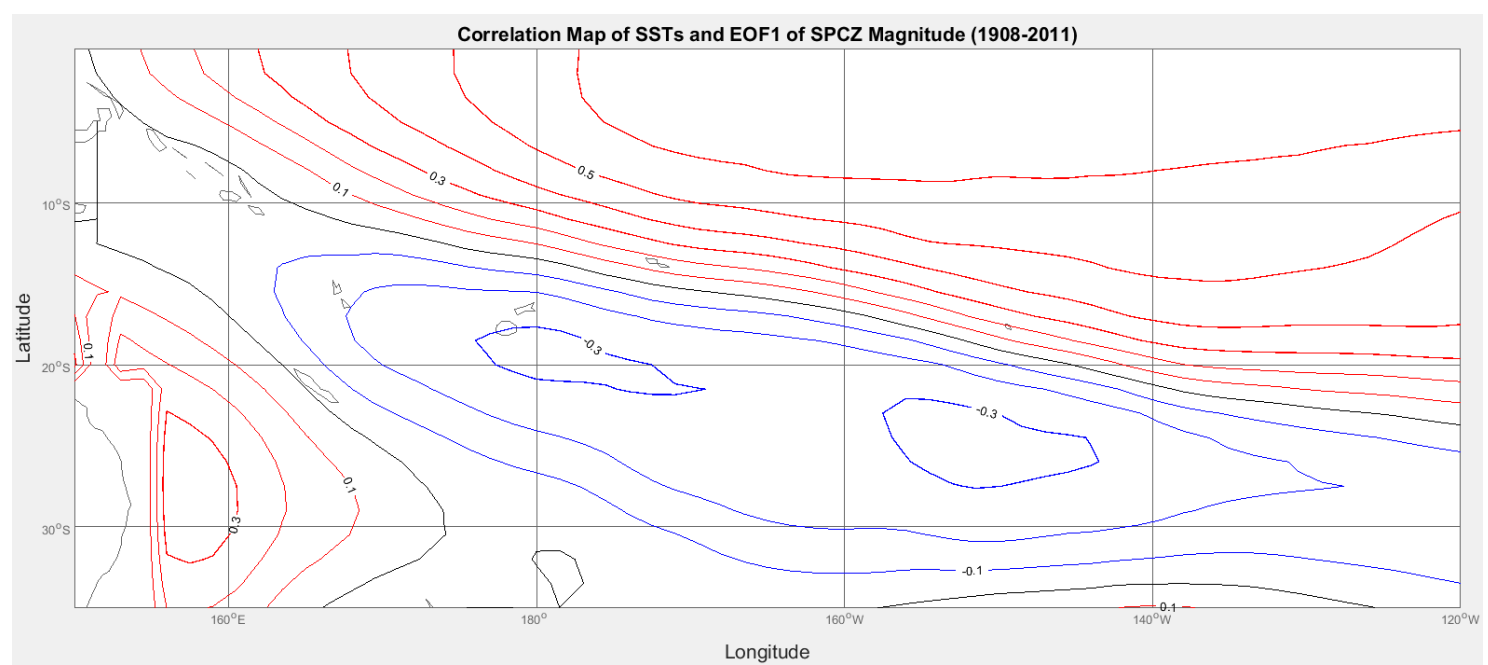

Figure 4.16 Correlation map of ERSSTv5 SST and EOF1 of SPCZ intensity from 20CRv2c for 1908-2011 period. Red contours represent positive correlations, blue contours represent negative correlations, and the black contour represents no correlation. Spacing of contours is 0.1 .

This illustrates that when the intensity of the SPCZ varies in the EOF1 pattern (correlated with ENSO) there is a positive correlation with SSTs in the tropical Pacific Ocean, and a negative correlation in the subtropics. This would be seen as an increase in intensity near (and east of) the IDL coinciding with increased SSTs in the tropical Pacific Ocean and a decrease in SSTs over the subtropics (with an exception immediately to the east of Australia).

The SST anomaly regression map (Figure 4.17) shows the expression of SST anomalies when the SPCZ intensity varies in the EOF1 pattern, with positive anomalies in the tropical Pacific Ocean (up to $0.7^{\circ} \mathrm{C}$ at the equator), and negative anomalies in the subtropics (up to $-0.2^{\circ} \mathrm{C}$ ). This pattern of SST anomalies is similar to what would be expected during an El Niño. 


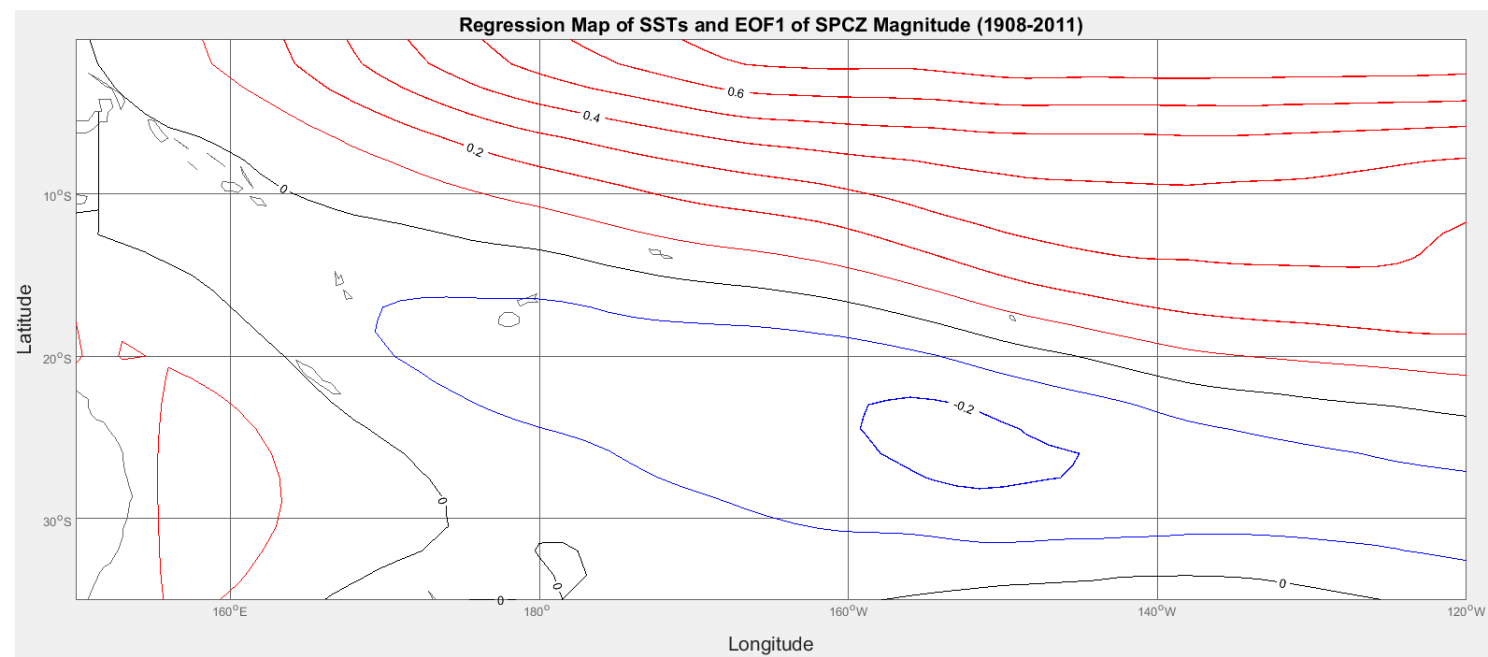

Figure 4.17 SST anomaly regression map from ERSSTv5 when plotted with EOF1 of SPCZ intensity from 20CRv2c for 1908-2011 period. Red contours represent positive SST anomalies, blue contours represent a negative SST anomaly. The black contour represents no SST anomaly. Spacing of contours is $0.1^{\circ} \mathrm{C}$.

\subsubsection{IPO: Location}

The relationship between IPO phase and the mean DJF position of the SPCZ is less evident when compared to the SPCZ-ENSO relationship. There appears to be no significant difference between the negative IPO phase from 1908-1924 and the positive IPO phase from 1925-1946 (purple and orange lines in Figure 4.18 respectively), as they undulate north and south of each other across the entire SPCZ region. Due to the undulating nature of the representation of the SPCZ during both of these IPO phases, it must be questioned whether this pattern is a physical response in relation to the IPO, or whether it could be a result of sparser data during the earlier part of the twentieth century.

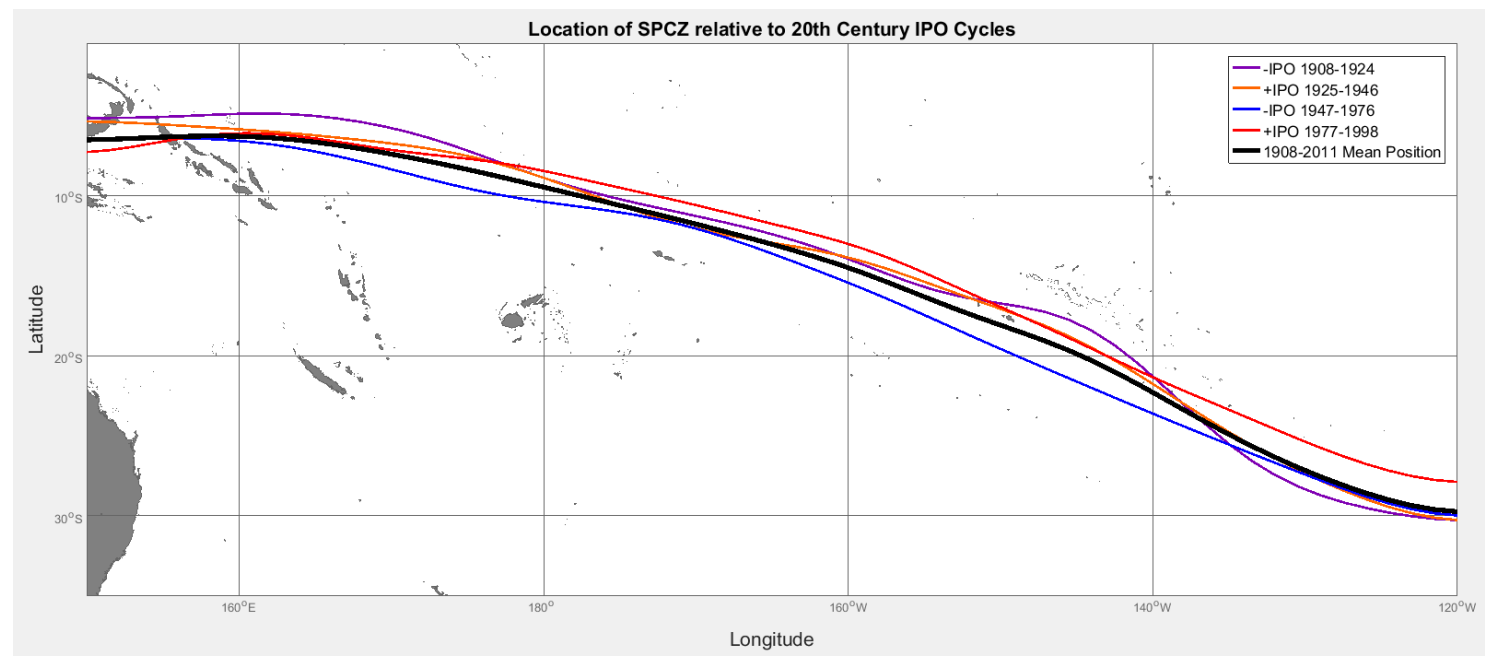

Figure 4.18 The mean DJF SPCZ location relative to twentieth century IPO cycles. The negative IPO from 19081924 is shown in purple, the positive IPO from 1925-1946 is shown in orange, the negative IPO from 1947-1976 is shown in dark blue, and the positive IPO from 1977-1998 is shown in red. The mean DJF 1908-2011 SPCZ location is shown in black. 
Looking at the two most recent complete IPO phases (negative from 1947-1976 (blue line) and positive from 1977-1998 (red line)), a more distinct pattern emerges. The position of the SPCZ lies consistently further north during the 1977-1998 positive IPO across the entire plot apart from in the very far west near $150^{\circ} \mathrm{E}$. This result is closer to what would be expected when investigating the position of the SPCZ during IPO phases, as positive IPO phases generally have a higher frequency of El Niño events which help to shift the mean location of the SPCZ equatorward.

The time series of the first EOF of the SPCZ position and the TPI time series from 1908-1998 also appeared to show a relatively strong relationship (Figure 4.19). This was confirmed when correlation analysis was performed, resulting in a value of 0.76 (n $=91$, d.f. $=89, \mathrm{p}<0.01)$. Due to the apparent difference in SPCZ position and IPO phase relationship between the first and second half of the twentieth century (Figure 4.18), the same correlation analysis was performed, but separated into two time periods; 1908-1946 and 1947-1998. The correlation was $0.77(n=39$, d.f. $=37, p<0.01)$ for the earlier period and $0.76(\mathrm{n}=52$, d.f. $=50, \mathrm{p}<0.01)$ for the latter, which demonstrated the relationship between the leading pattern of variability in the position of the SPCZ and the IPO remains consistent through the entire analysis period.

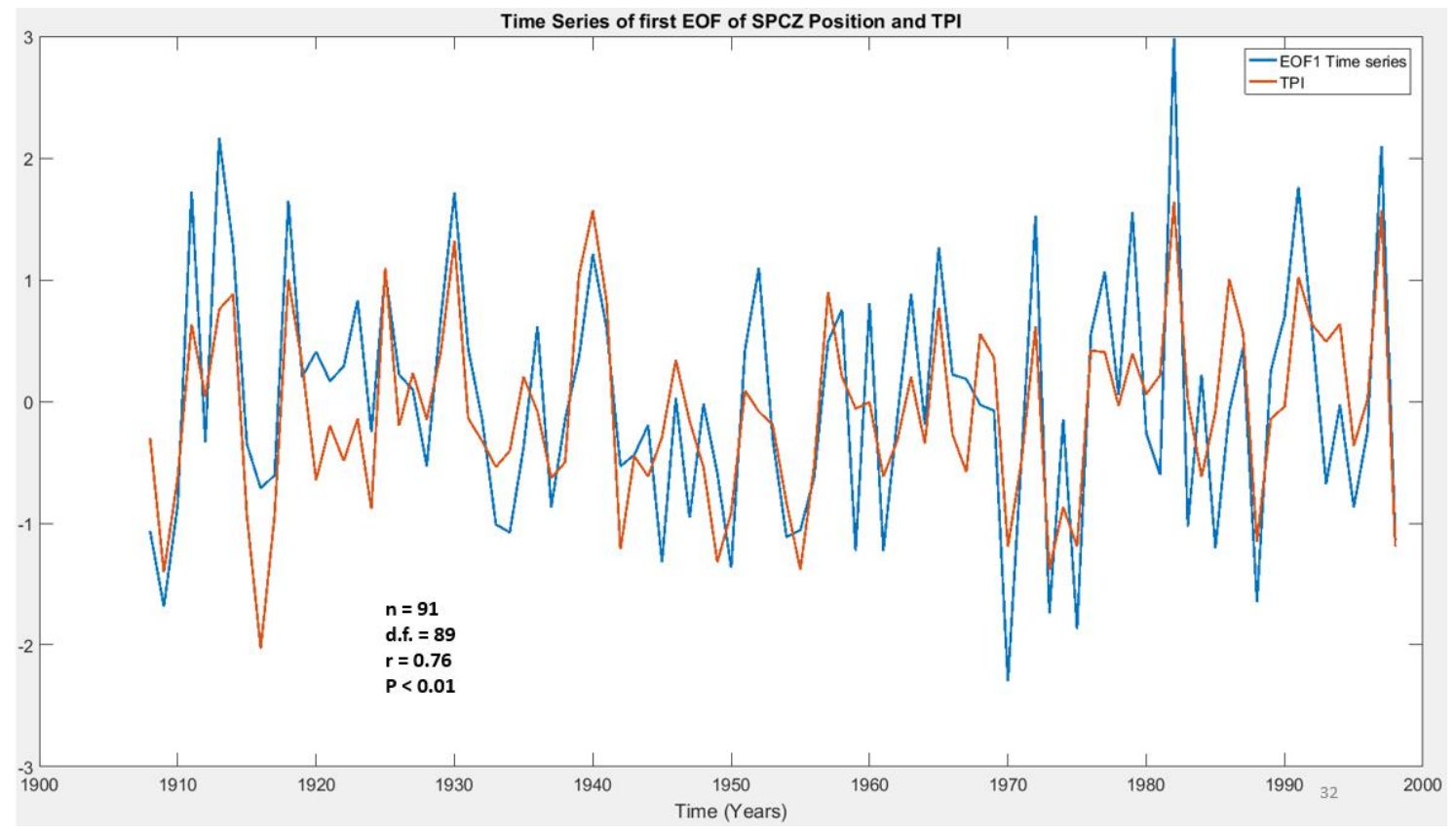

Figure 4.19 Time series of EOF1 of SPCZ position and the TPI time series from 1908-1998. The time EOF1 time series is shown by the blue line and the TPI time series is shown by the orange line. 


\subsubsection{IPO: Intensity}

The relationship between mean DJF SPCZ intensity and IPO phase is slightly more distinguishable than when looking at SPCZ location (Figure 4.20). The 1977-1998 positive IPO has the lowest intensity at the western edge of the SPCZ region before increasing to reach a peak at the IDL and decreasing significantly to the east. The peak intensity is higher than the other three IPO phases and it remains consistently higher heading east from the dateline. The peak intensity of the 1925-1946 positive IPO also occurs east of the western edge of the SPCZ region, at $\sim 175^{\circ} \mathrm{E}$, but is not as strong as the more recent positive IPO. The intensity of the 1925-1946 positive IPO is also lower than the 1977-1998 event to the east of the IDL, and more in line with the two -IPO phases.

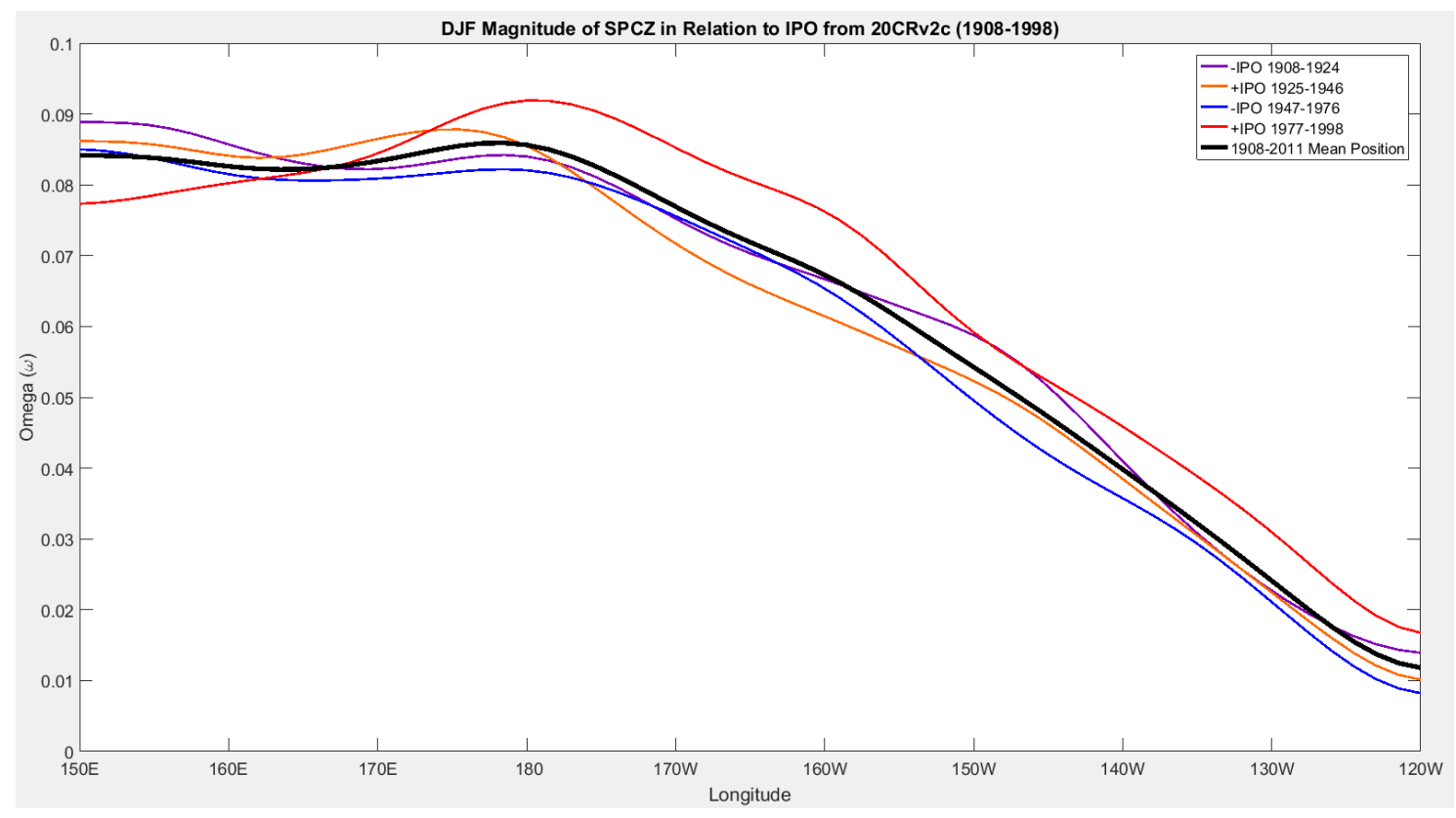

Figure 4.20 The mean DJF SPCZ intensity relative to twentieth century IPO cycles. The negative IPO from 19081924 is shown in purple, the positive IPO from 1925-1946 is shown in orange, the negative IPO from 1947-1976 is shown in blue, and the positive IPO from 1977-1998 is shown in red. The mean DJF 1908-2011 SPCZ intensity is shown in black.

The two -IPO phases both show similar patterns, with the peak intensity occurring at $150^{\circ} \mathrm{E}$. They both show a slow decline in intensity to the IDL, before the intensity decreases more rapidly east of the IDL. The largest difference is that the more recent IPO period from 1947-1976 is consistently weaker in intensity than the earlier -IPO period from 1908-1924 across the whole SPCZ region. Figure 4.20 illustrates that SPCZ intensity peaks further east near the IDL during positive IPO events, while it peaks further west $\left(150^{\circ} \mathrm{E}\right)$ during $-\mathrm{IPO}$ periods. 
Plotting the time series of the first EOF of SPCZ intensity and the TPI time series indicated a significant relationship (Figure 4.21), and correlation analysis was performed over the entire 1908-1998 period, as well as the two separated (1908-1946 and 1947-1998) periods. The overall correlation was $0.63(n=91$, d.f. $=89, p<0.01)$ indicating a significant relationship between variability in the intensity of the SPCZ and IPO phase. This holds for the two separate periods, with the correlation coming out as $0.70(\mathrm{n}=39$, d.f. $=37, \mathrm{p}<0.01)$ for the 1908-1946 period, and $0.60(\mathrm{n}=52$, d.f. $=50, \mathrm{p}$ $<0.01$ ) for the 1947-1998 period. This demonstrates that the relationship between the leading pattern of variability of SPCZ intensity and the IPO is rather consistent through time, although slightly stronger in the earlier 1908-1946 period.

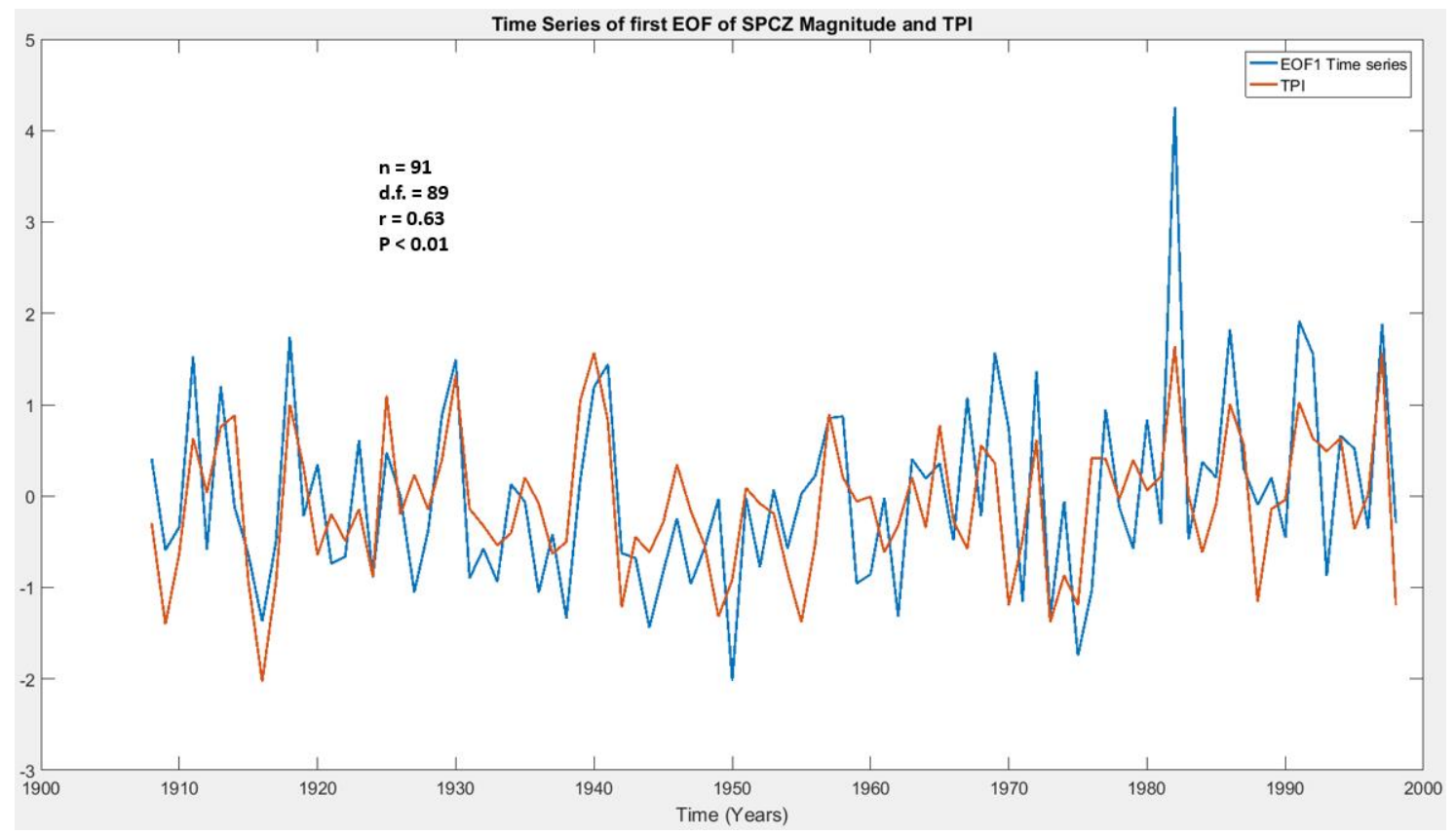

Figure 4.21 Time series of EOF1 of SPCZ intensity and the TPI time series from 1908-1998. The EOF1 time series is shown by the blue line and the TPI time series is shown by the orange line.

\subsubsection{Twentieth Century Trends: Location}

When looking at the mean DJF position of the SPCZ through time, there is not a pattern or trend that stands out across the majority of the SPCZ area (Figure 4.22). The mean positions are largely similar, with the time periods often alternating north and south of one another across the region. 


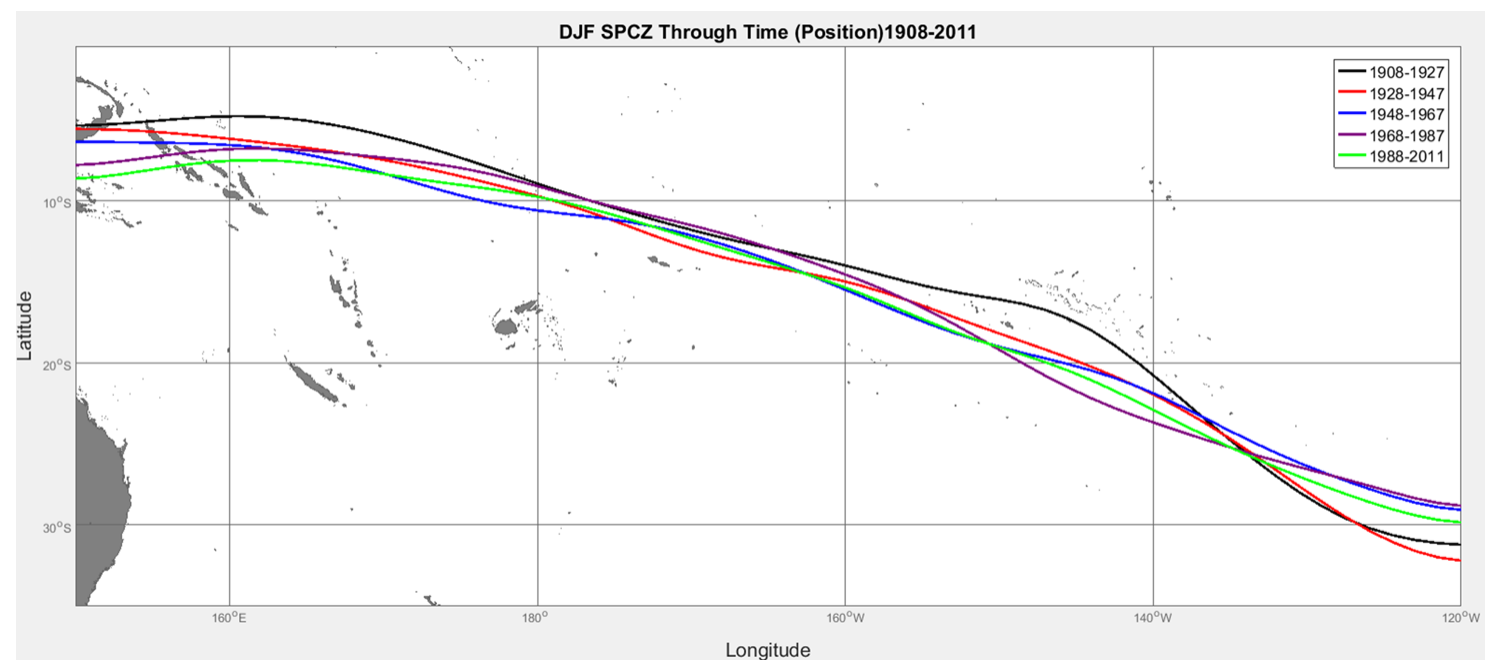

Figure 4.22 The mean DJF SPCZ position from 1908-2011 using twenty year blocks of time. The black line represents 1908-1927, the red line represents 1928-1947, the blue line represents 1948-1967, the purple line represents 1968-1987, and the green line represents 1988-2011.

However, in the far west of the SPCZ area (west of $\sim 170^{\circ} \mathrm{E}$ ) there does appear to be a progressive southward trend in SPCZ position through time from 1908-2011. Analysis of the latitude of the SPCZ position from 1908-2011 by longitude showed that a slight southward trend existed in the far west of the region (example from $150^{\circ} \mathrm{E}$ shown in Figure 4.23).

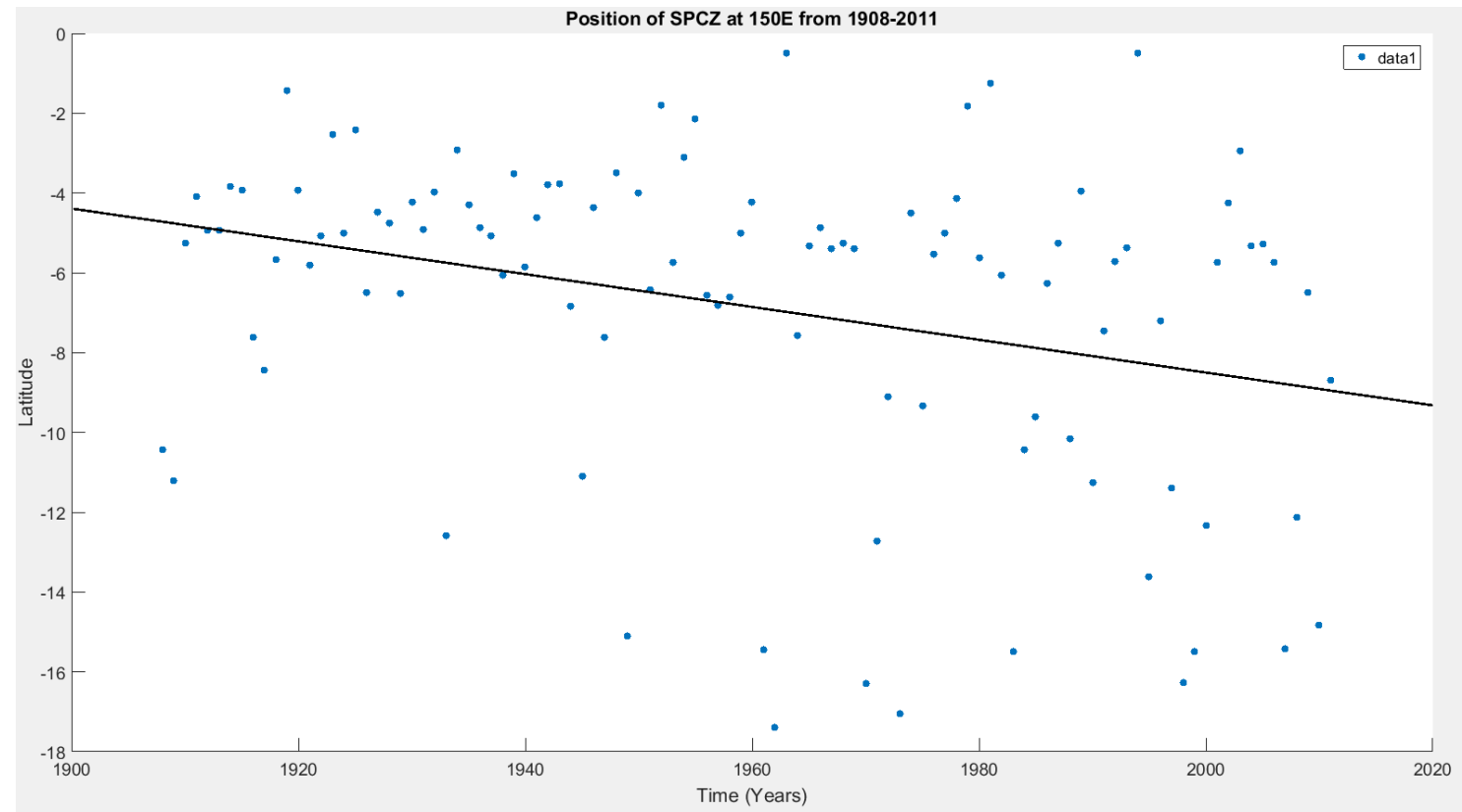

Figure 4.23 Position of the SPCZ from $20 \mathrm{CRv} 2 \mathrm{c}$ at $150^{\circ} \mathrm{E}$ for the $1908-2011$ period. Blue dots represent the latitude of the SPCZ at $150^{\circ} \mathrm{E}$ for each year. The black line represents the line of best fit through the data (linear) which has a $p$ value of 0.001 and $r^{2}$ of -0.31 .

Correlation analysis between latitude of SPCZ and year showed that this indication of a southward trend was statistically significant from $150^{\circ} \mathrm{E}$ to $\sim 170^{\circ} \mathrm{E}$ (Table 4.4 ), despite relatively low correlation coefficients of -0.2 to $-0.31(n=104$, d.f. $=102, p<0.01)$. 
Significant $\mathrm{p}$ values $(<0.05)$ existed over this region (and at $\sim 145^{\circ} \mathrm{W}$ ). This trend through time could be calculated by using the slope of the line of best fit, which resulted in values of -4.1 to $-2.5^{\circ}$ latitude/century from $150^{\circ} \mathrm{E}$ to $\sim 170^{\circ} \mathrm{E}$. Outside of this area (and $\sim 145^{\circ} \mathrm{W}$ ) no significant trend over the course of the twentieth century existed.

Table 4.4 Representation of $\mathrm{p}$ values and trend of SPCZ position from 1908-2011 by longitude. P values in bold are statistically significant at the $95 \%$ level, and the trend is in ${ }^{\circ}$ latitude/century.

\begin{tabular}{|c|c|c|c|c|c|c|c|c|c|c|c|c|c|c|c|c|}
\hline \multicolumn{17}{|c|}{ Twentieth Century trend of SPCZ Position by Longitude } \\
\hline & $150^{\circ} \mathrm{E}$ & $156^{\circ} \mathrm{E}$ & $162^{\circ} \mathrm{E}$ & $168^{\circ} \mathrm{E}$ & $174^{\circ} \mathrm{E}$ & 180 & $174^{\circ} \mathrm{W}$ & $168^{\circ} \mathrm{W}$ & $162^{\circ} \mathrm{W}$ & $156^{\circ} \mathrm{W}$ & $150^{\circ} \mathrm{W}$ & $144^{\circ} \mathrm{W}$ & $138^{\circ} \mathrm{W}$ & $132^{\circ} \mathrm{W}$ & $126^{\circ} \mathrm{W}$ & $120^{\circ} \mathrm{W}$ \\
\hline$P$ value & \begin{tabular}{|l|}
0.001 \\
\end{tabular} & \begin{tabular}{|l|l|}
0.003 \\
\end{tabular} & 0.01 & 0.04 & \begin{tabular}{|l|}
0.22 \\
\end{tabular} & 0.72 & 0.96 & 0.94 & 0.69 & 0.32 & \begin{tabular}{|l|}
0.07 \\
\end{tabular} & 0.04 & 0.23 & 0.78 & 0.09 & 0.08 \\
\hline Trend $\left({ }^{\circ}\right.$ latitude/Century) & -4.1 & -3.4 & -2.8 & -2.5 & -1.7 & -0.5 & 0.06 & 0.1 & -0.5 & -1.4 & -2.8 & -3.5 & -2.1 & 0.4 & 2.6 & 2.8 \\
\hline
\end{tabular}

These statistically significant results confirm what is suggested when looking at Figure 4.22 , in that a southward trend of SPCZ position in the far west (tropical) component is apparent over the course of the twentieth, and early twenty-first century.

\subsubsection{Twentieth Century Trends: Intensity}

The mean DJF SPCZ intensity through time is similar to the other intensity plots that have been studied, with peak intensity occurring at, and west of the IDL, and decreasing rapidly to the east (Figure 4.24). Three periods (1928-1947 (red line), 1968-1987 (purple line), and 1988-2011 (green line)) have peak intensities near the IDL, while the other two periods (1908-1928 (blue line) and 1948-1967 (yellow line)) have peak intensities located in the far west of the SPCZ region. The period that contains the highest mean peak intensity of the SPCZ is 1988-2011, while, 1948-1967 is the period that has the lowest peak intensity. The mean peak intensity is very similar for the other three time periods. 


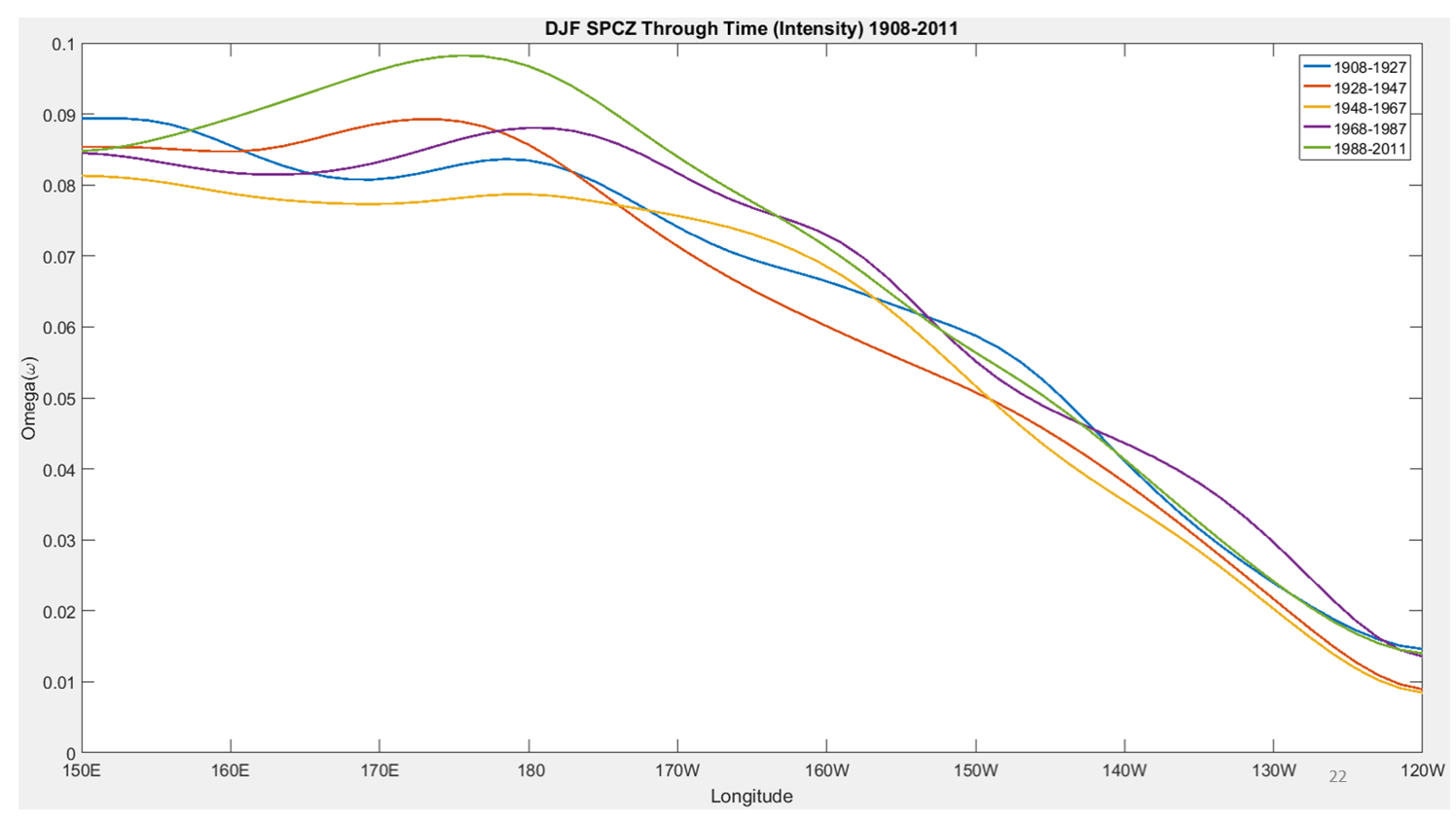

Figure 4.24 The mean DJF SPCZ intensity through 1908-2011 using twenty year blocks of time. The blue line represents 1908-1927, the orange line represents 1928-1947, the yellow line represents 1948-1967, the purple line represents 1968-1987, and the green line represents 1988-2011.

It seems probable that IPO periods are having an influence on where the location of peak SPCZ intensity has been occurring. The 1908-1927 and 1948-1967 periods fall largely within negative IPO periods, and peak intensity occurs for these periods in the far west of the SPCZ area. The other three periods (1928-1947, 1968-1987, and 19882011) all have peak intensities between $170^{\circ} \mathrm{E}$ and the IDL, with each of them containing positive IPO periods for at least half of their timespans (1928-1947 is almost entirely within a positive IPO period). Due to there being no noticeable progressive trend in SPCZ intensity through from 1908-2011, the linear trend regression analysis performed in section 4.3 .5 was not pursued. 


\section{Chapter 5 Discussion}

Chapter 5 of this thesis synthesises the results discussed in chapter 4 with, where necessary, relevant literature and studies on the SPCZ. Part one focuses on the representation of SPCZ location and intensity across all of the reanalysis and satellite products from 1979-2011, with specific emphasis on the performance of the 20CRv2c product. Part two focuses on the representation of the SPCZ between the two 20CR products, extending the analysis to 1908. A primary discussion point includes detail about whether the addition of extra data in the SPCZ region between 20CRv2 and 20CRv2c has improved the performance of the 20CR product. Finally, the effect of inter-annual and decadal variability on the SPCZ will be discussed, with particular focus on ENSO, the IPO, and twentieth century trends.

\subsection{Inter-comparison of Reanalysis and Satellite Products}

The initial aim of this study was to compare the representation of the SPCZ in the $20 \mathrm{CRv} 2$ and v2c products with various other reanalysis and observational satellite products. This was to see if the 20CR products, which ingest only surface observations to run their analysis, were able to accurately depict the SPCZ, and therefore indicate whether it has potential efficacy for outlining long-term SPCZ history prior to the classic reanalysis period (pre 1948).

Austral summer (DJF) from 1979-2011 had an overlap of all products within the satellite era (with the exception of TRMM, which begins in 1998). The method of using observational satellite products to assess reanalyses has been widely used in other studies (e.g. Brown et al., 2013; Matthews, 2012; Widlansky et al., 2011), however, it has not been used to assess the 20CR products in the Southwest Pacific region. For this study, minimum $10 \mathrm{~m}$ wind divergence and $500 \mathrm{hPa}$ omega were assessed to locate the SPCZ in the reanalyses, and found vertical motion to be superior to $10 \mathrm{~m}$ divergence. Maximum rainfall/minimum OLR were used to locate the SPCZ for the observational satellite products. 
The use of the $500 \mathrm{hPa}$ omega field in the reanalyses to identify the position of the SPCZ showed a close fit to the observational satellite products (Figure 4.1). Good agreement was found between all products for DJF 1979-2011, especially between the two 20CR products, ERA Interim, TRMM, and GPCP. NCEP/NCAR1 and the OLR products are still very similar, but diverge away from the other five, especially in the subtropical region to the east. The southward movement of the OLR field to the east of $150^{\circ} \mathrm{E}$ is not surprising, as the strong relationship that exists between minimum OLR and precipitation in the tropics breaks down as you move further poleward, due to decreased atmospheric and surface temperatures (Van Der Wiel et al., 2015b). The zonal bias seen in the NCEP/NCAR1 reanalysis was an interesting finding, and is most likely a symptom of it being the oldest product analysed, and the tendency of many models to represent the SPCZ too zonally (e.g. Brown et al., 2013; Brown et al., 2012; Niznik et al., 2015; Vincent et al., 2011). Regardless of the slight differences seen with these two products, spatial correlations of above 0.99 confirm what can clearly be seen in Figure 4.1 , in that there is a very similar depiction of the average DJF 1979-2011 SPCZ position between all analysed products. In addition to this, correlations in time period at each longitude (Table 4.1) range from 0.6-0.9, demonstrating that the products vary similarly to each other from year to year, further supporting the similarity between products in the depiction of the SPCZ.

Analysis of average SPCZ intensity also showed good agreement overall between most products. When looking at Figure 4.2 it can be seen that, with the exception of the ERA Interim reanalysis and OLR satellite product, all the analysed products have a peak intensity between $170^{\circ} \mathrm{E}$ and the IDL. Despite the ERA Interim reanalysis having the strongest intensity in the far west of the plot, the magnitude of the intensity is comparable to the two 20CR reanalysis products across most of the SPCZ region. The NCEP/NCAR1 reanalysis product depicts the SPCZ as significantly less intense as the other three reanalyses, although it has a similar spatial structure. The difference in intensity is again most likely explained by the NCEP/NCAR1 product being older than the other three reanalyses.

The GPCP and TRMM products produce a spatially similar plot of SPCZ maximum intensity, with TRMM being slightly higher in magnitude (maximum of 14mm/day compared to $12 \mathrm{~mm} /$ day). This difference does not detract from the fact that these two products represent the intensity of the SPCZ very similarly. This just leaves the OLR 
product as giving a slightly different representation of the SPCZ (maximum intensity in the far west) when looking at the observational satellite products. It was hard to compare the actual intensity values of the SPCZ between the reanalysis and satellite products, due to the different units of the fields used to identify the SPCZ (e.g. omega vs precipitation). This meant interpreting where the location of maximum intensity lies between products was largely relied on for analysis, rather than the magnitude of that maximum intensity.

Regardless of these slight differences discussed above, 20CRv2c had a spatial correlation of 0.89 or greater with all of the other analysed products when looking at the maximum intensity of the SPCZ. Temporal correlations of SPCZ intensity over the 1979-2011 period between 20CRv2c and OLR, ERA Interim, and GPCP, show some diversity in the inter-annual variability between the products (Table 4.2). 20CRv2c had weaker correlations with the other three products ( 0.17 to 0.34 for OLR, 0 to 0.3 for ERA Interim, and 0.3 to 0.4 for GPCP) west of $160^{\circ} \mathrm{E}$ before it increased to more significant $(0.4-0.9)$ for the rest of the longitudinal range. This implies that these products vary similarly year to year in the depiction of SPCZ intensity across most of the longitudinal range, with the exception of the far west of the SPCZ region.

The 20CR products integrate only surface observations, so the $500 \mathrm{hPa}$ omega field is derived from these through NWP model dynamics. Regardless of this possible limitation, the representation of the SPCZ is very similar to that of the other reanalyses and satellite products that contain upper atmosphere observations. The similarities in the depiction of the atmospheric circulation in the southwest Pacific region during the satellite era suggest a good degree of realism for 20CR, and that it is also feasible to base reanalyses on surface observations alone (Compo et al., 2011). The analysis also demonstrates that the 20CR performs well in the satellite period, and as such, it was deemed appropriate to use the 20CRv2c product for analysis extending back to 1908 . However, it is realised that just because the product performs well from 1979-2011, it does not mean the performance will be as good for the entire twentieth century, largely due to decreased data density further back in time. 


\subsection{Twentieth Century Reanalysis Comparison:}

The comparison in the depiction of the SPCZ between 20CRv2 and 20CRv2c suggested that there is a slight difference in performance between the two products in the earlier time period (1908-1957), while they seem to perform very similarly in the more recent time period (1958-2011). This pattern was evident in both the comparison of SPCZ position (Figure 4.6) and SPCZ intensity (Figure 4.7).

The closely related depiction of the SPCZ between 20CRv2 and 20CRv2c during 19582011 (Figure 4.6b) suggests the underlying data that is assimilated into the GCM producing the reanalysis is the same, or at least very similar. This result could be expected, as the performance of 20CR products rely heavily on spatio-temporal data density. More recent observations are also more accessible, and would be assimilated into both 20CRv2 and 20CRv2c, producing the similar depiction between the two products. Data rescue efforts to improve performance of the 20CR products are largely for periods earlier in the reanalysis, especially in the Southern Hemisphere where data sparseness is significantly more prevalent.

A visual difference between $20 \mathrm{CRv} 2$ and $20 \mathrm{CRv} 2 \mathrm{c}$ could be seen in the representation of SPCZ position for the 1908-1958 period (Figure 4.6a). The difference exists between the two products from $\sim 160^{\circ} \mathrm{E}$ to the IDL (the "western section"), and from the $\sim 170^{\circ} \mathrm{W}$ to $\sim 155^{\circ} \mathrm{W}$ (the "eastern section"). This difference was found to be statistically significant at the $90 \%$ level (two-tailed $\mathrm{t}$ test) between $\sim 163^{\circ} \mathrm{E}$ and $\sim 167^{\circ} \mathrm{E}$, as well as $\sim 168^{\circ} \mathrm{W}$ to $\sim 166^{\circ} \mathrm{W}$ (Table 4.3 ), which indicated there was likely an improvement in performance between 20CRv2 and 20CRv2c for the 1908-1957 period. Further evidence of this improvement was seen when plotting residual omega fields for chosen El Niño and La Niña DJF periods (both prior to, and after 1958) (Appendix B). The residual fields showed a coherent pattern for both the 1916/1917 La Niña and 1930/1931 El Niño, suggesting that there was a change in how the large-scale atmospheric circulation was represented in the SPCZ region between 20CRv2 and 20CRv2c. The lack of significant coherency in the residual plots for the 1982/1983 El Niño and 2010/2011 La Niña also showed that in more recent times, there is less difference between 20CRv2 and 20CRv2c, and that the representation of atmospheric circulation in the SPCZ region is relatively similar between the two products. 
The visual difference that can be seen between 20CRv2 and 20CRv2c in the "eastern section" and "western section" (see Figure 4.6a), and the difference in residual omega fields between the pre and post 1958 period indicated an improvement in performance for the 20CRv2c product. This assertion was supported by the statistically significant difference that is seen from $\sim 163^{\circ} \mathrm{E}$ to $\sim 167^{\circ} \mathrm{E}$, and from $\sim 168^{\circ} \mathrm{W}$ to $\sim 166^{\circ} \mathrm{W}$. These results indicated that the addition of five stations of data from the Cook Islands (Table 3.1) into ISDP 3.0 between 20CRv2 and 20CRv2c in the 1908-1958 period has helped improve performance between the 20CR products in the SPCZ region.

\subsection{SPCZ Modulators and Trends:}

After the reliability of the 20CRv2c product had been tested, and it was confirmed the product performed well, it was used to perform extended analysis over the course of the twentieth and early twenty-first century. This analysis included looking at the relationship between the SPCZ and ENSO and the IPO, and investigating whether there are any obvious trends that emerge through the twentieth century.

\subsubsection{ENSO}

Analysis of the link between ENSO and the SPCZ for this thesis (sections 4.3.1 and 4.3.2) produced results in line with previous studies documenting the well-known relationship (e.g. Borlace et al., 2014; Kidwell et al., 2016; Kiladis et al., 1989; Vincent et al., 2011 and others). Even though the method for classifying ENSO events was different than previous studies (description in section 3.1.3.), the well-documented north (and east) displacement during El Niño events and south (and west) displacement during La Niña events was still seen (Figure 4.8). In this study, the pattern was enhanced during strong ENSO events (strongest $20 \%$ for both El Niño and La Niña) with the average position of the SPCZ moving significantly northeast during strong El Niño events, and significantly southwest during strong La Niña events.

The first EOF of SPCZ position (Figure 4.9) shows a northward (or southward) displacement across the entire SPCZ region, with a maximum amplitude in the east $\left(\sim 140^{\circ} \mathrm{W}\right)$. This pattern accounts for $55 \%$ of variability in the SPCZ position and the time series has a correlation of 0.83 with the MEI. Warm SST anomalies were seen across most tropical Pacific Ocean (with the exception of the far west) when SST correlation and regression maps were plotted with EOF1 of the SPCZ position (Figure 4.11 and Figure 4.12). In the positive EOF1 scenario, the SPCZ would be seen to shift 
northward across the entire region (maximum amplitude $\sim 140^{\circ} \mathrm{W}$ ), in response to $\mathrm{El}$ Niño forced changes in underlying SSTs and a breakdown of trade winds in the central and eastern Pacific Ocean. Conversely, cooler SSTs in the central Pacific Ocean and stronger trade winds force the SPCZ south-westwards during La Niña conditions. This analysis shows that there is a close relationship between ENSO phase and the leading mode of variability in SPCZ position. The patterns seen in the investigation of ENSOSPCZ relationship aligns with studies (e.g. Folland et al., 2002; Kiladis et al., 1989; Vincent et al., 2011) that outline the importance of warm SSTs for SPCZ related convection, especially in the western tropical component. The occurrence of the maximum amplitude of positional change at $\sim 140^{\circ} \mathrm{W}$, however, is most likely not fully explained by the underlying changes in SSTs over the tropical Pacific Ocean. Instead, the El Niño related breakdown of the trade winds in the central Pacific Ocean likely plays an important role enhancing the northward swing of the SPCZ in this region, as discussed by Lintner and Neelin (2008), and Takahashi and Battisti (2007).

In addition to the positional changes associated with ENSO, this study showed that the intensity of the SPCZ also shows a distinct ENSO pattern (Figure 4.13). Not only does the location of maximum intensity shift towards the IDL in response to ENSO, the intensity itself is also noticeably greater when compared to neutral and La Niña years. This pattern is particularly prominent when looking at strong El Niño years, and still exists during weak El Niño years, although at a lesser magnitude.

EOF analysis of SPCZ intensity showed that the leading pattern of variability showed a decrease (increase) in intensity in the far west of the SPCZ region, and an increase (decrease) in intensity across the rest of the area, with a maximum amplitude near the IDL (Figure 4.14). This pattern accounted for $44.5 \%$ of the variability of SPCZ intensity and had a correlation of 0.69 with the MEI. Warm SST anomalies were again seen across most of the tropical Pacific Ocean (with the exception of the far west) when SST correlation and regression maps were plotted with the first EOF of SPCZ intensity (Figure 4.16 and Figure 4.17). In the positive EOF1 scenario, El Niño-forced increase in SSTs in the central and eastern Pacific Ocean, along with the breakdown of the trade winds, would see SPCZ-associated convection decrease in the vicinity of the WPWP, and increase near the IDL. At the same time as the convection shifts towards the central Pacific, there is also an increase in intensity of convection in the SPCZ during El Niño events, when compared to other ENSO phases. This shift in the location of maximum 
convection, and general increase in intensity is noted by various studies (e.g. Borlace et al., 2014; Brown et al., 2011; Kidwell et al., 2016; Vincent et al., 2011).

This section showed that the well-documented relationship between ENSO and the SPCZ remains consistent through the twentieth and early twenty-first century when performing analysis using the 20CRv2c product. Previous studies documenting the ENSO-SPCZ relationship have largely focussed on the satellite period, so to see this pattern holding true until the early twentieth century suggests the effect of ENSO on the position of the SPCZ has remained largely unchanged over the past century.

Additionally, this result provides further evidence that the extended 20CRv2c product performs admirably prior to the satellite period, and back to 1908, at least when it comes to the ENSO-SPCZ relationship.

\subsubsection{IPO}

Analysis of the IPO-SPCZ relationship (sections 4.3.3 and 4.3.4) produced similar results to those of past studies that have investigated this link (e.g. Folland et al., 2002; Kidwell et al., 2016; Mantua \& Hare, 2002). The accepted theory of this relationship is the north-eastward movement in the position of the SPCZ during positive IPO phases and south-westward movement during negative IPO phases. This is what was observed during this study (Figure 4.18), however, the pattern was stronger for the more recent complete IPO periods (1947-1976, and 1977-1998), than for the two earlier (1908-1924 and 1935-1946) periods. The position of the SPCZ during the 1977-1998 positive IPO phase is distinctly further north and east than during the 1947-1976 negative IPO. This pattern is a result of the warmer SSTs in the central Pacific Ocean, in conjunction with generally weakened trade winds, which allows the SPCZ to migrate north-east-wards during positive IPO periods. Conversely, cooler SSTs in the central Pacific Ocean and stronger trade winds seen during negative IPO phases push the position of the SPCZ south-westward. A correlation coefficient of 0.74 between the TPI and the time series of the first EOF of the SPCZ position for 1908-2011 statistically confirmed the SPCZ-IPO relationship that can be seen in Figure 4.18 between the more recent positive and negative IPO phases.

In addition to these SPCZ positional changes observed in response to the IPO, the intensity of the SPCZ also shows IPO signals (Figure 4.20). The longitude of maximum convection occurs at $150^{\circ} \mathrm{E}$ during the two negative IPO phases, while the maximum 
convection occurs nearer to the IDL for positive IPO phases. The most recent positive IPO phase (1977-1998) displays the highest intensity at the IDL, while it has the lowest intensity at $150^{\circ} \mathrm{E}$. This movement is in response to the IPO related changing SST and trade wind patterns which have been discussed in various studies (e.g. Folland et al., 2002; Kidwell et al., 2016; Salinger et al., 2014). Negative IPO conditions restrict the maximum convection associated with the SPCZ to the WPWP (near $150^{\circ} \mathrm{E}$ ) due to warm SST anomalies in this region forced by increased trade winds and associated cooling of the central equatorial Pacific Ocean. During positive IPO phases, the trade winds weaken and the warm SSTs move farther east, allowing maximum convection in the SPCZ to occur farther east near the IDL. A correlation coefficient of 0.62 between the TPI and the first EOF of SPCZ intensity from 1908-2011 confirmed that there is a significant statistical relationship between the variability in SPCZ intensity and the IPO, helping explain the pattern seen in Figure 4.20.

The discrepancy between the first and second half of the twentieth century raised questions of whether the physical SPCZ-IPO relationship has changed over time, or whether it has come about as a result of data sparseness prior to 1946. It was difficult to test whether this discrepancy was a result of data issues, and more analysis is needed to clarify this. However, two outcomes of this study suggested that the discrepancy could be due to a change in the SPCZ-IPO relationship: Firstly, correlation coefficients between the first EOF of SPCZ position and the IPO remain similar from 1908-1998 at 0.73 from 1908-1946, and 0.76 from 1947-1998, compared to 0.74 overall. This suggests that the strength of the relationship between variability in the position of the SPCZ and the IPO phase has remained consistent over the course of the twentieth century. However, this is not expressed when the SPCZ mean position is plotted relative to IPO periods. Second, the strength of the ENSO-SPCZ relationship seen through the whole analysis period suggests that 20CRv2c performs well extending back until 1908 . This being the case, a good representation of the SPCZ-IPO relationship should be observed throughout the entire twentieth century when plotting the SPCZ relative to IPO periods, but this does not hold true. These two factors indicate that the change seen between the first and second half of the twentieth century are more likely related to the physical SPCZ-IPO relationship changing, rather than issues with 20CRv2c performance related to data density issues. These changes may be a result of the generally lower amplitude ENSO events in the first half of the twentieth century (see 
MEI time series in Figure 4.10) resulting in a smaller departure from mean position when compared to the more recent IPO periods.

\subsubsection{Twentieth Century Trends}

Initially, there did not seem to be any coherent patterns across the analysis domain when investigating potential SPCZ trends from 1908-2011 (Figure 4.22). The specified twenty year periods (1908-1927, 1928-1947, 1948-1967, 1968-1997, and 1998-2011) generally undulated north and south of each other to the east of $\sim 170^{\circ} \mathrm{E}$. However, west of $\sim 170^{\circ} \mathrm{E}$ there was a slight progressive southward trend in the SPCZ position evident through the course of the twentieth century. This trend was tested by plotting the latitudinal position of the SPCZ at particular longitudes and fitting time trends from 1908-2011 (example from $150^{\circ} \mathrm{E}$ shown in Figure 4.23). The results suggested a southward trend of between $4.1^{\circ}$ and $2.5^{\circ}$ latitude/century from $150^{\circ} \mathrm{E}$ to $170^{\circ} \mathrm{E}$ (Table 4.4). Correlation analysis between the latitude of the SPCZ and time showed relatively low correlations of -0.2 to -0.3 for this region, however, $\mathrm{p}$ values of $<0.05$ suggested that the southward trend in SPCZ position was statistically significant throughout the twentieth century from $150^{\circ} \mathrm{E}$ to $170^{\circ} \mathrm{E}$. This southward trend could be an expression of climate change related expansion of the Hadley Cell near the region of the WPWP. This theory is in line with studies which have investigated Hadley Cell expansion (e.g. Hu \& Fu, 2007; Lu et al., 2007). In addition to this, a latitudinal movement of between 2.5 and $4.1^{\circ}$ west of $170^{\circ} \mathrm{E}$ between 1908 and 2011 is similar to a total expansion of the Hadley Cell of 2 to $4.5^{\circ}$ since 1979, as tested by $\mathrm{Hu}$ and $\mathrm{Fu}(2007)$.

When investigating the intensity of the SPCZ there did not seem to be any coherent trend with time through the course of the twentieth century. Instead, the variance of the magnitude and location of maximum intensity seemed to be largely controlled by IPO cycles. The time periods that contained predominantly negative IPO conditions (19081927 and 1948-1967) had the location of maximum SPCZ convection in the far west of the SPCZ area at $150^{\circ} \mathrm{E}$, while the time periods that spanned considerable portions of positive IPO phases (1928-1947, 1968-1987, and 1988-2011) all had the location of maximum SPCZ convection displaced towards the IDL. This result is not very surprising, as cool SST anomalies in the central Pacific Ocean and strengthened trade winds would restrict maximum convection to the WPWP during the periods containing mainly negative IPO conditions. Conversely, weakened trade winds and warmer SSTs 
in the central Pacific Ocean would allow increased convection near the IDL for periods with the IPO is predominantly positive. 


\section{Chapter 6 Conclusions and Future Work}

The overall aim of this thesis was to test the performance of the 20CR product in the satellite era via inter-comparison with other reanalysis and satellite products, before using 20CR to investigate the SPCZ extending back to 1908. Additionally, 20CRv2 and 20CRv2c were compared to assess whether extra data added in the SPCZ region improved performance between these two products. Well-established statistical techniques were used to compare the SPCZ between reanalysis and satellite products, and to investigate relationships between the SPCZ and ENSO and the IPO. Key findings of this study are:

- The 20CR products perform well in the 1979-2011 period when analysing the SPCZ. This is demonstrated by similar depiction of the mean DJF position and intensity of the SPCZ when compared with other reanalysis and observational satellite products. Strong spatial and temporal correlations between the products reinforced this finding.

- Analysis suggests that 20CRv2c does show some improvement in the SPCZ area when compared to 20CRv2 for the 1908-1957 period. This is likely a result of the five extra stations of surface data added to ISPD 3 for this period between the two products. The indication of performance improvement should encourage the continuation of data rescue efforts in the South Pacific region in an effort to keep improving the performance of the extended twentieth century reanalysis product.

- The well documented ENSO-SPCZ relationships are present when using 20CRv2c for analysis. The mean position moves north-eastward with a subsequent increase in intensity near the IDL in response to El Niño condition, while it is displaced south-westward with the highest intensity in the WPWP during La Niña conditions. These relationships remain consistent throughout the period of analysis back to 1908 .

- The documented SPCZ-IPO relationships are also present, particularly in the two more recent IPO periods, however, it is not as apparent in first half of 
twentieth century. This is possibly related to the performance of 20CRv2c and a lack of data in first half of twentieth century, but is more likely due a change in the relationship between the SPCZ and IPO over the course of the twentieth century.

- Analysis of twentieth century trends show there has been a progressive southward movement in the position of the $\mathrm{SPCZ}$ from $150^{\circ} \mathrm{E}$ to $170^{\circ} \mathrm{E}$ from 1908-2011 according to 20CRv2c. This is possibly a result of climate change related expansion of the Hadley circulation or the WPWP.

\section{Future Work:}

This thesis identified various avenues of future work to be explored. Recommendations for future work include:

- The continuation of inter-comparison work between various reanalysis and satellite products in the SPCZ region based upon the framework provided by this study. In particular, a comparison of 20CRv3 (when it is released) with $20 \mathrm{CRv} 2 \mathrm{c}$ to investigate any further improvements between versions of the 20CR product. This would help document whether data rescue efforts are continuing to improve the performance of the 20CR in the SPCZ region.

- Use 20CRv2c to perform further analysis now that it is shown to perform admirably back until the early twentieth century. This could include:

- Investigating in greater detail the ENSO-SPCZ relationship throughout the entire twentieth century.

- Investigating the potential change of the IPO-SPCZ relationship between the first and second half of the twentieth century.

- Further investigate the southward trend in the SPCZ that is evident through the twentieth and early twenty-first century in the west of the region. This could help give insight into potential climate change related expansion of the Hadley Cell in the WPWP region. 


\section{Bibliography:}

Adler, R. F., Huffman, G. J., Chang, A., Ferraro, R., Xie, P.-P., Janowiak, J., . . . Bolvin, D. (2003). The version-2 global precipitation climatology project (GPCP) monthly precipitation analysis (1979-present). Journal of hydrometeorology, 4(6), 1147-1167.

Alexander, M. (2010). Extratropical Air-Sea Interaction, Sea Surface Temperature Variability, and the Pacific Decadal Oscillation. Climate Dynamics: Why Does Climate Vary?, 123-148.

Alexander, M. A., \& Deser, C. (1995). A mechanism for the recurrence of wintertime midlatitude SST anomalies. Journal of physical oceanography, 25(1), 122-137.

Australian Bureau of Meterology and CSIRO. (2011). Climate Change in the Pacific: Scientific Assessment and New Research. Retrieved from

Basher, R., \& Zheng, X. (1995). Tropical cyclones in the southwest Pacific: Spatial patterns and relationships to Southern Oscillation and sea surface temperature. Journal of Climate, 8(5), 1249-1260.

Bergeron, T. (1930). Richtlinien einer dynamischen Klimatologie. Meteorologische Zeitschrift, 47(7), 246-262.

Bjerknes, J. (1969). Atmospheric teleconnections from the equatorial Pacific. Monthly Weather Review, 97(3), 163-172.

Borlace, S., Santoso, A., Cai, W., \& Collins, M. (2014). Extreme swings of the South Pacific Convergence Zone and the different types of El Niño events. Geophysical Research Letters, 41(13), 4695-4703.

Briegel, L. M., \& Frank, W. M. (1997). Large-scale influences on tropical cyclogenesis in the western North Pacific. Monthly Weather Review, 125(7), 1397-1413.

Brown, J. R., Moise, A. F., \& Colman, R. A. (2013). The South Pacific Convergence Zone in CMIP5 simulations of historical and future climate. Climate dynamics, 41(7-8), 2179-2197.

Brown, J. R., Moise, A. F., \& Delage, F. P. (2012). Changes in the South Pacific Convergence Zone in IPCC AR4 future climate projections. Climate dynamics, 39(1-2), 1-19. 
Brown, J. R., Power, S. B., Delage, F. P., Colman, R. A., Moise, A. F., \& Murphy, B. F. (2011). Evaluation of the South Pacific Convergence Zone in IPCC AR4 climate model simulations of the twentieth century. Journal of Climate, 24(6), 15651582.

Cai, W., Borlace, S., Lengaigne, M., Van Rensch, P., Collins, M., Vecchi, G., . . Wu, L. (2014). Increasing frequency of extreme El Niño events due to greenhouse warming. Nature climate change, 4(2), 111-116.

Cai, W., Lengaigne, M., Borlace, S., Collins, M., Cowan, T., McPhaden, M. J., . . . Menkes, C. (2012). More extreme swings of the South Pacific convergence zone due to greenhouse warming. Nature, 488(7411), 365-369.

Camargo, S. J., Emanuel, K. A., \& Sobel, A. H. (2007). Use of a genesis potential index to diagnose ENSO effects on tropical cyclone genesis. Journal of Climate, 20(19), 4819-4834.

Cayan, D. R., Dettinger, M. D., Diaz, H. F., \& Graham, N. E. (1998). Decadal variability of precipitation over western North America. Journal of Climate, 11(12), 3148-3166.

Collins, M., An, S.-I., Cai, W., Ganachaud, A., Guilyardi, E., Jin, F.-F., . . . Timmermann, A. (2010). The impact of global warming on the tropical Pacific Ocean and El Niño. Nature Geoscience, 3(6), 391-397.

Compo, G. P., Whitaker, J. S., Sardeshmukh, P. D., Matsui, N., Allan, R. J., Yin, X., . . Bessemoulin, P. (2011). The twentieth century reanalysis project. Quarterly Journal of the Royal Meteorological Society, 137(654), 1-28.

Dee, D., Uppala, S., Simmons, A., Berrisford, P., Poli, P., Kobayashi, S., . . Bauer, P. (2011). The ERA-Interim reanalysis: Configuration and performance of the data assimilation system. Quarterly Journal of the Royal Meteorological Society, 137(656), 553-597.

Diamond, H., Lorrey, A., Knapp, K., \& Levinson, D. (2012). Development of an enhanced tropical cyclone tracks database for the southwest Pacific from 1840 to 2010. International Journal of Climatology, 32(14), 2240-2250.

Diamond, H. J., Lorrey, A. M., \& Renwick, J. A. (2013). A southwest Pacific tropical cyclone climatology and linkages to the El Niño-Southern Oscillation. Journal of Climate, 26(1), 3-25. 
Ebbesmeyer, C. C., Cayan, D. R., McLain, D. R., Nichols, F. H., Peterson, D. H., \& Redmond, K. T. (1991). 1976 step in the Pacific climate: forty environmental changes between 1968-1975 and 1977-1984.

Evans, J., Bormann, K., Katzfey, J., Dean, S., \& Arritt, R. (2016). Regional climate model projections of the South Pacific Convergence Zone. Climate dynamics, 47(3-4), 817-829.

Evans, J. L., \& Allan, R. J. (1992). El Niño/Southern Oscillation modification to the structure of the monsoon and tropical cyclone activity in the Australasian region. International Journal of Climatology, 12(6), 611-623.

Fauchereau, N., Pohl, B., \& Lorrey, A. (2016). Extratropical Impacts of the MaddenJulian oscillation over New Zealand from a weather regime perspective. Journal of Climate, 29(6), 2161-2175.

Folland, C., Renwick, J., Salinger, M., \& Mullan, A. (2002). Relative influences of the inter-decadal Pacific oscillation and ENSO on the South Pacific convergence zone. Geophysical Research Letters, 29(13).

Frank, W. M., \& Roundy, P. E. (2006). The role of tropical waves in tropical cyclogenesis. Monthly Weather Review, 134(9), 2397-2417.

Frankignoul, C., \& Reynolds, R. W. (1983). Testing a dynamical model for mid-latitude sea surface temperature anomalies. Journal of physical oceanography, 13(7), 1131-1145.

Gray, W. (1975). Tropical cyclone genesis. Dept. of Atmospheric Sciences Paper 234, Colorado State University, Ft. Collins, CO, 121 pp.[Available from Department of Atmospheric Science, Colorado State University, Fort Collins, CO 80523.], 1979: Hurricanes: Their formation, structure and likely role in the tropical circulation. Meteorology over the Tropical Oceans, 155-218.

Gray, W. M., \& Brody, L. (1967). Global view of the origin of tropical disturbances and storms: Colorado State University, Department of Atmospheric Science.

Gruber, A., \& Krueger, A. F. (1984). The status of the NOAA outgoing longwave radiation data set. Bulletin of the American meteorological Society, 65(9), 958962.

Gruber, A., \& Winston, J. S. (1978). Earth-atmosphere radiative heating based on NOAA scanning radiometer measurements. Bulletin of the American meteorological Society, 59(12), 1570-1573. 
Haffke, C., \& Magnusdottir, G. (2013). The South Pacific Convergence Zone in three decades of satellite images. Journal of Geophysical Research: Atmospheres, $118(19)$.

Hamada, J.-I., D YAMANAKA, M., Matsumoto, J., Fukao, S., Winarso, P. A., \& Sribimawati, T. (2002). Spatial and temporal variations of the rainy season over Indonesia and their link to ENSO. Journal of the Meteorological Society of Japan. Ser. II, 80(2), 285-310.

Hastings, P. A. (1990). Southern Oscillation influences on tropical cyclone activity in the Australian/south-west Pacific region. International Journal of Climatology, 10(3), 291-298.

Hendon, H. H., \& Salby, M. L. (1994). The life cycle of the Madden-Julian oscillation. Journal of the atmospheric sciences, 51(15), 2225-2237.

Hendon, H. H., Zhang, C., \& Glick, J. D. (1999). Inter-annual variation of the MaddenJulian oscillation during austral summer. Journal of Climate, 12(8), 2538-2550.

Henley, B. J., Gergis, J., Karoly, D. J., Power, S., Kennedy, J., \& Folland, C. K. (2015). A tripole index for the Inter-decadal Pacific Oscillation. Climate dynamics, 45(11-12), 3077-3090.

Hirons, L., Inness, P., Vitart, F., \& Bechtold, P. (2013). Understanding advances in the simulation of intraseasonal variability in the ECMWF model. Part I: The representation of the MJO. Quarterly Journal of the Royal Meteorological Society, 139(675), 1417-1426.

Hu, Y., \& Fu, Q. (2007). Observed poleward expansion of the Hadley circulation since 1979. Atmospheric Chemistry and Physics, 7(19), 5229-5236.

Huang, B., Thorne, P. W., Banzon, V. F., Boyer, T., Chepurin, G., Lawrimore, J. H., . . Zhang, H.-M. (2017). Extended reconstructed sea surface temperature, version 5 (ERSSTv5): upgrades, validations, and Inter-comparisons. Journal of Climate, 30(20), 8179-8205.

Hubert, L. F. (1961). A subtropical convergence line of the South Pacific: A case study using meteorological satellite data. Journal of Geophysical Research, 66(3), 797-812.

Huffman, G. J., Bolvin, D. T., Nelkin, E. J., Wolff, D. B., Adler, R. F., Gu, G., . . Stocker, E. F. (2007). The TRMM multisatellite precipitation analysis (TMPA): Quasi-global, multiyear, combined-sensor precipitation estimates at fine scales. Journal of hydrometeorology, 8(1), 38-55. 
Julian, P. R., \& Chervin, R. M. (1978). A study of the Southern Oscillation and Walker Circulation phenomenon. Monthly Weather Review, 106(10), 1433-1451.

Kalnay, E., Kanamitsu, M., Kistler, R., Collins, W., Deaven, D., Gandin, L., . . . Woollen, J. (1996). The NCEP/NCAR 40-year reanalysis project. Bulletin of the American meteorological Society, 77(3), 437-471.

Kidwell, A., Lee, T., Jo, Y.-H., \& Yan, X.-H. (2016). Characterization of the variability of the South Pacific Convergence Zone using satellite and reanalysis wind products. Journal of Climate, 29(5), 1717-1732.

Kiladis, G. N., Von Storch, H., \& Loon, H. (1989). Origin of the South Pacific convergence zone. Journal of Climate, 2(10), 1185-1195.

Knutson, T. R., Weickmann, K. M., \& Kutzbach, J. E. (1986). Global-scale intraseasonal oscillations of outgoing longwave radiation and $250 \mathrm{mb}$ zonal wind during Northern Hemisphere summer. Monthly Weather Review, 114(3), 605-623.

Kripalani, R., \& Kulkarni, A. (1997). Climatic impact of El Niño/La Niña on the Indian monsoon: A new perspective. Weather, 52(2), 39-46.

Krishnamurti, T., Stefanova, L., \& Misra, V. (2013). Madden Julian Oscillation Tropical Meteorology (pp. 143-168): Springer.

Kuleshov, Y., Qi, L., Fawcett, R., \& Jones, D. (2008). On tropical cyclone activity in the Southern Hemisphere: trends and the ENSO connection. Geophysical Research Letters, 35(14).

Kumar, K. K., Rajagopalan, B., Hoerling, M., Bates, G., \& Cane, M. (2006). Unraveling the mystery of Indian monsoon failure during El Niño. Science, 314(5796), 115119.

Kumar, K. K., Soman, M., \& Kumar, K. R. (1995). Seasonal forecasting of Indian summer monsoon rainfall: a review. Weather, 50(12), 449-467.

Latif, M., Anderson, D., Barnett, T., Cane, M., Kleeman, R., Leetmaa, A., . . . Schneider, E. (1998). A review of the predictability and prediction of ENSO. Journal of Geophysical Research: Oceans, 103(C7), 14375-14393.

Latif, M., Barnett, T., Cane, M., Flügel, M., Graham, N. v., Von Storch, H., . . Zebiak, S. (1994). A review of ENSO prediction studies. Climate dynamics, 9(4-5), 167179.

Latif, M., \& Barnett, T. P. (1994). Causes of decadal climate variability over the North Pacific and North America. Science, 266(5185), 634-638. 
Latif, M., \& Barnett, T. P. (1996). Decadal climate variability over the North Pacific and North America: Dynamics and predictability. Journal of Climate, 9(10), 2407-2423.

Lau, K.-M., \& Chan, P. H. (1985). Aspects of the 40-50 day oscillation during the northern winter as inferred from outgoing longwave radiation. Monthly Weather Review, 113(11), 1889-1909.

Lau, K.-M., \& Chan, P. H. (1988). Intraseasonal and inter-annual variations of tropical convection: A possible link between the 40-50 day oscillation and ENSO? Journal of the atmospheric sciences, 45(3), 506-521.

Liebmann, B., \& Smith, C. A. (1996). Description of a complete (interpolated) outgoing longwave radiation dataset. Bulletin of the American meteorological Society, 77(6), 1275-1277.

Linsley, B., Wellington, G., Schrag, D., Ren, L., Salinger, M., \& Tudhope, A. (2004). Geochemical evidence from corals for changes in the amplitude and spatial pattern of South Pacific inter-decadal climate variability over the last 300 years. Climate dynamics, 22(1), 1-11.

Lintner, B. R., \& Neelin, J. D. (2008). Eastern margin variability of the South Pacific convergence zone. Geophysical Research Letters, 35(16).

Liu, Z., \& Alexander, M. (2007). Atmospheric bridge, oceanic tunnel, and global climatic teleconnections. Reviews of Geophysics, 45(2).

Lorrey, A., Dalu, G., Renwick, J., Diamond, H., \& Gaetani, M. (2012). Reconstructing the South Pacific Convergence Zone position during the presatellite era: A La Niña case study. Monthly Weather Review, 140(11), 3653-3668.

Lu, J., Vecchi, G. A., \& Reichler, T. (2007). Expansion of the Hadley cell under global warming. Geophysical Research Letters, 34(6).

Madden, R. A., \& Julian, P. R. (1994). Observations of the 40-50-day tropical oscillation-A review. Monthly Weather Review, 122(5), 814-837.

Mantua, N. J., \& Hare, S. R. (2002). The Pacific decadal oscillation. Journal of oceanography, 58(1), 35-44.

Mantua, N. J., Hare, S. R., Zhang, Y., Wallace, J. M., \& Francis, R. C. (1997). A Pacific inter-decadal climate oscillation with impacts on salmon production. Bulletin of the American meteorological Society, 78(6), 1069-1079. 
Matthews, A. J. (2012). A multiscale framework for the origin and variability of the South Pacific Convergence Zone. Quarterly Journal of the Royal Meteorological Society, 138(666), 1165-1178.

Matthews, A. J., Hoskins, B. J., Slingo, J. M., \& Blackburn, M. (1996). Development of convection along the SPCZ within a Madden-Julian oscillation. Quarterly Journal of the Royal Meteorological Society, 122(531), 669-688.

McPhaden, M. J., Zebiak, S. E., \& Glantz, M. H. (2006). ENSO as an integrating concept in earth science. Science, 314(5806), 1740-1745.

Meehl, G. A., Hu, A., Arblaster, J. M., Fasullo, J., \& Trenberth, K. E. (2013). Externally forced and internally generated decadal climate variability associated with the Inter-decadal Pacific Oscillation. Journal of Climate, 26(18), 7298-7310.

Miller, A. J., Cayan, D. R., Barnett, T. P., Graham, N. E., \& Oberhuber, J. M. (1994). The 1976-77 climate shift of the Pacific Ocean. Oceanography, 7(1), 21-26.

Minobe, S. (2000). Spatio-temporal structure of the pentadecadal variability over the North Pacific. Progress in Oceanography, 47(2), 381-408.

Namias, J., \& Born, R. M. (1970). Temporal coherence in North Pacific sea-surface temperature patterns. Journal of Geophysical Research, 75(30), 5952-5955.

Namias, J., \& Born, R. M. (1974). Further studies of temporal coherence in North Pacific sea surface temperatures. Journal of Geophysical Research, 79(6), 797798.

Newman, M., Alexander, M. A., Ault, T. R., Cobb, K. M., Deser, C., Di Lorenzo, E., . . . Nakamura, H. (2016). The Pacific decadal oscillation, revisited. Journal of Climate, 29(12), 4399-4427.

Newman, M., Compo, G. P., \& Alexander, M. A. (2003). ENSO-forced variability of the Pacific decadal oscillation. Journal of Climate, 16(23), 3853-3857.

Nguyen, K. C., Katzfey, J. J., \& McGregor, J. L. (2012). Global 60 km simulations with CCAM: evaluation over the tropics. Climate dynamics, 39(3-4), 637-654.

Niznik, M. J., Lintner, B. R., Matthews, A. J., \& Widlansky, M. J. (2015). The role of tropical-extratropical interaction and synoptic variability in maintaining the South Pacific Convergence Zone in CMIP5 models. Journal of Climate, 28(8), 3353-3374.

Parker, D., Folland, C., Scaife, A., Knight, J., Colman, A., Baines, P., \& Dong, B. (2007). Decadal to multidecadal variability and the climate change background. Journal of Geophysical Research: Atmospheres, 112(D18). 
Philander, G. (1989). El Niño and La Niña. American Scientist, 77(5), 451-459.

Power, S., Casey, T., Folland, C., Colman, A., \& Mehta, V. (1999). Inter-decadal modulation of the impact of ENSO on Australia. Climate dynamics, 15(5), 319324.

Power, S., Haylock, M., Colman, R., \& Wang, X. (2006). The predictability of interdecadal changes in ENSO activity and ENSO teleconnections. Journal of Climate, 19(19), 4755-4771.

Revell, C. G., \& Goulter, S. W. (1986). South Pacific tropical cyclones and the Southern Oscillation. Monthly Weather Review, 114(6), 1138-1145.

Risbey, J. S., Pook, M. J., McIntosh, P. C., Wheeler, M. C., \& Hendon, H. H. (2009). On the remote drivers of rainfall variability in Australia. Monthly Weather Review, 137(10), 3233-3253.

Roundy, P. E. (2008). Analysis of convectively coupled Kelvin waves in the Indian Ocean MJO. Journal of the atmospheric sciences, 65(4), 1342-1359.

Salinger, M., McGree, S., Beucher, F., Power, S. B., \& Delage, F. (2014). A new index for variations in the position of the South Pacific convergence zone 1910/112011/2012. Climate dynamics, 43(3-4), 881-892.

Schneider, N., \& Cornuelle, B. D. (2005). The forcing of the Pacific decadal oscillation. Journal of Climate, 18(21), 4355-4373.

Sinclair, M. R. (2002). Extratropical transition of southwest Pacific tropical cyclones. Part I: Climatology and mean structure changes. Monthly Weather Review, $130(3), 590-609$.

Streten, N. A., \& Troup, A. (1973). A synoptic climatology of satellite observed cloud vortices over the Southern Hemisphere. Quarterly Journal of the Royal Meteorological Society, 99(419), 56-72.

Sulca, J., Takahashi, K., Espinoza, J. C., Vuille, M., \& Lavado-Casimiro, W. (2017). Impacts of different ENSO flavors and tropical Pacific convection variability (ITCZ, SPCZ) on austral summer rainfall in South America, with a focus on Peru. International Journal of Climatology.

Takahashi, K., \& Battisti, D. S. (2007). Processes controlling the mean tropical Pacific precipitation pattern. Part II: The SPCZ and the southeast Pacific dry zone. Journal of Climate, 20(23), 5696-5706.

Trenberth, K. E. (1976). Spatial and temporal variations of the Southern Oscillation. Quarterly Journal of the Royal Meteorological Society, 102(433), 639-653. 
Trenberth, K. E. (1990). Recent observed inter-decadal climate changes in the Northern Hemisphere. Bulletin of the American meteorological Society, 71(7), 988-993.

Trenberth, K. E. (1997). The definition of El Niño. Bulletin of the American meteorological Society, 78(12), 2771-2777.

Van Der Wiel, K., Matthews, A. J., Joshi, M. M., \& Stevens, D. P. (2015a). The influence of diabatic heating in the South Pacific Convergence Zone on Rossby wave propagation and the mean flow. Quarterly Journal of the Royal Meteorological Society.

Van Der Wiel, K., Matthews, A. J., Stevens, D. P., \& Joshi, M. M. (2015b). A dynamical framework for the origin of the diagonal South Pacific and South Atlantic Convergence Zones. Quarterly Journal of the Royal Meteorological Society, 141(691), 1997-2010.

Vincent, D. G. (1994). The South Pacific convergence zone (SPCZ): A review. Monthly Weather Review, 122(9), 1949-1970.

Vincent, D. G., Sperling, T., Fink, A., Zube, S., \& Speth, P. (1991). Intraseasonal oscillation of convective activity in the tropical Southern Hemisphere: May 1984-April 1986. Journal of Climate, 4(1), 40-53.

Vincent, E. M., Lengaigne, M., Menkes, C. E., Jourdain, N. C., Marchesiello, P., \& Madec, G. (2011). Inter-annual variability of the South Pacific Convergence Zone and implications for tropical cyclone genesis. Climate dynamics, 36(9-10), 1881-1896.

Walker, G. (1928). World weather. Quarterly Journal of the Royal Meteorological Society, 54(226), 79-87.

Wang, C., Deser, C., Yu, J.-Y., DiNezio, P., \& Clement, A. (2017). El Niño and Southern Oscillation (ENSO): A review Coral Reefs of the Eastern Tropical Pacific (pp. 85-106): Springer.

Wang, C., \& Fiedler, P. C. (2006). ENSO variability and the eastern tropical Pacific: A review. Progress in Oceanography, 69(2), 239-266.

Wang, X. L., Feng, Y., Compo, G., Swail, V., Zwiers, F., Allan, R., \& Sardeshmukh, P. (2013). Trends and low frequency variability of extra-tropical cyclone activity in the ensemble of twentieth century reanalysis. Climate dynamics, 40(11-12), 2775-2800. 
Weickmann, K. M., Lussky, G. R., \& Kutzbach, J. E. (1985). Intraseasonal (30-60 day) fluctuations of outgoing longwave radiation and $250 \mathrm{mb}$ streamfunction during northern winter. Monthly Weather Review, 113(6), 941-961.

Whan, K., \& Zwiers, F. (2017). The impact of ENSO and the NAO on extreme winter precipitation in North America in observations and regional climate models. Climate dynamics, 48(5-6), 1401-1411.

Wheeler, M. C., \& Hendon, H. H. (2004). An all-season real-time multivariate MJO index: Development of an index for monitoring and prediction. Monthly Weather Review, 132(8), 1917-1932.

Widlansky, M. J., Timmermann, A., Stein, K., McGregor, S., Schneider, N., England, M. H., . . Cai, W. (2013). Changes in South Pacific rainfall bands in a warming climate. Nature climate change, 3(4), 417-423.

Widlansky, M. J., Webster, P. J., \& Hoyos, C. D. (2011). On the location and orientation of the South Pacific Convergence Zone. Climate dynamics, 36(3-4), 561-578.

Wilks, D. S. (2011). Statistical methods in the atmospheric sciences (Vol. 100): Academic press.

Wolter, K., \& Timlin, M. S. (1993). Monitoring ENSO in COADS with a seasonally adjusted principal component index. Paper presented at the Proc. of the 17th Climate Diagnostics Workshop.

Yoneyama, K., Zhang, C., \& Long, C. N. (2013). Tracking pulses of the Madden-Julian oscillation. Bulletin of the American meteorological Society, 94(12), 1871-1891.

Zehr, R. M. (1992). Tropical cyclogenesis in the western North Pacific.

Zhang, C. (2005). Madden-julian oscillation. Reviews of Geophysics, 43(2).

Zhang, P. (2007). Inter-decadal-Decadal Climate Variability from Multi-Coral Oxygen Isotope Records in the South Pacific Convergence Zone Region Since 1650AD. 
Appendix A: Calculated MEI and TPI Values

\begin{tabular}{|c|c|c|}
\hline Year & $\begin{array}{c}\text { MEI } \\
\text { Value }\end{array}$ & $\begin{array}{c}\text { TPI } \\
\text { Value }\end{array}$ \\
\hline 1908 & -0.90 & -0.30 \\
\hline 1909 & -1.55 & -1.40 \\
\hline 1910 & -0.97 & -0.63 \\
\hline 1911 & 0.82 & 0.64 \\
\hline 1912 & -0.05 & 0.04 \\
\hline 1913 & 0.76 & 0.76 \\
\hline 1914 & 1.14 & 0.88 \\
\hline 1915 & -0.71 & -0.93 \\
\hline 1916 & -1.75 & -2.03 \\
\hline 1917 & -1.08 & -0.94 \\
\hline 1918 & 1.41 & 1.00 \\
\hline 1919 & 0.44 & 0.30 \\
\hline 1920 & -0.35 & -0.65 \\
\hline 1921 & -0.35 & -0.20 \\
\hline 1922 & -0.64 & -0.49 \\
\hline 1923 & 0.38 & -0.14 \\
\hline 1924 & -0.66 & -0.88 \\
\hline 1925 & 1.53 & 1.10 \\
\hline 1926 & 0.02 & -0.20 \\
\hline 1927 & 0.30 & 0.23 \\
\hline 1928 & -0.14 & -0.15 \\
\hline 1929 & 0.67 & 0.39 \\
\hline 1930 & 1.91 & 1.32 \\
\hline 1931 & 0.39 & -0.14 \\
\hline 1932 & -0.22 & -0.32 \\
\hline 1933 & -1.04 & -0.54 \\
\hline 1934 & -0.34 & -0.41 \\
\hline 1935 & 0.30 & 0.20 \\
\hline 1936 & 0.24 & -0.08 \\
\hline 1937 & -0.38 & -0.63 \\
\hline 1938 & -0.85 & -0.50 \\
\hline 1939 & 0.89 & 1.04 \\
\hline 1940 & 1.55 & 1.57 \\
\hline 1941 & 1.13 & 0.82 \\
\hline 1942 & -0.98 & -1.22 \\
\hline & & \\
\hline
\end{tabular}

\begin{tabular}{|c|c|c|}
\hline Year & $\begin{array}{c}\text { MEI } \\
\text { Value }\end{array}$ & $\begin{array}{c}\text { TPI } \\
\text { Value }\end{array}$ \\
\hline 1943 & -0.04 & -0.45 \\
\hline 1944 & -0.43 & -0.62 \\
\hline 1945 & -0.17 & -0.29 \\
\hline 1946 & 0.02 & 0.34 \\
\hline 1947 & 0.21 & -0.16 \\
\hline 1948 & -0.11 & -0.54 \\
\hline 1949 & -1.11 & -1.32 \\
\hline 1950 & -1.05 & -0.91 \\
\hline 1951 & 0.25 & 0.09 \\
\hline 1952 & 0.24 & -0.08 \\
\hline 1953 & -0.05 & -0.19 \\
\hline 1954 & -1.08 & -0.83 \\
\hline 1955 & -1.45 & -1.38 \\
\hline 1956 & -0.37 & -0.53 \\
\hline 1957 & 1.29 & 0.90 \\
\hline 1958 & 0.54 & 0.21 \\
\hline 1959 & -0.19 & -0.06 \\
\hline 1960 & -0.18 & -0.01 \\
\hline 1961 & -0.90 & -0.62 \\
\hline 1962 & -0.71 & -0.32 \\
\hline 1963 & 0.25 & 0.20 \\
\hline 1964 & -0.41 & -0.35 \\
\hline 1965 & 0.98 & 0.77 \\
\hline 1966 & -0.74 & -0.27 \\
\hline 1967 & -0.67 & -0.58 \\
\hline 1968 & 0.58 & 0.56 \\
\hline 1969 & 0.28 & 0.36 \\
\hline 1970 & -1.53 & -1.19 \\
\hline 1971 & -0.49 & -0.47 \\
\hline 1972 & 1.27 & 0.62 \\
\hline 1973 & -1.80 & -1.38 \\
\hline 1974 & -0.78 & -0.87 \\
\hline 1975 & -1.43 & -1.19 \\
\hline 1976 & 0.41 & 0.42 \\
\hline 1977 & 0.73 & 0.41 \\
\hline
\end{tabular}

\begin{tabular}{|c|c|c|}
\hline Year & $\begin{array}{c}\text { MEI } \\
\text { Value }\end{array}$ & $\begin{array}{c}\text { TPI } \\
\text { Value }\end{array}$ \\
\hline 1978 & 0.33 & -0.03 \\
\hline 1979 & 0.77 & 0.39 \\
\hline 1980 & 0.16 & 0.06 \\
\hline 1981 & -0.09 & 0.22 \\
\hline 1982 & 2.76 & 1.64 \\
\hline 1983 & -0.11 & 0.01 \\
\hline 1984 & -0.59 & -0.62 \\
\hline 1985 & -0.17 & -0.08 \\
\hline 1986 & 1.45 & 1.01 \\
\hline 1987 & 0.80 & 0.56 \\
\hline 1988 & -1.11 & -1.15 \\
\hline 1989 & 0.47 & -0.14 \\
\hline 1990 & 0.37 & -0.04 \\
\hline 1991 & 1.84 & 1.02 \\
\hline 1992 & 0.94 & 0.63 \\
\hline 1993 & 0.35 & 0.49 \\
\hline 1994 & 0.95 & 0.64 \\
\hline 1995 & -0.47 & -0.36 \\
\hline 1996 & -0.23 & 0.02 \\
\hline 1997 & 2.60 & 1.57 \\
\hline 1998 & -1.00 & -1.19 \\
\hline 1999 & -1.01 & -1.13 \\
\hline 2000 & -0.47 & -0.55 \\
\hline 2001 & 0.03 & -0.44 \\
\hline 2002 & 0.91 & 0.69 \\
\hline 2003 & 0.28 & 0.16 \\
\hline 2004 & 0.70 & 0.31 \\
\hline 2005 & -0.51 & -0.64 \\
\hline 2006 & 0.52 & 0.47 \\
\hline 2007 & -1.21 & -1.27 \\
\hline 2008 & -0.58 & -0.81 \\
\hline 2009 & 1.22 & 0.69 \\
\hline 2010 & -1.57 & -1.33 \\
\hline 2011 & -0.59 & -0.83 \\
\hline & & \\
\hline
\end{tabular}




\section{Appendix B: El Niño and La Niña Residual Plots}

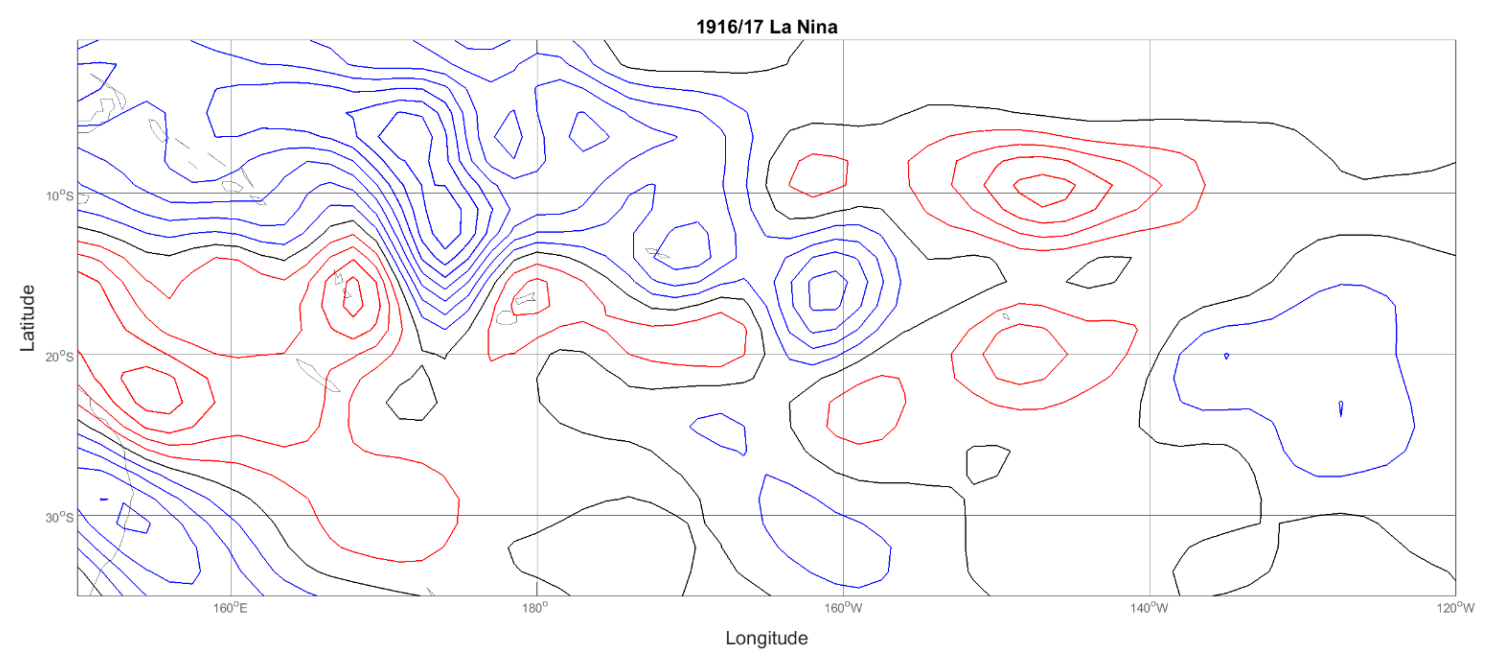

Fig. B1: Residual omega field (20CRv2 - 20CRv2c) for strong La Niña in 1916/1917.

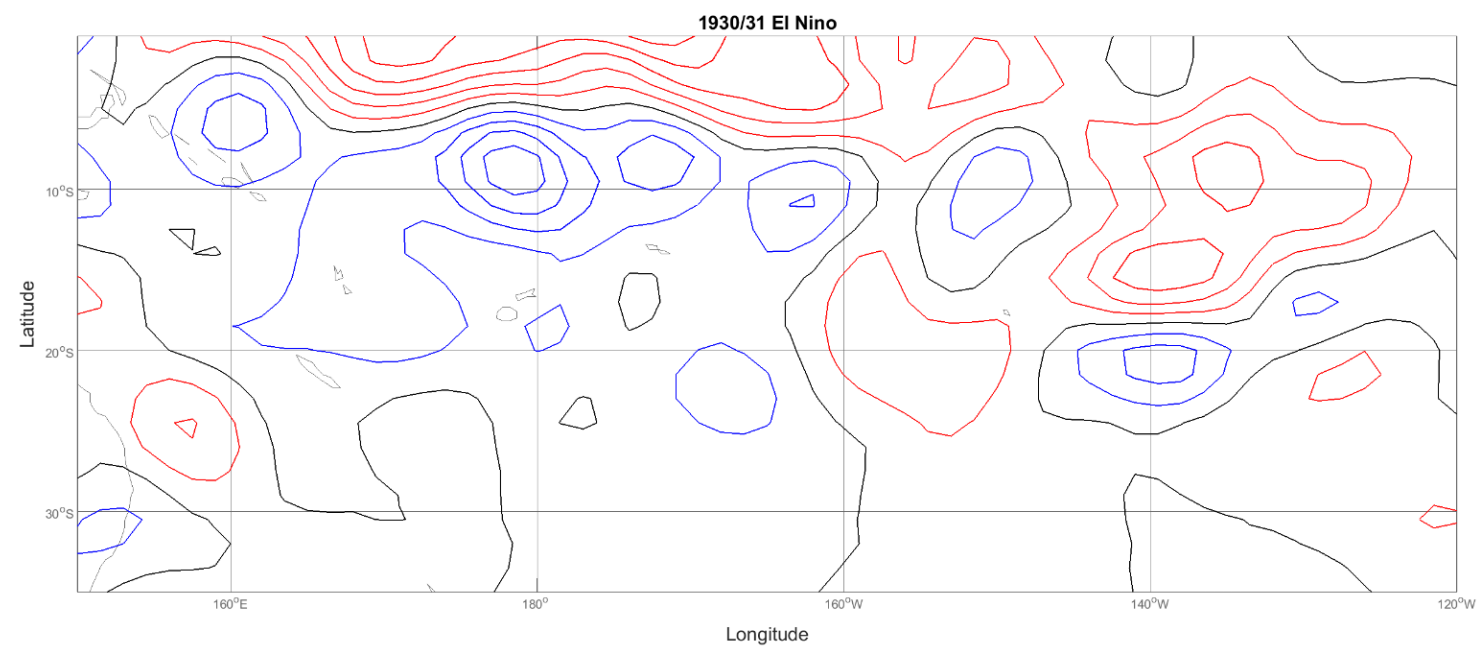

Fig. B2: Residual omega field (20CRv2 - 20CRv2c) for strong El Niño in 1930/1931 


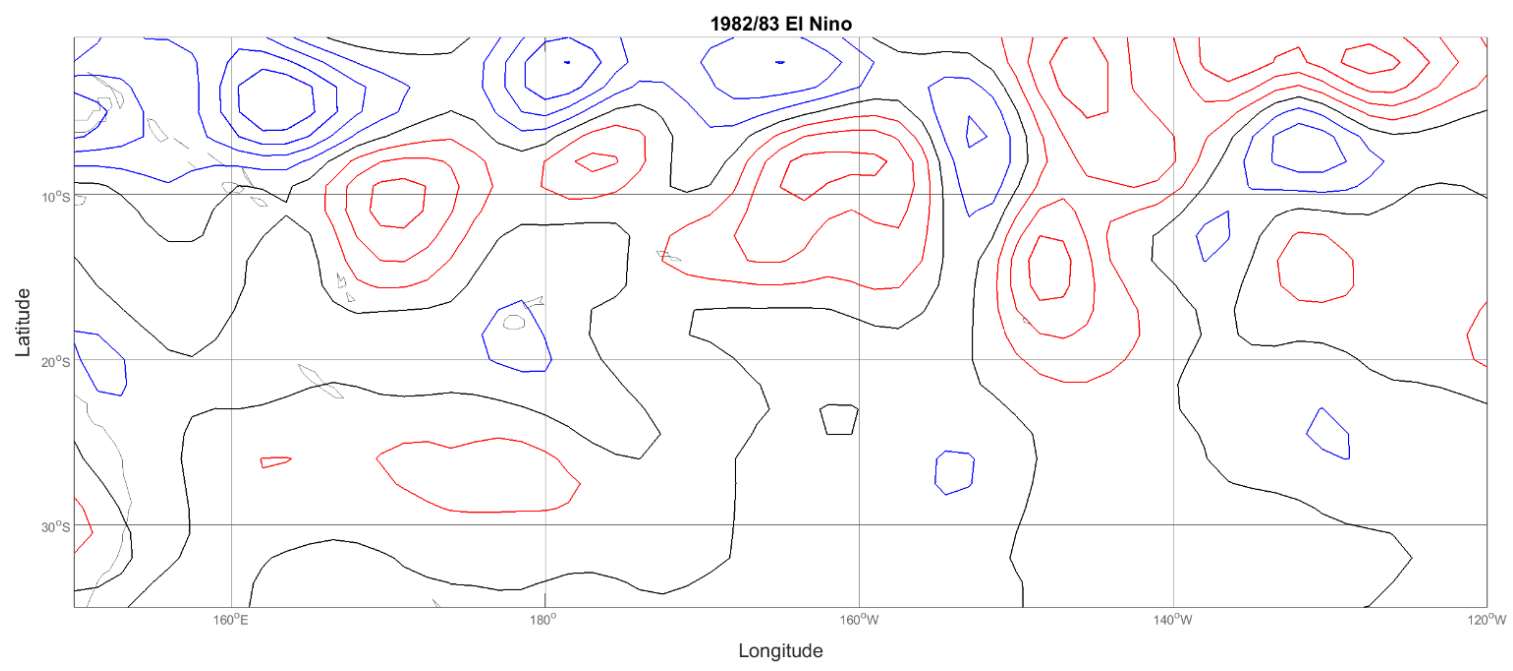

Fig. B3: Residual omega field (20CRv2 - 20CRv2c) for strong El Niño in 1982/1983

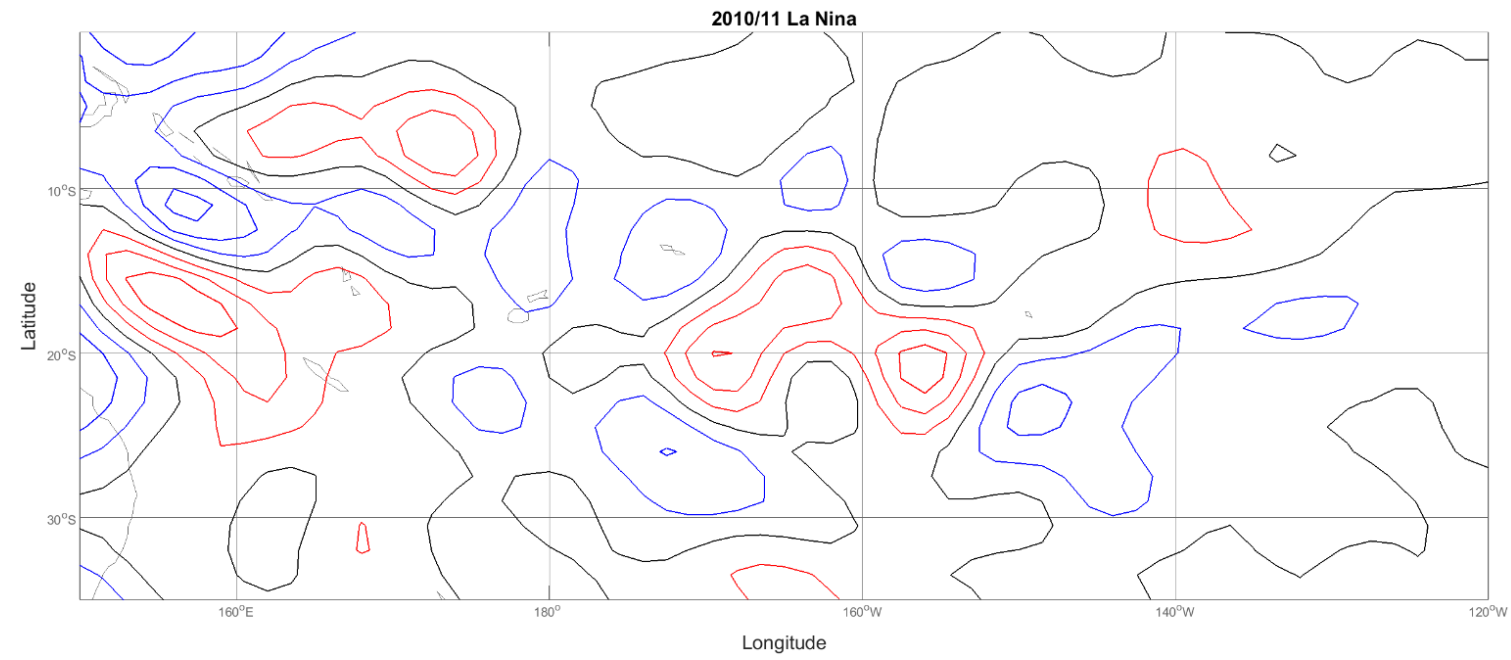

Fig. B2: Residual omega field (20CRv2 - 20CRv2c) for strong La Niña in 2010/2011 
